\title{
Finite element modeling of crack detection in aircraft structures using electrical current
}

\author{
Ramkumar Kumar Geetha \\ West Virginia University
}

Follow this and additional works at: https://researchrepository.wvu.edu/etd

\section{Recommended Citation}

Kumar Geetha, Ramkumar, "Finite element modeling of crack detection in aircraft structures using electrical current" (2004). Graduate Theses, Dissertations, and Problem Reports. 1496.

https://researchrepository.wvu.edu/etd/1496

This Thesis is protected by copyright and/or related rights. It has been brought to you by the The Research Repository @ WVU with permission from the rights-holder(s). You are free to use this Thesis in any way that is permitted by the copyright and related rights legislation that applies to your use. For other uses you must obtain permission from the rights-holder(s) directly, unless additional rights are indicated by a Creative Commons license in the record and/ or on the work itself. This Thesis has been accepted for inclusion in WVU Graduate Theses, Dissertations, and Problem Reports collection by an authorized administrator of The Research Repository @ WVU. For more information, please contact researchrepository@mail.wvu.edu. 


\title{
Finite Element Modeling of Crack Detection in Aircraft Structures Using Electrical Current.
}

\author{
Ramkumar Kumar Geetha \\ requirements for the degree of \\ Master of Science \\ In \\ Mechanical Engineering \\ Bruce. S. Kang, Ph.D., Chair \\ Kenneth Means, Ph.D. \\ Charles Stanley, Ph.D.
}

Thesis submitted to the College of Engineering and Mineral Resources at West Virginia University in partial fulfillment of the

Mechanical and Aerospace Engineering Department, West Virginia University

Morgantown, West Virginia

2004

Keywords: Non-destructive testing, ECD, FEM, CFM micro-gauge 


\section{ABSTRACT \\ Finite Element Modeling of Crack Detection in Aircraft \\ Structures Using Electrical Current \\ Ramkumar Kumar Geetha}

Various non-destructive test methods have been developed for the detection of cracks in metallic structures. Electromagnetic non-destructive testing (NDT) is one of the widely used non-destructive methods used for the detection and characterization of cracks. Utilizing the principle of electromagnetic induction, this technique is used in the areas of nuclear, aerospace, power, transport, petroleum and other industries to inspect defects in metallic sheets, plates and tubes that have good electrical conductivity.

Aircraft structures and wings are made of aluminum sheets riveted together. Cracks are often found emanating from the edge of the rivet holes which are covered by the rivets and are difficult to be detected. Electromagnetic NDT, which involves flow of electrical current and a resultant magnetic field, can be applied to detect these cracks.

In this research, a finite element model was developed which utilizes the principle of electromagnetic NDT. Electrical current density analyses were carried out on aluminum plate with cracks of various shapes and sizes, and demonstrated how electromagnetic NDT can help detect cracks emanating from edge of rivet holes. 


\section{ACKNOWLEDGEMENTS}

Firstly, I would like to thank my parents for their support and encouragement, without whom none of this would have been possible.

I would like to thank my research advisor, Dr Bruce S Kang, for his advice and guidance to me throughout the course of this project. His indispensable contributions and special attention will never be forgotten.

I am very thankful to my committee members Dr. Kenneth Means and Dr. Charles Stanley for their timely advice and for helping me understand some of the related issues.

I would like to thank Shazia Rehman for her never-ending support and encouragement that I received throughout this research work. I would like to thank Bobby John, Vinu Mathew, Ajith Anthony and Sam George for their invaluable help and support.

I would like to thank Mr. Srikanth Ramasubramonian for his timely guidance in design using SOLIDWORKS ${ }^{\mathrm{TM}}$ software. His expertise in design helped me immensely in the design stages of my thesis. I am thankful to all my friends who directly and indirectly helped me in the successful completion of the work assigned to me.

Finally, I would like to express my gratitude to God for providing me the opportunity to pursue higher education and a wonderful research life. 


\section{TABLE OF CONTENTS}

LIST OF FIGURES ................................................................................................................................... vi

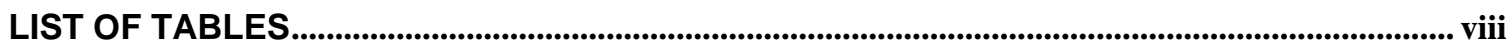

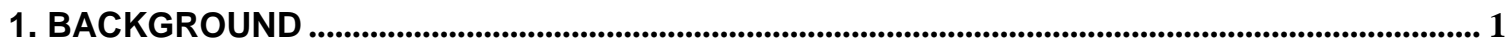

1.1 AIRCRAFT STRUCTURES AND COMMON NDE TECHNIQUES ........................................ 1

1.1.1 Ultrasonic Testing ……………………….............................................................. 3

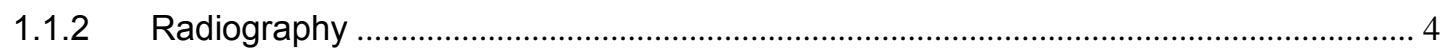

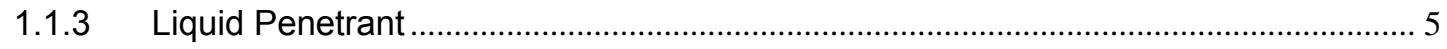

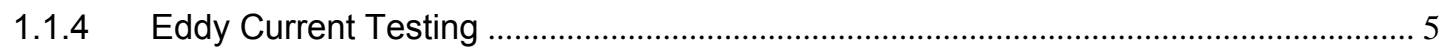

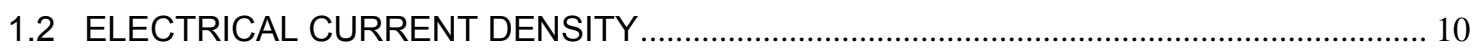

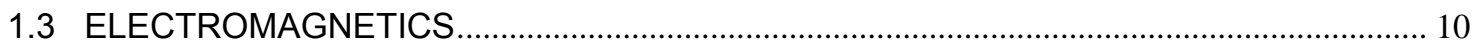

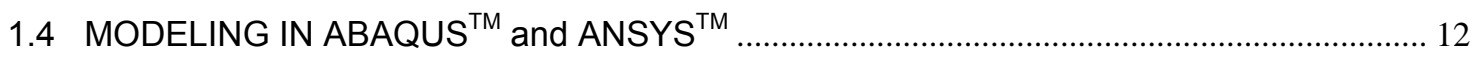

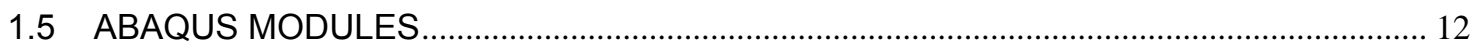

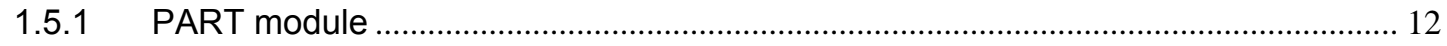

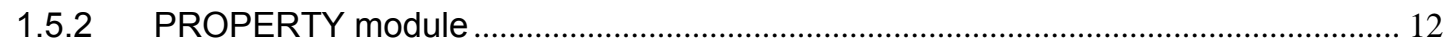

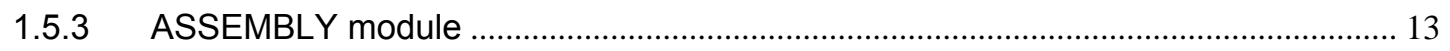

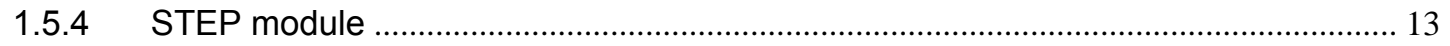

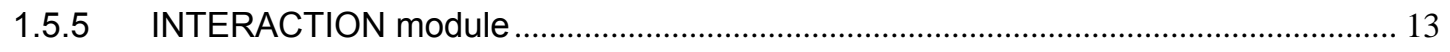

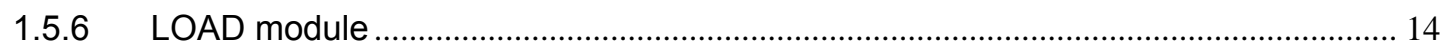

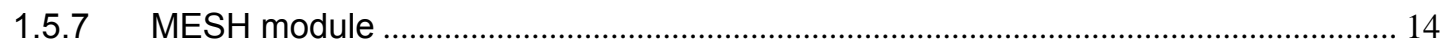

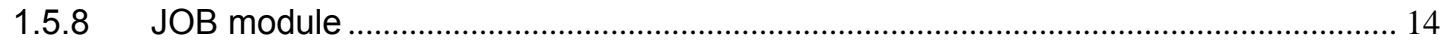

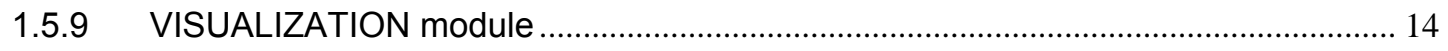

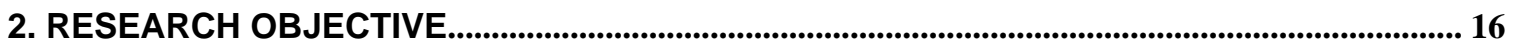

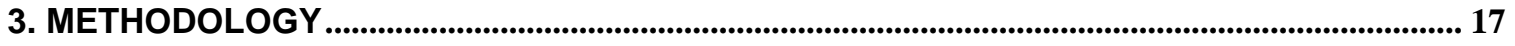

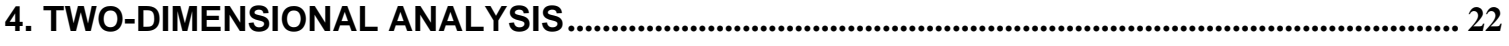

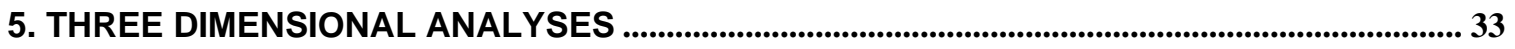


6. COMPARISON OF ELECTRICAL ANALYSIS OF MODELS WITH DIFFERENT CRACK LENGTHS ALONG THE THICKNESS (IN THE Z-DIRECTION) OF THE ALUMINUM PLATE. . 52

6.1 ANALYSIS OF RESULTS 61

7. COMPARISON OF ELECTRICAL ANALYSIS OF MODELS WITH THROUGH CRACKS OF

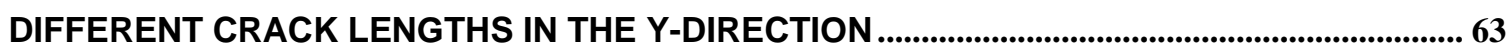

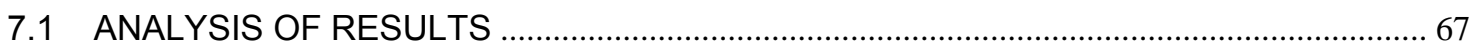

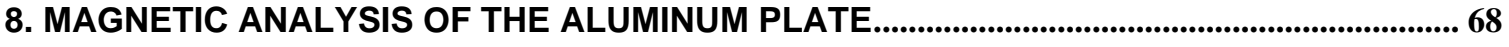

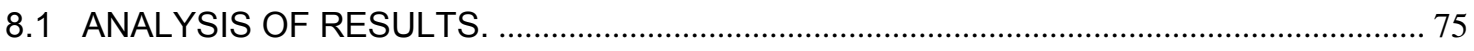

9. CONCLUSIONS DRAWN FROM ANALYSIS......................................................................................... 78

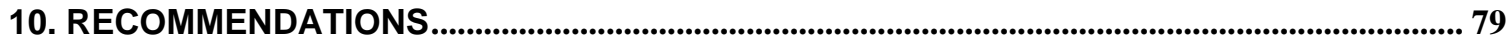

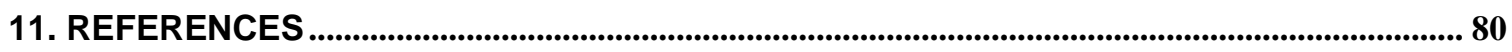

VITA 


\section{LIST OF FIGURES}

Figure 1. Model from paper of Buzz Wincheski [13]............................................................................... 8

Figure 2. Aircraft structure and Eddy Current Set-up......................................................................... 8

Figure 3. Two-Dimensional cracks modeled in PART module of ABAQUSTM........................... 22

Figure 4. Close-up view of cracks starting from the rivet hole. ..................................................... 23

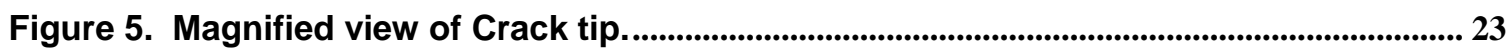

Figure 6. Meshing the two-dimensional Model .......................................................................... 25

Figure 7. Magnified View of the Mesh at the Tip of the crack. ......................................................... 25

Figure 8. Element labels at the tip of the crack ..................................................................................... 26

Figure 9. Electrical Current Density of the crack before force. ...................................................... 27

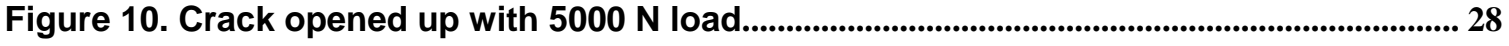

Figure 11. Crack opened up by a force of $10000 \mathrm{~N}$............................................................................. 29

Figure 12. Change in the value of ECD with the change in load .................................................. 31

Figure 13. Front view of the model of the Aluminum Plate. .............................................................. 34

Figure 14. Isometric view of the model with the crack. .................................................................... 37

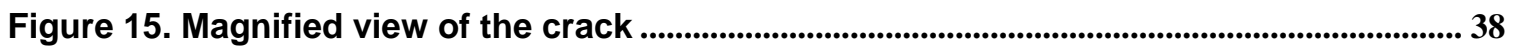

Figure 16. Another magnified view of the crack.................................................................................... 38

Figure 17. Front magnified view of the crack........................................................................................ 39

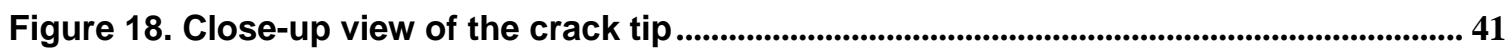

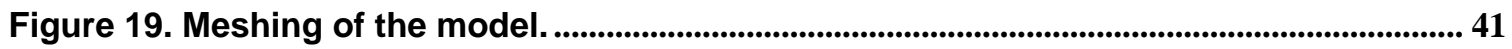

Figure 20. Elements near the tip of the crack. ...................................................................................... 42

Figure 21. Contour plot of the Electrical Analysis on closed crack............................................. 43

Figure 22. Close up view of the tip of the crack. ................................................................................... 43

Figure 23. Contour plot of Electrical Analysis of Open crack. ........................................................ 45

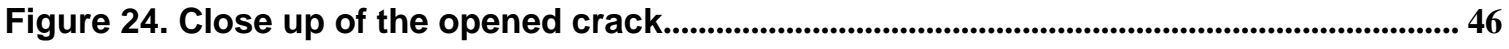

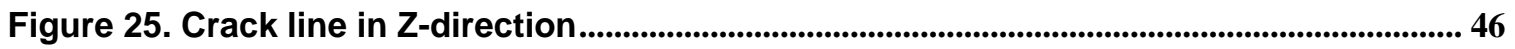

Figure 26. Cross-sectional ECD plot of the closed crack model .................................................. 47 
Figure 27. Cross-sectional ECD plot of the open crack model....................................................... 48

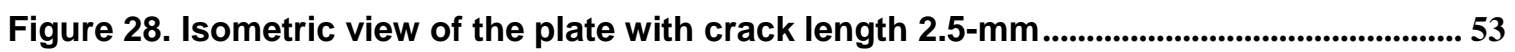

Figure 29. Isometric view of the plate with crack length $5.7-\mathrm{mm}$.................................................. 53

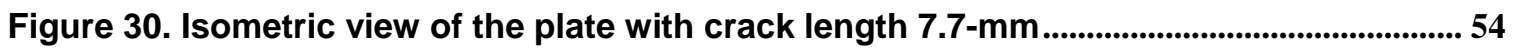

Figure 31. Isometric view of the plate with crack length $9.7-\mathrm{mm}$................................................ 54

Figure 32. Isometric view of the plate with a through crack ......................................................... 55

Figure 34. Sectional cuts denoting increase of crack length along Z-direction ....................... 56

Figure 35. Sectional view of $1.1 \mathrm{~mm}$ crack. .................................................................................... 57

Figure 36. Sectional view of $2.5 \mathrm{~mm}$ crack ................................................................................................. 57

Figure 37. Sectional view of $5.3 \mathrm{~mm}$ crack ............................................................................................... 58

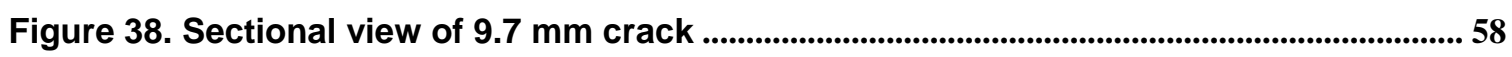

Figure 39. Sectional view of a through-crack................................................................................ 59

Figure 40. Change in Electrical Current density with change in length in Z-direction.......... 60

Figure 41. Crack length increase in the Y-direction $(, 2.5 \mathrm{~mm}, 3.5 \mathrm{~mm}, 4.5 \mathrm{~mm}$, and $5.7 \mathrm{~mm}) 65$

Figure 42. Change in ECD with change of length along Y-direction............................................. 66

Figure 43. Contour plot for magnetic flux density. ................................................................................ 70

Figure 44. Contour plot for magnetic field................................................................................................ 71

Figure 45. Close-up views of the magnetic field near the crack. ................................................... 71

Figure 46. Close-up views of the magnetic flux density near the crack. ...................................... 72

Figure 47. Change of Magnetic flux intensity with change in length.......................................... 74

Figure 48. Change in Magnetic field with change in length. ............................................................ 74 


\section{LIST OF TABLES}

Table 1. ECD values for two-dimensional cracks.................................................................................... 30

Table 2. ECD Values for three-dimensional model ....................................................................... 49

Table 3. Comparison of ECD values for different crack lengths in the Z-direction................. 59

Table 4. Comparison of ECD values for different crack lengths in the Y-direction ............... 65

Table 5. Magnetic field and Magnetic Flux density vs. crack length............................................. 73 


\section{BACKGROUND}

\subsection{AIRCRAFT STRUCTURES AND COMMON NDE TECHNIQUES}

The detection of defects in aging aircraft structures has been the major goal of NDE community. There are quite a number of defects common in aircraft structures especially in aircraft wings. Also, numerous non-destructive test (NDT) mechanisms have been found and applied for the detection of cracks emanating from the sides or edges of rivet holes. These non-destructive testing mechanisms replace all cumbersome methods used earlier for detection of such cracks.

Corrosion and fatigue cracks are always expected in aging aircraft structure. Corrosion is a critical problem of aircraft structure, which directly affects the airworthiness and reliability of an aircraft. Corrosion causes thinning of aircraft structure skins lead to a degradation of structural integrity. Fatigue cracks also occur in multi-layered riveted joint especially in aluminum-alloy structures. These cracks can develop under suitable fatigue loading condition and extend to such an undesirable degree, that these may cause severe problems for service engineers and maintenance engineers.

Structural cracking is a direct result of aircraft flight operation and aging. Corrosion cracking occurs from the exposure of the aircraft materials to various corrosive environments like humid air, saltwater, sump tank water and latrine leakage, and because of the inadequate or deterioration of corrosion protection systems.

Corrosion is a relatively slow materials degradation process to which metallic aircraft structures are subjected during service. It is a general term that 
describes the oxidative degradation of metals caused by a local galvanic cell between the base metals (acting as anodic sites), at sites of defective protective coating, having the passive sites sustaining cathode reaction. The corrosion process converts the metal into its oxide or hydroxide forms resulting in deterioration of its mechanical properties. Dulling or pitting of the area, and sometimes by white or red powdery deposits can, often recognizes corrosion in aluminum alloys and plated steel surfaces. It may also be the origin of, or revealed by, de-lamination, cracking, metal thinning, fretting, etc. Corrosion can appear in many forms, depending on the type of metal, how it is processed and the surrounding structure and service conditions. Corrosion results from exposure to humid or corrosive environments and involves primarily electrochemical action at chemical/metallurgical/physical heterogeneity, with dissimilar potentials.

There are wide ranges of non-destructive mechanisms used for detecting cracks. NDT is inspection method used to search for the presence of defects in components without causing any effects on the properties of the components. The types of defects detectable are cracks, porosity, voids, inclusions, etc.

Modern NDT is used by manufacturers to: (a) ensure product integrity and reliability,(b) prevent failure,(c) prevent accidents and saving lives,(d) make profit for users,(e) ensure customer satisfaction, (e) aid in better product design;(f) control manufacturing process,(g) lower manufacturing costs,(h) maintain uniform quality level, and (i) ensure operational readiness. 
The various NDT methods widely used today are ultrasonic method, visual methods, radiography, Dye penetrant method, and Eddy current method.

\subsubsection{Ultrasonic Testing}

An ultrasonic inspection technique commonly used for the aircraft structures is based on ultrasonic spectroscopy. Commercially available instruments (bond testers) used for this test operate on the principle of mechanical resonance in a multilayer structure. A piezo-electric probe excited by a variable frequency sine signal is placed on the surface of the inspected structure. The instrument acquires a frequency spectrum in the range of some tens of $\mathrm{kHz}$ to several $\mathrm{MHz}$. A resonance in the layered structure occurs when echoes between two boundaries travel back and forth due to differences in acoustic impedances at the boundaries. For multilayer structures a number of resonances can be observed depending on their geometry and condition. For each particular defect-free structure and given transducer we obtain a characteristic resonance pattern, an ultrasonic signature, which can be used as a reference.

During the inspection of an unknown object the probe scans its surface and ultrasonic spectra are acquired for many discrete points. Detection is performed by the operator looking at some simple features of the acquired spectra, such as, center frequency and amplitude of the highest peak in a preselected frequency range. 
The ultrasonic principle is based on the fact that solid materials are good conductors of sound waves. This pulse of waves travels through the metal with some spreading and some attenuation and will be reflected or scattered at any surface or internal discontinuity such as an internal flaw in the specimen. This reflected or scattered energy can be detected by a suitably placed second piezoelectric disc on the metal surface and will generate a pulse of electrical energy in that disc. The time- interval between the transmitted and reflected pulse is a measure of the distance of the discontinuity from the surface, and the size of the return pulse can be a measure of the size of the flaw. This is the simple principle of the ultrasonic flaw detector and the ultrasonic thickness gauge.

\subsubsection{Radiography}

This process involves transmitting $\mathrm{X}$-rays or gamma rays through aircraft structures to a film on the opposite side of the piece being tested, thereby detecting the discontinuities on the inside of structure. The mobile units are equipped with 200 or 300 kilovolt X-ray machines. These X-ray units have, only a maximum thickness penetration of 2.5 inches of steel but has a higher thickness penetration when inspecting aluminum, plastics, ceramics, and certain other materials, depending on density. Most of the aircraft structures are made of aluminum and thus, X-rays penetrate the metal and affect the X-ray film, which provides the image. $\mathrm{X}$ - rays pass through the cracks (cracks have lesser density than un-deformed portion) and thus produce a darker image on the X-ray film. 


\subsubsection{Liquid Penetrant}

This process is a surface testing mechanism and therefore it is not capable to detect deeply buried flaws in aircraft structures. In this mechanism, the aircraft surface to be inspected is cleaned thoroughly to remove all traces of dirt and grease. A brightly colored or fluorescent liquid is then applied liberally to the component surface and allowed to penetrate any surface-breaking cracks or cavities. The time the liquid is allowed to soak into the material's surface is normally about 20 minutes. After soaking, the excess liquid penetrant is wiped from the surface and a developer applied. The developer is usually a dry white powder, which draws penetrant out of any cracks by reverse capillary action to produce indications on the surface. These (colored) indications are broader than the actual flaw and are therefore more easily visible. Liquid penetrant testing offers a fast, cheap and relatively simple means of surface inspection, making it attractive to a number of industries. The aerospace industry use automated fluorescent penetrant testing to look for fatigue cracking in turbine blades.

\subsubsection{Eddy Current Testing}

Eddy current testing is an electromagnetic technique and can only be used on conductive materials. Its applications range from crack detection, to the rapid sorting of small components for flaws, size variation, or material variation. Commonly it is used in the aerospace, automotive, marine and manufacturing industries. 
When an energized coil is brought near to the surface of a metal component, Eddy currents are induced into the specimen. These currents set up magnetic fields that tend to oppose the original magnetic field. The impedance of coil in close proximity to the specimen is affected by the presence of the induced Eddy currents in the specimen.

When the Eddy currents in the specimen are distorted by the presence of the flaws or material variations, the impedance in the coil is altered. This change is measured and displayed in a manner that indicates the type of flaw or material condition.

This method includes a system, which involves a rotating probe system designed specifically for the detection of deeply buried flaws in multilayer conductors. The design change incorporates a giant magneto resistive (GMR) sensor as the pickup device to improve the low frequency performance of the probe. The flaw detection capabilities of the GMR based probe are presented along with the status of the GMR based rotating probe system for detection of deeply buried flaws under installed fasteners.

The problem geometry for inspection under ferromagnetic protruding head fasteners is discussed. Finite element modeling results are then presented to show the electromagnetic field energy coupling into the critical region. Experimental data taken for EDM notches and actual fatigue cracks located under the installed fasteners follow the modeling results. A brief discussion of deep flaw detection under installed fasteners is contained in the next section. The problem geometry, resulting inspection system requirements, and 
experimental data for deep flaw detection using a GMR based very low frequency Eddy current probe are presented. The incorporation of this modified probe into the rotating probe system is planned to enhance the detection capabilities of the system as related to deeply buried fatigue cracks under installed fasteners.

Figure 1 displays a simplified geometry of a wing section on the A-10 aircraft. The lower surface of the wing is attached to the inner frame using fasteners. These high strength fasteners have a slightly protruding head and are fabricated from SAE 4340 steel. The loading on the wing during flight is such as to produce a high stress on the lower wing surface, just under the fastener head. The most likely location for fatigue crack formation and growth is at this location, as shown in Figure 1. Detecting these flaws at an early stage will greatly simplify the repair procedure.

The sample geometry discussed above significantly complicates the NDT inspection. Many NDT procedures rely on a relatively smooth surface across which to scan the Eddy current probe. This is eliminated by the presence of the protruding head fastener. In addition, the presence of a ferromagnetic layer covering the location of the fatigue crack significantly shields the flaw from diffusing Eddy currents originating at the surface of the structure. The effects caused by the presence of the raised head can be eliminated, however, if the probe is scanned outside of the outer diameter of the rivet head as depicted in Figure 1. A drawback of this approach is the displacement of the sensor from the fatigue crack location. This would appear to further reduce the field energy 
coupling into the damaged area shielded under the ferromagnetic fastener. As no other options appeared evident, this approach was investigated with finite element and experimental studies [13].

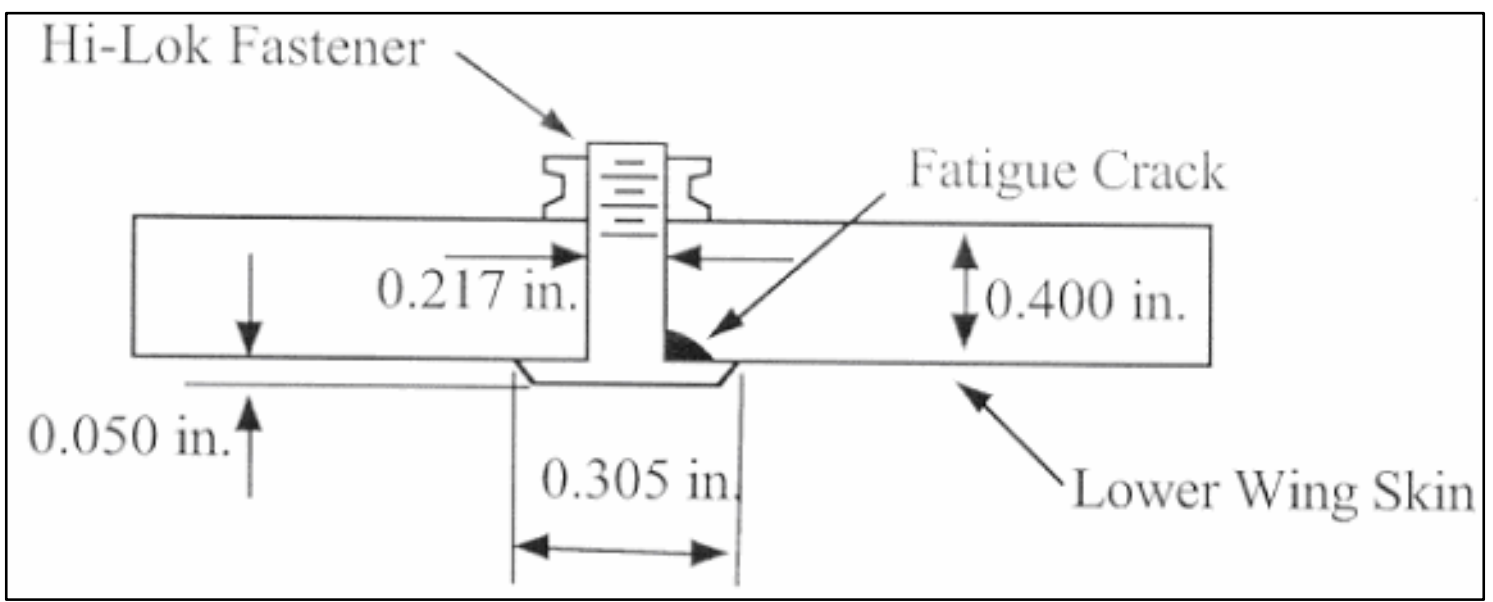

Figure 1. Model from paper of Buzz Wincheski [13].

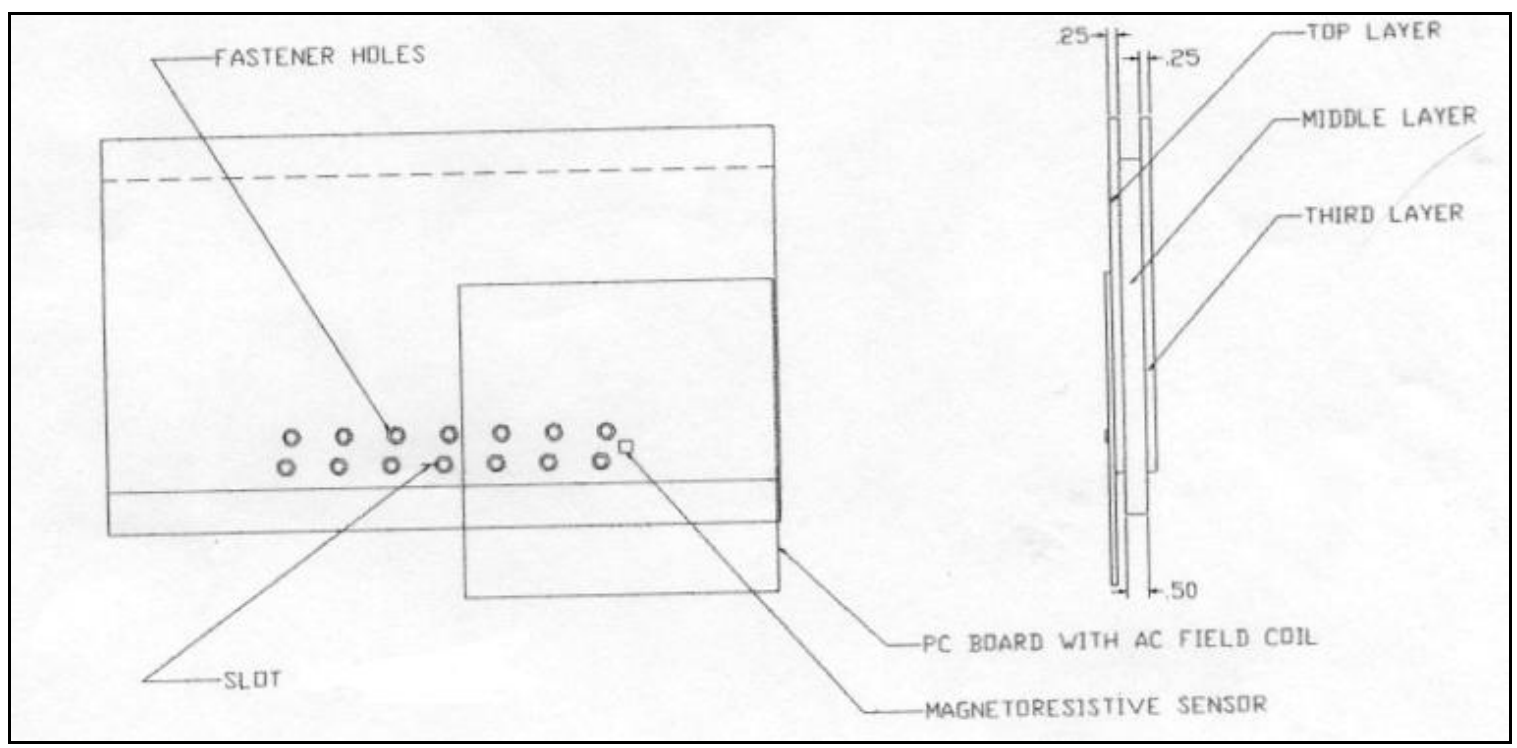

Figure 2. Aircraft structure and Eddy Current Set-up.

A FEM three-dimensional model was constructed to understand the principle of Eddy current testing. The probe is placed above the aluminum plate 
and outside the outer diameter of the fastener. The problem was solved using a $50 \mathrm{kHz}$ drive signal and respective boundary conditions on all outside edges. The difficulties raised by the presence of the protruding fastener have been minimized by scanning the probe over the base metal at the location outside the outer diameter of the rivet. The concerns regarding the shielding of the flaw by the ferromagnetic fastener head have also been eliminated. In fact, the finite element model predicts that the ferromagnetic fastener will increase the Eddy current density at the critical location where fatigue cracks are likely to occur. The use of the GMR device, combined with appropriate shielding and flux focusing has enabled the detection of fatigue cracks buried under more than 0.350 " $(9 \mathrm{~mm})$ of unflawed aluminum alloy plates. The output of GMR is represented as a function of angular position during the scan [13].

Modification to the rotating probe system have been presented to expand the capabilities of the system for the detection of fatigue cracks buried under protruding head ferromagnetic fasteners as well as deeply buried fatigue cracks. In the case of the inspection under ferromagnetic protruding head fasteners, no new hardware is required. Only a minor adjustment of the probe radius is necessary to enable the detection of fatigue cracks buried under the fastener head. The experimental results suggest that the depth of the flaw is equally as important as the flaw length in determining the probe output voltage [13]. 


\subsection{ELECTRICAL CURRENT DENSITY}

An electrical current flowing through a solid produces an electrical current density with units of 'charge per unit time per unit area' (measured in the direction perpendicular to the flow direction). For electrons with number density flowing through a solid with velocity $\mathbf{v}$, the resulting volume current or current density $\mathbf{J}$ is given by

$$
J=-e^{*} n_{e} v,
$$

\subsection{ELECTROMAGNETICS}

The magnetic field in a static magnetic analysis is produced in one of the following ways:

- Permanent magnets

- The steady flow of electric current

- An applied voltage

- A moving conductor.

- An applied external field.

Static magnetic analyses do not consider time-dependent effects such as Eddy currents.

Of particular interest is the magnetic field that is created as a result of the steady flow of electric current. This magnetic field is created by the principle of electromagnetic induction which states that for every electric field due to a flowing current, there would be a magnetic field and magnetic flux associated with it. Now the challenging task is to measure this magnetic field. Let's take a 
look into one of the laws of electromagnetic Induction called 'Bio-Savart's law' that draws a connection between induced magnetic field and the Electrical Current.

The magnetic field set up at a point by the current element ' $l d s$ ' turn out to be,

$$
d \vec{B}=\frac{\mu_{0}}{4 \pi} \frac{i \vec{s} \times \vec{r}}{r^{3}}
$$

Here 'dB', 'ds' and 'r' are vectors.

The above equation is called the Bio-Savart's law. The vector $d B$ is perpendicular both to ds (which is the direction of the current) and to the unit vector $\mathbf{r}$ directed from the element to a point where it is measured.

All the current elements along the current loop can contribute to the magnetic field at the point.

The direction of 'ds' is in the direction of the current and where the vector points from the short segment of current to the observation point where we are to compute the magnetic field. Since current must flow in a circuit, integration is always required to find the total magnetic field at any point. The constant $\mu_{\mathrm{o}}$ is chosen so that when the current is in amps and the distances are in meters, the magnetic field is correctly given in units of Tesla. Its value in our SI units is exactly $4 \pi * 10^{-7} \mathrm{~T} \cdot \mathrm{m}^{2} / \mathrm{A}$.

There are two simple cases where the magnetic field integrations are easy to carry out, and fortunately they are in geometries that are of practical use. We use the formula for the magnetic field of an infinitely long wire whenever we want 
to estimate the field near a segment of wire, and we use the formula for the magnetic field at the center of a circular loop of wire whenever we want to estimate the magnetic field near the center of any loop of wire.

\subsection{MODELING IN ABAQUS ${ }^{\mathrm{TM}}$ and ANSYS ${ }^{\mathrm{TM}}$}

Two softwares were used for the finite element modeling analysis. The

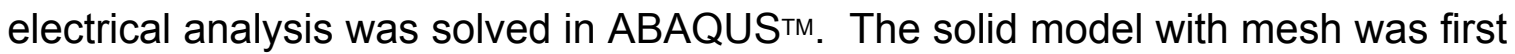
constructed using SOLIDWORKS ${ }^{\text {тм }}$ and then exported to ANSYS ${ }^{\text {тм }}$ for magnetic analysis. This magnetic analysis is carried out to provide us with the magnetic field and magnetic flux for the corresponding electrical current density output.

\subsection{ABAQUS MODULES}

The various modules in this software, which helps us accomplish these three parts of analysis, are,

\subsubsection{PART module}

In this module, the part or various parts that have to be assembled is made using the various user-interactive tools. Now modeling part of this software is comparatively weak. Therefore the best way in which we could create a part for analysis is design the part in design software like IDEAS ${ }^{\mathrm{TM}}$ or $A U T O C A D^{\mathrm{TM}}$ or SOLIDWORKS ${ }^{\mathrm{TM}}$ and then save this file as an IGES file and then import it into ABAQUS ${ }^{\mathrm{TM}}$.

\subsubsection{PROPERTY module}


In this module, sections are created with the material properties desired and then one section or more than one section is assigned to the part created. If more than one property has to be designated to the various sections of the part made in the part module, we partition the part into various sections and then assign different material properties to different sections.

\subsubsection{ASSEMBLY module}

In this module, the various parts made are assembled according to the requirement or design of the component. If there is just one part present in the assembly, then just import the part into this module and we are ready to move onto the next module.

\subsubsection{STEP module}

In this module, the analysis step is defined. We determine which analysis has to be considered. If an electrical analysis is done then we define the electrical analysis in this module. Now we also determine the maximum and minimum load increments and the no of increments in which the analysis has to be completed. This module also provided the various output options available for the type of analysis provided.

\subsubsection{INTERACTION module}

In this module, the thermal and mechanical interactions between regions of the model or interactions between the model and its surroundings are defined. Mere physical proximity of two surfaces in an assembly is not enough to indicate or represent any interaction between the surfaces. Also, the interaction module is 
step-dependant module. We have to specify the analysis steps in which they are active.

\subsubsection{LOAD module}

In this module, the load and the boundary conditions are applied to the model to be analyzed. The load and the boundary conditions are normally applied to the various nodes of the assembly. Load and boundary conditions are step-dependant criteria, which mean that they have to be applied to the analysis steps in which they are active.

\subsubsection{MESH module}

This module helps us generate the mesh on the assembly created. The assembly is divided into a lot of elements, which connects the nodes of the assembly. This module also helps us define the element type and the element controls to be assigned to the elements of the model.

\subsubsection{JOB module}

This module helps to create a job and run the analysis on the model with respect to the load and boundary conditions applied to the model. We can not only submit the job, but also monitor the results at various load increments as specified in the step module.

\subsubsection{VISUALIZATION module}


This module provided graphical display of the finite element models and results. It obtains the model and the output information from the output database, which works according to the output requests given in the step module. 


\section{RESEARCH OBJECTIVE}

The objective of this research is to study the principle of electromagnetic NDT to detect rivet cracks in aircraft structures. This type of non-destructive mechanism is one in which electrical current and magnetic sensors are used to detect cracks emanating from the edge of rivet.

The finite element modeling analysis is to obtain the flow of electric current, around the crack. Thus by the density of electric current obtained, the associated magnetic field can be assessed to facilitate the placement of the Eddy current probe. The electric current density values of the elements close to the crack were analyzed and thus the pattern of electric current flow and magnetic field associated with it studied. 


\section{METHODOLOGY}

There are various types of cracks in aircraft structures that mainly are caused by either fatigue loading or corrosion. The fatigue cracking or structural cracking is caused due to varying load and stress cycles, while the environments like humid air, saltwater and sump water can produce cracks due to corrosion. These mechanisms can produce cracks that are buried under the airframe rivets as well as longer cracks that extend beyond the edge of the rivet. Fatigue cracks originate at the base of the rivet and progress away from the rivet center.

There are numerous NDT mechanisms to detect fatigue cracks in aircraft structures. The most commonly used methods are Eddy current testing, ultrasonic testing, current field-testing and optical testing. Electromagnetic NDT is one of the prominent methods of crack detection and is widely used in all forms of industry. Crack detection in aircraft structures is very important because fatigue cracks may hamper airworthiness of the aircraft and render it unsuitable for flying.

When a magnet is placed on a frame it produces a magnetic field. When a electrical conductor moves with respect to this magnet, it produces an electric field in addition to the already present magnetic field that is roughly proportional to the relative velocity of motion. This mechanism is applicable in the reverse direction also. Similarly when an electric current is passed across a conductor, the conductor produces a magnetic field. This follows the principle of electromagnetic induction. Wherever there is an electrical field, there would be a magnetic field associated with it. 
This principle can be utilized in the detection of cracks in aircraft wing structures. Fatigue cracks can be detected and sized by electromagnetic means and, finite element models can be utilized to simulate the electromagnetic field around a crack. A current flowing across the crack produces a distinct electrical current density around and at the tip of the crack, and correspondingly there would be an electromagnetic field associated with it. The locations and the values of the peaks and troughs in this electronic instrument have been proved successful in crack detection and sizing. For example, CFM (Current Field Measurement) micro-gauge was applied to capture the electromagnetic perturbation. Corresponding signals produced as an output (detected by a magnetic sensor) are as a result of the change of the inductance of the inductance coil of the micro-gauge. The value of inductance is proportional to the size and shape of the crack.

This method utilized electrical current for the non-destructive testing and evaluation of surface breaking fatigue cracks in metals. The flow of an electrical current through an aluminum sheet is disturbed by the presence of defects like fatigue cracks and this disturbed current will in turn change the magnetic field associated with it. Now the magnetic sensor detected this change in the magnetic field and thus one can deduce the size and the shape of the crack by studying the magnitude of this crests and troughs produced as a result of the change of inductance in the coil. This mechanism allowed non-destructive evaluation of the materials in a non-contacting manner. This method is, thus a very effective way for non-destructive evaluation. 
The magnitude of magnetic field differs at the tip of the crack where the maximum electric current density is present. A magnetic sensor can then be used to determine and detect this change of magnetic field at this portion of the aluminum sheet and thus determine the size and shape of the crack. The value of the magnetic field would change when various sizes and shapes of the crack are under question.

This finite element model was made using $A B A Q U S^{T M}$ CAE version 6.3 and consisted of an aluminum sheet with a rivet hole and a crack emanating from the edge of the hole. An artificial line crack, which originated from the edge of the rivet hole, was introduced and an electrical analysis was run to obtain electrical current density plot. Then, force was applied to open up this artificial crack and then the electrical analysis was run again. The electrical current density contour plots were obtained for both the cracks and comparative evaluation was carried out.

The analysis was done on a model, which was developed by Buzz Wincheski [13]. This two-dimensional model with a defined thickness was recreated in the PART module of the ABAQUS ${ }^{\mathrm{TM}}$ software and then applying proper load and boundary conditions, subjected to finite element analysis. The model consisted of an aluminum sheet with length 3 inches, width 2 inches and thickness of 0.4 inch with a rivet hole at the center. The diameter of the rivet hole is 0.217 inch. A line crack was modeled from the edge of the crack and this represented a fatigue crack developed due to excessive fatigue load conditions. 
An electrical analysis was carried out and an electrical current density contour plot obtained around the line crack. The maximum current density was obtained at the tip of the crack. This in turn produced a gradient magnetic field due to the perturbed flow of electrical current.

The nodes on one side of the plate were constrained completely, i.e. all degrees of freedom were constrained. A concentrated force was applied to all the nodes at the other side of the plate. This represents a classic example of tensile tension or loading that occurs in an aircraft wing. This large force applied caused the crack to open up and thus nodal coordinates of the crack were then updated. The new coordinates of the model were obtained from the DAT file of the ABAQUS $^{\mathrm{TM}}$ output-section and then substituted for the old values of the nodal coordinates. This revised input file was imported back to the ABAQUS ${ }^{\mathrm{TM}}$ server and the electrical analysis executed again with the same current and voltage conditions. The electrical current density contour plot was obtained and analyzed. There is a distinct change in the current density values along the crack and at the tip of the crack and these values were also different from the values obtained from the contour plot of the original crack. Thus it is confirmed that the values of the magnetic field around an opened crack are different from the original closed crack.

Three-dimensional cracks of various sizes are developed using SOLIDWORKS ${ }^{\mathrm{TM}}$ software. The change in size was affected by increasing the length of the crack in the direction of the thickness of the aluminum plate i.e. in the z-direction till the crack cut throughout the cross-section along the entire 
thickness of the aluminum plate. Also analysis was carried out on the plate where the through crack was maintained, and the crack length in the y-direction increased. The analysis was carried out on all cracks and the contour plots for Electrical Current Density were obtained for all the cases.

The next task is to calculate the magnetic field based on the current density field at the crack tip region. Literature review suggests that Bio-Savart's law can calculate the magnetic field due to current density field. It would be very cumbersome and highly tedious to calculate the magnetic field for all the current elements using this law. Moreover we also have to know the length of the current element if we have to calculate the magnetic field for the particular element. Therefore, Bio-Savart's law cannot be fully applicable or helpful in the calculation of Magnetic field. Therefore magnetic field is calculated at the elements in and around the plate again by ANSYS ${ }^{\mathrm{TM}}$ finite element analysis software. It should be noted that ABAQUS ${ }^{T M}$ software doesn't allow users to run a magnetic analysis. Therefore ANSYS ${ }^{\mathrm{TM}}$ software is used to run the magnetic analysis for the current carrying conductor. To study how the magnetic field works in and around the crack tip, the magnetic analysis is run for the model with the closed crack alone. The length along the Z-direction and the $\mathrm{Y}$-direction is changed and the magnetic analysis runs with the same load and boundary conditions as the electrical analysis. 


\section{TWO-DIMENSIONAL ANALYSIS}

The electrical analysis was first carried out on a two dimensional model. The model geometry was obtained from reference [13]. The 'Part Module' of A

ABAQUS $^{T M}$ software modeled the specimen to be analyzed, which consisted of a plate with a rivet crack. The shape and size of the crack was also well defined in [13]. For the two-dimensional analysis, a crack was also included in the analysis.

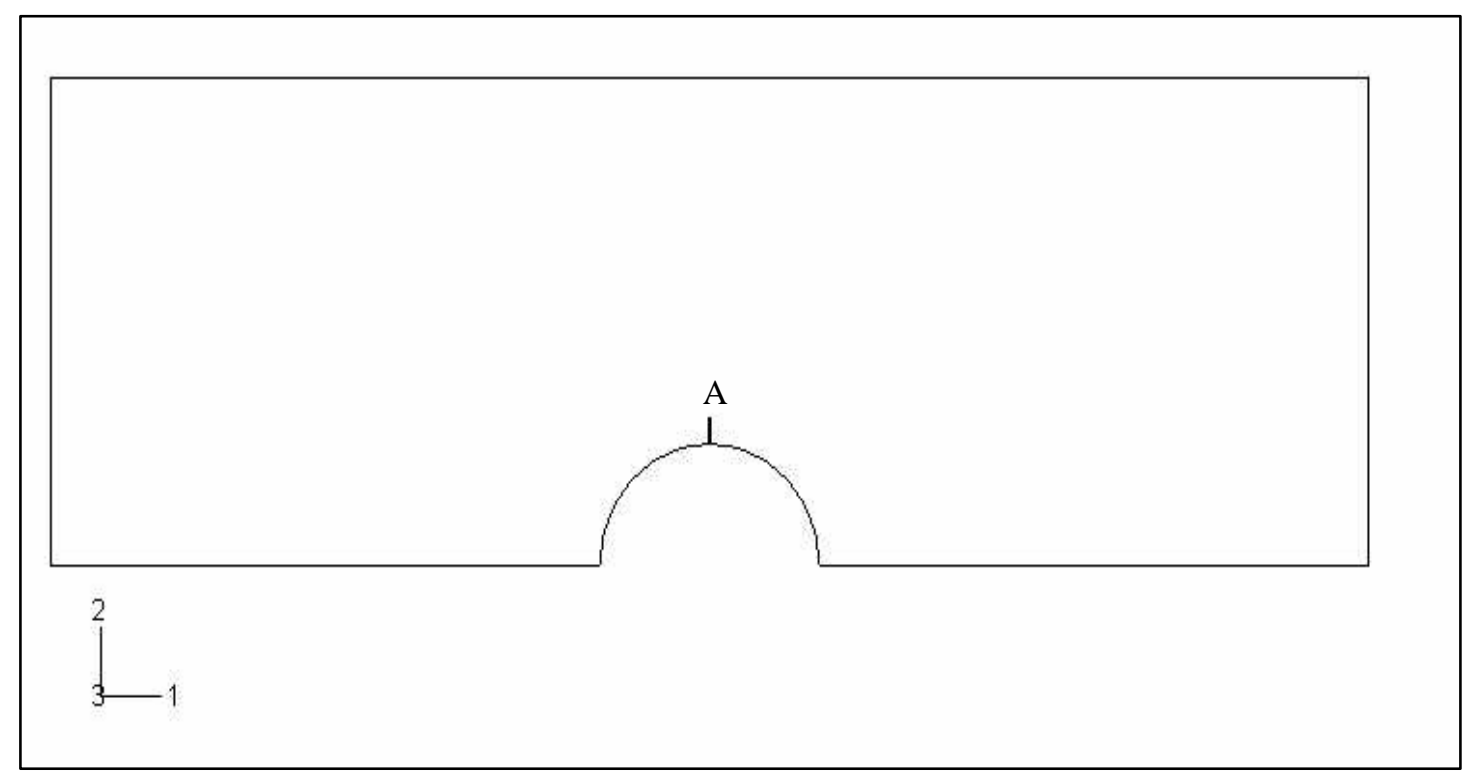

Figure 3. Two-Dimensional cracks modeled in PART module of ABAQUSTM

The figure above represents a through two-dimensional crack. The closeup view of the crack reveals the shape of the crack at the tip of the crack. This model of the crack is regarded as the ideal shape of the crack. The close-up of the crack is shown in Figures 4 and 5. 


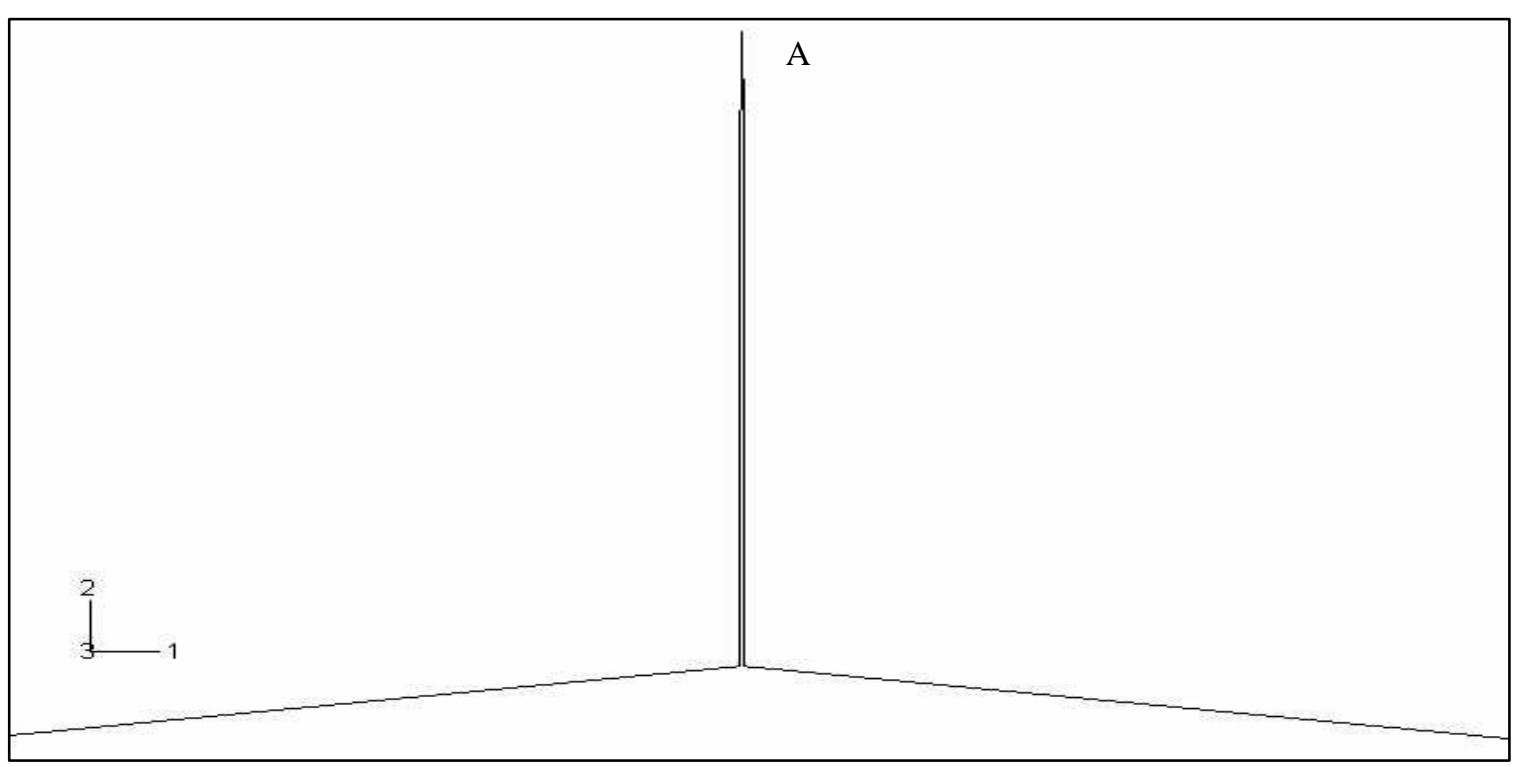

Figure 4. Close-up view of cracks starting from the rivet hole.

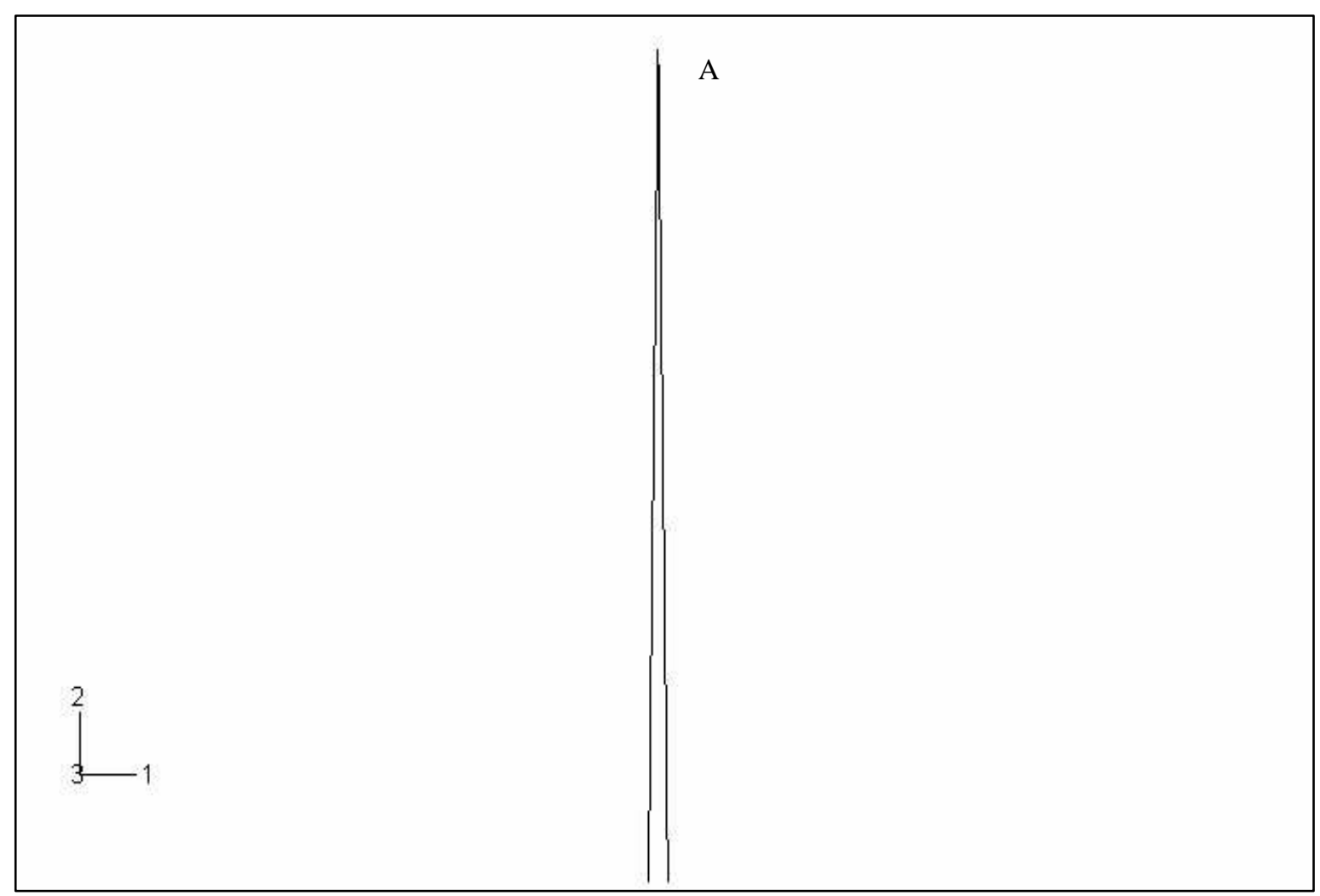

Figure 5. Magnified view of Crack tip. 
Figure 3 shows the crack emanating from the circumference of the rivet hole while Figures 4 and 5 show the magnified views of the crack tip.

The plate with the rivet hole was assigned the properties of the Aluminum metal because this is the typical metal used for Aircraft wings and other structures. The young's modulus is taken as 73000 and the Poisson's ratio as 0.33. The Density of the material was defined in the property module of the software as $2700 \mathrm{~kg} / \mathrm{m}^{3}$.

The load and boundary conditions were defined in the 'LOAD Module' of the ABAQUS ${ }^{T M}$ software. The nodes on one side of the model were maintained at a potential of zero so that the current flows from the region of higher potential to a region of lower potential. The current load was applied to all nodes on the side, which is maintained at higher potential. A current of $1 \mathrm{amp}$ is applied at all the nodes at this side and the current allowed flowing from one side to the other. The flow of the electrical current through a conductor is perturbed by the presence of defects like fatigue cracks and the perturbed current field in turn changes the magnetic field outside the metal conductor.

The 2-dimensional model is meshed using a Quadrangular mesh with the high density of quadrangular elements near the edge of the crack, which gradually decreases as we move away from the crack tip. The model of the mesh is as shown in the Figure 6 below: 


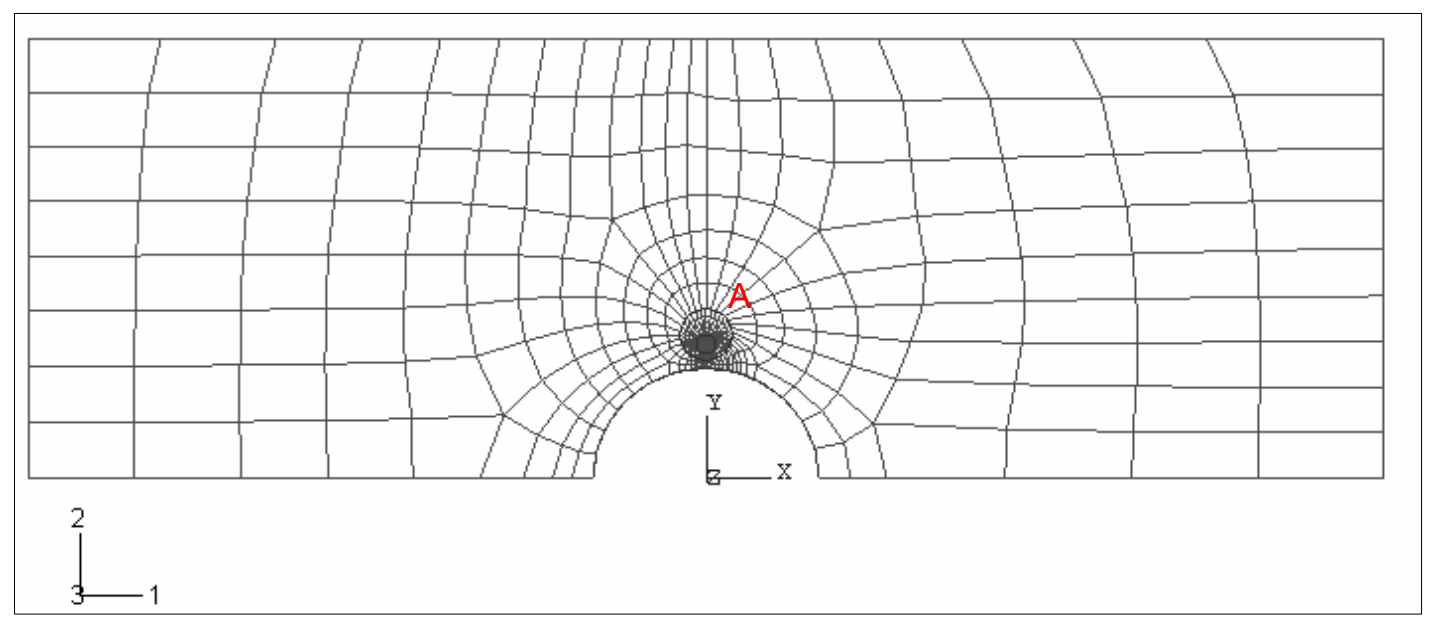

Figure 6. Meshing the two-dimensional Model

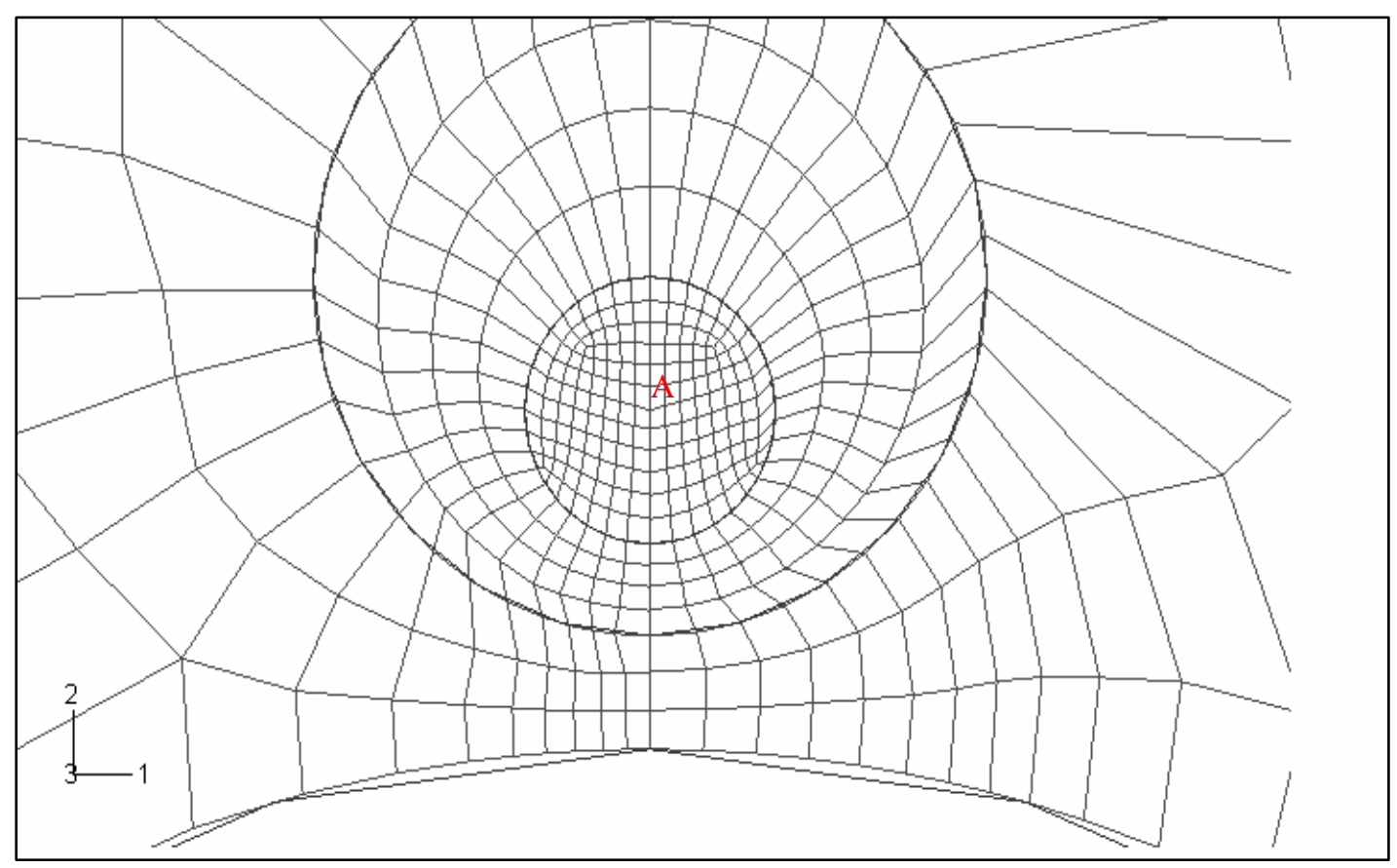

Figure 7. Magnified View of the Mesh at the Tip of the crack.

The Figures $6 \& 7$ denote the meshing carried out on the 2-Dimensional model with the density increase towards the tip of the crack. The electrical analysis is carried out on the model with the above said boundary conditions. It is 
quite necessary to study the values of the electrical current density at the elements at the tip of the crack and therefore we include a command line in the input file to obtain all the elemental values of the ECD (Electrical Current Density) at the elements close to the crack tip. This is obtained as an output from the DAT file (output file) of the analysis done. The close-up view of the Element labels near the crack tip region is shown in the Figure 8 below.

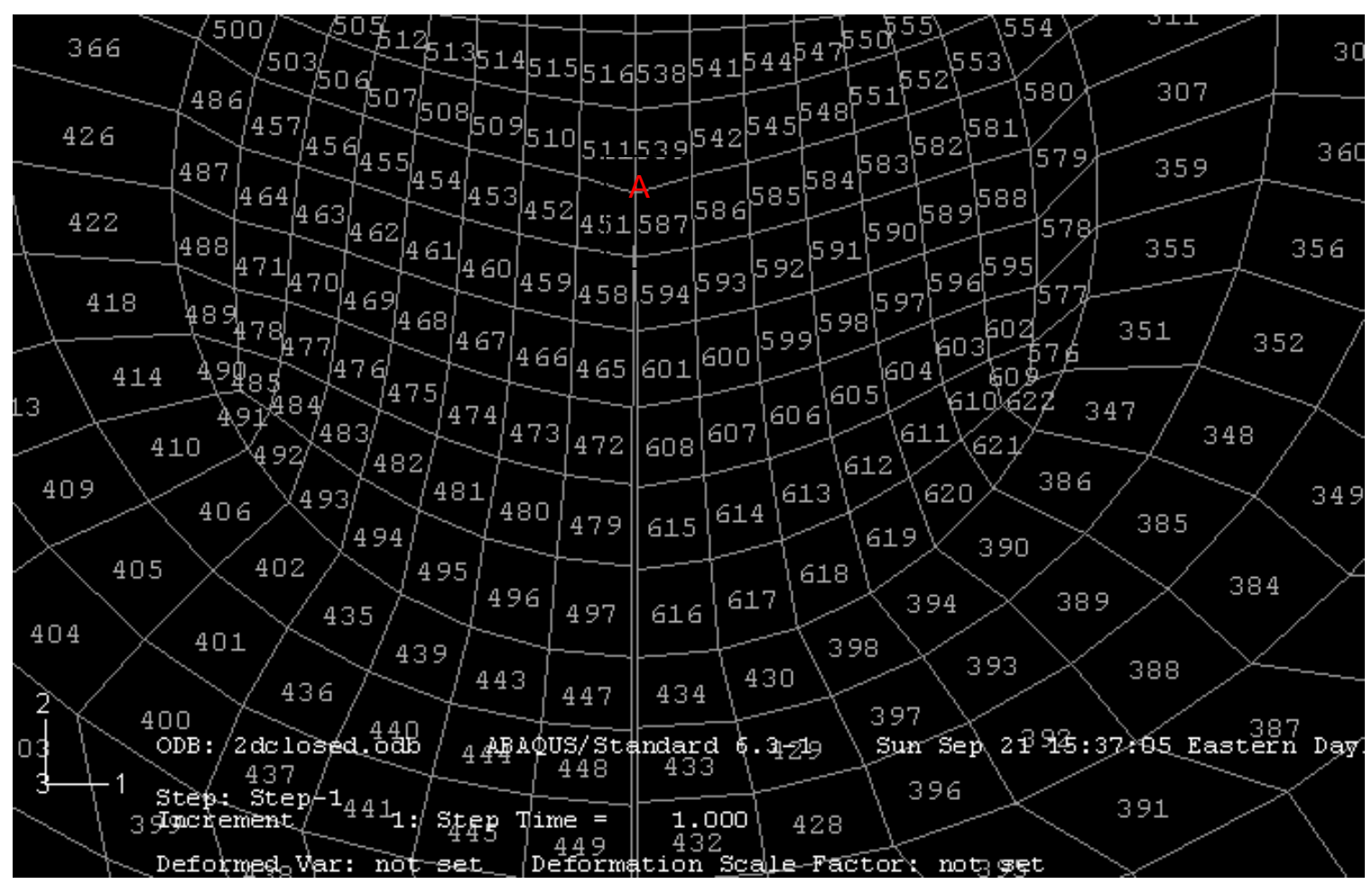

Figure 8. Element labels at the tip of the crack

When the analysis is run and the output request for electrical current density is submitted, the contour plot of the model with the output of ECD is obtained. The ECD contour plot for the 2-dimensional analysis is shown below. The intensity of the ECD at the tip of the crack and around the crack is obtained from the contour plot Figure 9 shown below. 


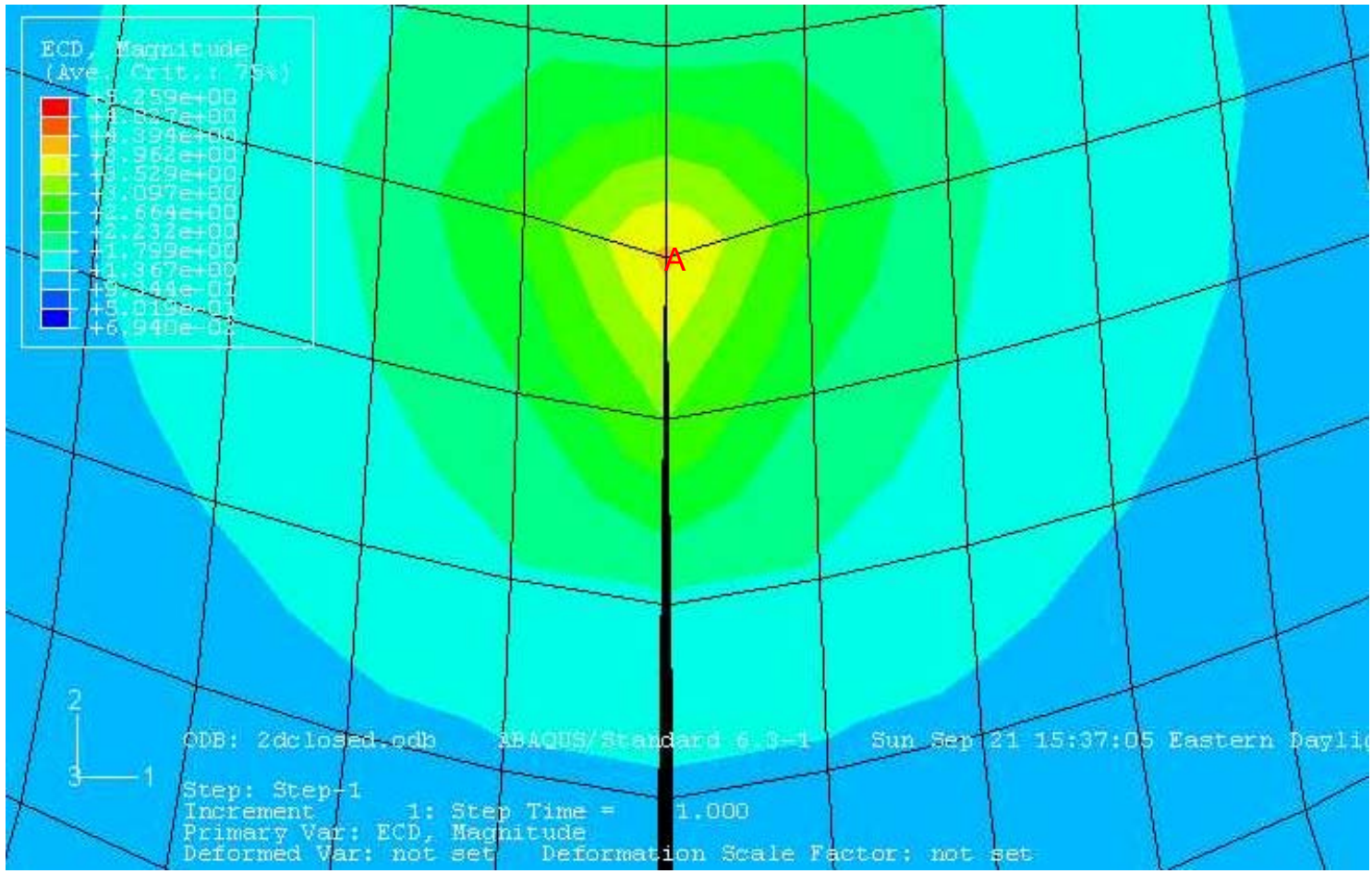

Figure 9. Electrical Current Density of the crack before force.

The Figure 9 above clearly shows that the Electric Current density at the tip of the crack is high compared to the other areas of the model. This is because of the fact that the current accumulates at the tip of the crack after flowing along the sides and thus the value of the current density at the tip will be higher than any other position in the model. The values of the Electrical Current density of the elements at the tip of the crack are obtained from the output file.

Due to the fatigue loading in the aircraft the crack might get wider and longer. As the crack opens up, due to tensile loading of the aircraft structures, it might cause severe problems as far as the maintenance of the aircraft is 
concerned. Therefore, the Electrical Analysis of the revised model (model obtained after the application of the force) is carried out to check if there is any change in the values of the ECD for the elements of the model. Forces of 10000 $\mathrm{N}$ and $5000 \mathrm{~N}$ are applied to the model so that the crack opens up. The nodal coordinates of the new model are obtained by adding a command line in the input file to obtain the new coordinates in the respective output file. The new nodal coordinates are substituted in the place of the old nodal coordinates. Then the Electrical Analysis with the same boundary conditions as the electrical model of the closed crack is carried out on the model with the updated coordinates. Then the ECD contour plot is analyzed and the new values of the ECD for the elements are obtained from the output file. The ECD plots of the open cracks are as shown in the Figures 10 and 11 below.

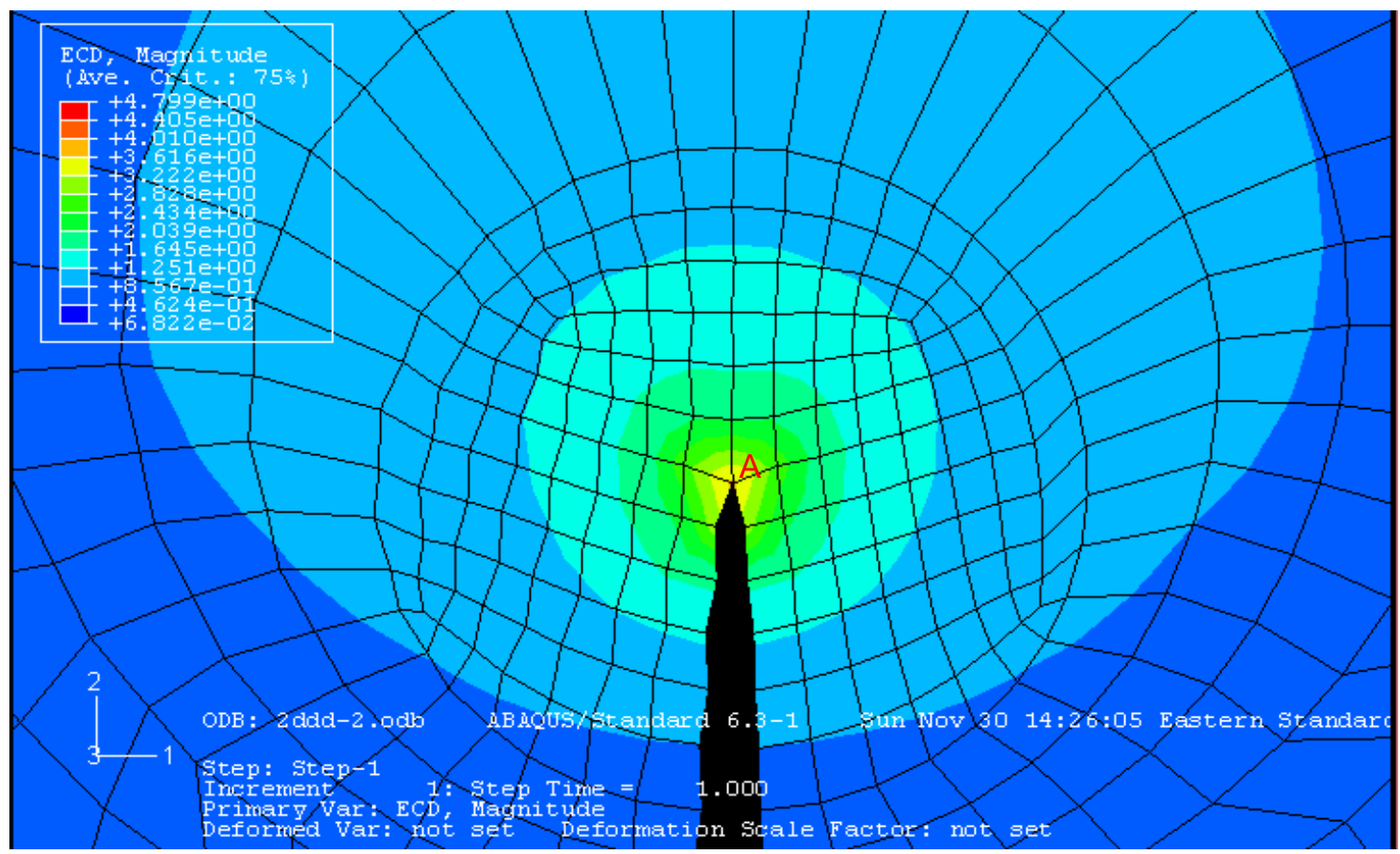

Figure 10. Crack opened up with $5000 \mathrm{~N}$ load 


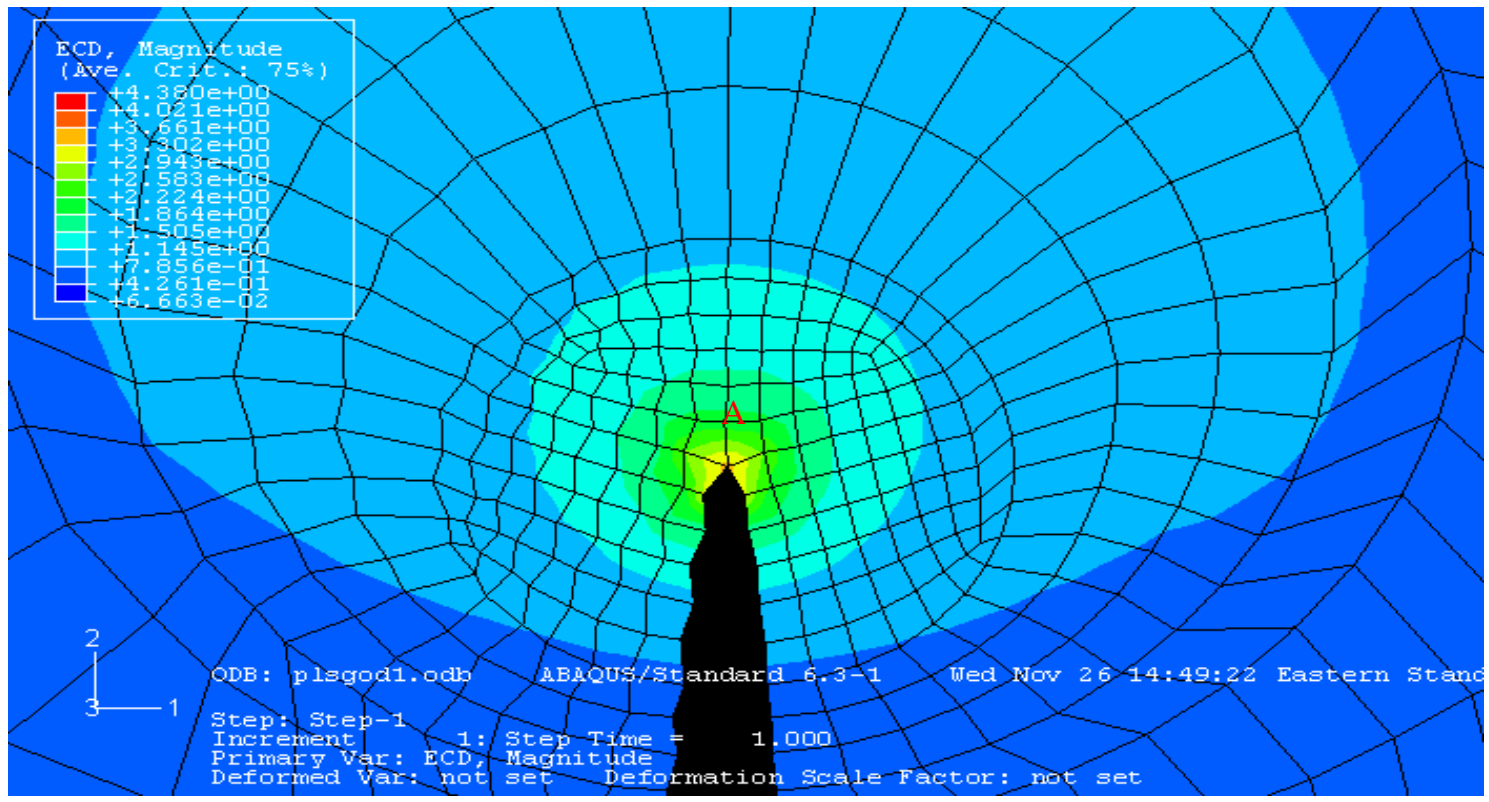

Figure 11. Crack opened up by a force of $10000 \mathrm{~N}$

The elements at the tip of the crack are considered, because the Electric current density is highest at the tip of the crack. The Electric Current Density changes in the models with different nodal coordinates, before and after the application of the force (models with the closed and opened cracks). The elemental output is obtained from the Electrical Current density before and after the force was applied is studied. The Electrical Current density of the elements at the tip of the crack is only taken into consideration at the moment because this is the area, which is of utmost the output file of the particular job file. The ECD values of the elements at tip of the crack according to Figures 10 and 11 is taken into consideration and made into a tabular column. This tabular column is shown below. 


\begin{tabular}{|c|c|c|}
\hline $\begin{array}{c}\text { Element } \\
\text { No }\end{array}$ & Closed & $\begin{array}{c}\text { Opened (5000 } \\
\mathrm{N})\end{array}$ \\
\hline 451 & 5.256 & 4.742 \\
\hline 452 & 2.4 & 2.248 \\
\hline 458 & 1.981 & 1.814 \\
\hline 465 & 1.461 & 1.372 \\
\hline 510 & 1.951 & 1.91 \\
\hline 511 & 3.063 & 2.873 \\
\hline 516 & 1.93 & 1.901 \\
\hline 521 & 1.585 & 1.568 \\
\hline 538 & 1.697 & 1.628 \\
\hline 539 & 2.236 & 2.171 \\
\hline 542 & 2.017 & 1.982 \\
\hline 537 & 1.468 & 1.444 \\
\hline 587 & 3.736 & 3.534 \\
\hline 594 & 1.997 & 1.828 \\
\hline
\end{tabular}

Opened $(10000 \mathrm{~N})$

4.294

2.131

1.729

1.31

1.888

2.729

1.879

1.447

1.598

2.121

1.956

1.329

3.35

1.769

Table 1. ECD values for two-dimensional cracks 


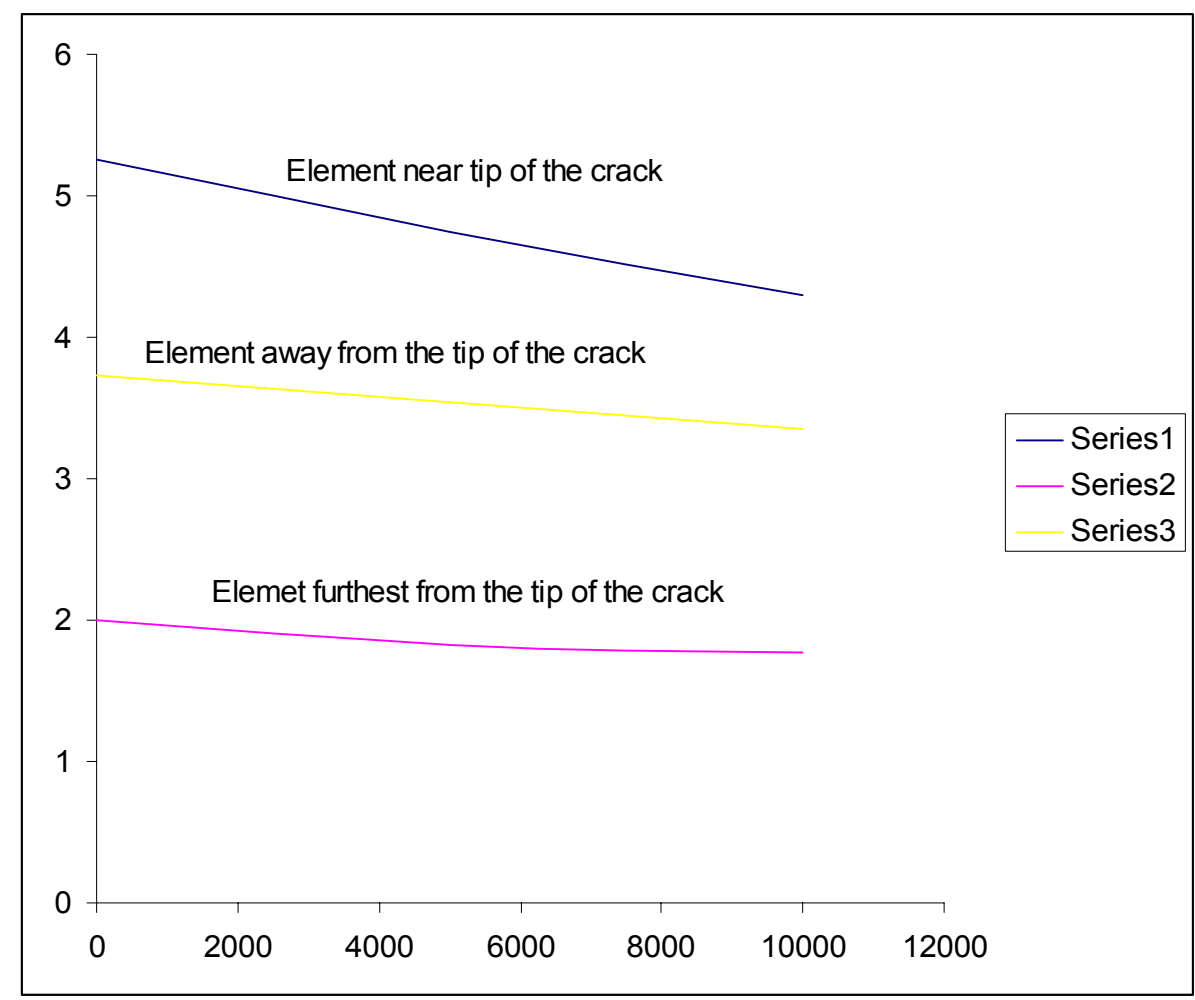

Figure 12. Change in the value of ECD with the change in load

- Table 1 clearly shows that the ECD values of the elements near the opened crack tip are higher compared to the ECD values of the elements at other parts of the plate. The values of ECD gradually decrease, away from the crack-tip region.

- The table and the plot also show that the ECD values of the elements of the open crack models are lesser than the ECD values of the elements of the closed crack model.

The explanation for the two conclusions is as follows,

- $\quad$ The governing equations for the current flow through a cracked medium are theoretically similar to those of the cracked structure under loads, i.e. they all are characterized as Poisson equations and thus analogous to the stress analysis on sharp and V-shape cracks, stresses at a sharp crack tip are 
higher than those at a v-shape crack. Similarly, the ECD values at the opened crack tip region would be lesser than the ECD values at the closed crack tip region.

- The ECD at the tip of the crack is higher than the rest of the body because the current flows across the sharp edge of the crack with higher current flow gradients. Thus it accumulates more ECD intensity. 


\section{THREE DIMENSIONAL ANALYSES}

As discussed earlier, for the two-dimensional analysis the model developed by Buzz Wincheski is used for three-dimensional analysis. The difference obviously between the two-dimensional and three-dimensional analyses is that the model used for three-dimensional analyses has a welldefined thickness unlike the one used for the two dimensional analyses. This model is one, which was imported from software package called 'SOLIDWORKS ${ }^{\mathrm{TM}}$, wherein, the model was saved as an IGS file and then imported on to ABAQUS CAE ${ }^{\mathrm{TM}} \vee 6.3$ to carry on with the analysis part of it. This model is too complex to be made in the part module of the ABAQUS ${ }^{\mathrm{TM}}$ software because this contains a crack in the shape of a triangle extending through the thickness of the plate. According to the journal of fracture mechanics and good study of the crack shape and size, it was made sure that the crack had a Vshape in its front view. Because it is practically impossible to design this crack in the part module of the ABAQUS ${ }^{\mathrm{TM}}$ software, it was modeled in SOLIDWORKS ${ }^{\mathrm{TM}}$ and then imported as an IGS file. The crack was swept in the direction of thickness in the shape of a triangle. Now the crack and the semicircle whose edge the crack is emanating from simulated the actual crack, which emanates from the edge of the rivet hole.

As discussed earlier, the model consisted of an aluminum plate with length 6 inches, width 4 inches and thickness of 0.4 inches. The diameter of the 


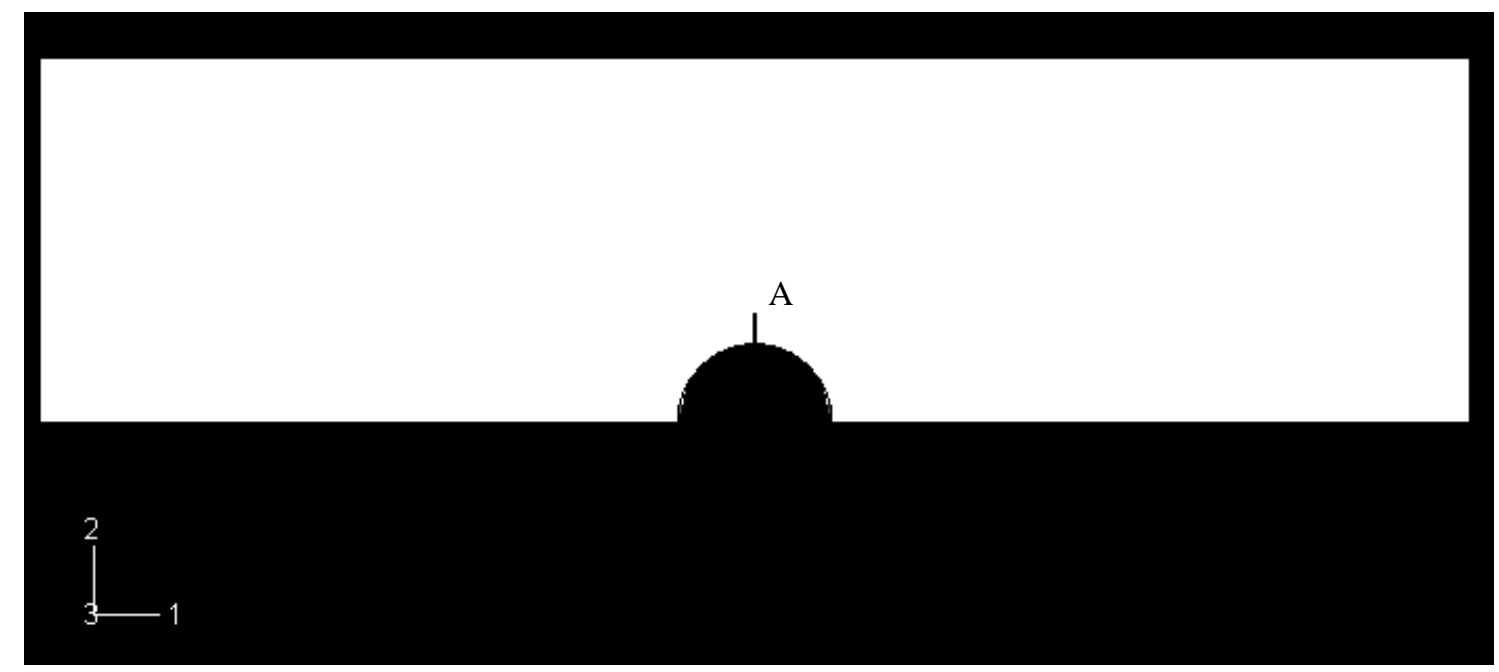

Figure 13. Front view of the model of the Aluminum Plate.

Rivet hole is 0.217 inch. This crack simulated a crack emanating from the rivet hole of the aircraft wing due to excessive fatigue load conditions.

Since the size and dimensions of the crack can vary unpredictably with respect to the fatigue load conditions it was quite necessary to carry out the electrical analyses on cracks with various dimensions. The crack was first given the smallest of dimensions and then analysis was carried out for various cracks, which change its dimensions in the Y-direction, and also in the Z-direction. The length of the crack is altered in SOLIDWORKS ${ }^{\mathrm{TM}}$ and then imported onto ABAQUS $^{\mathrm{TM}}$ and then electrical analysis done. Closed crack depicts the crack at its initial condition when a fatigue loading is not applied, while an open crack depicts the crack condition when the crack is opened up due to the excessive loading conditions. Then as mentioned earlier the plate with the crack in the original condition i.e. the closed crack is subjected to electrical simulation and 
condition. The electrical current is send from one side to another maintaining the zero potential at the other side of the plate following the principle that the current flows from a region of higher potential to the region of lower potential. The fatigue load conditions are applied to the closed crack. As expected the crack opens up under extreme load conditions. The electrical conditions are applied to this model so that we can study the change in the electrical current density plots and values as a result of the opening of the rivet crack. The closed crack is subjected to a small fatigue loading, which changes its shape, as it opens up. The coordinates of the opened crack is obtained from the output file of the ABAQUS $^{\mathrm{TM}}$ folder and then imported again as a new model so that we could carry out the electrical analysis on the new model. This model when imported is automatically meshed because this was derived from the first part of the electrical analysis on the closed model. We start of with the minimum dimensions for the crack.

The length of the crack in the $\mathrm{Y}$-Direction was taken as $1.1 \mathrm{~mm}$ or 0.043 inch. The top portion of the front view is assumed a V-shape and then swept as a triangle in the form of a triangle prism except for the V-shape at the top. This is as shown in the figure 14 . Point $A$ in figure 15 represent the crack tip at the front portion of the crack and Point B represent the crack tip at the bottom portion of the crack. The various steps discussed earlier are carried on to this model and the change in the electrical field is analyzed and studied for each model.

Different models with cracks increasing the size in z-direction but having the same shape are modeled and analysis carried out. The cracks are thus 
increased in length until it becomes a through crack, which extends throughout the thickness of the plate. The various lengths of the cracks used are,

- $1.1 \mathrm{~mm}$ or 0.043 inches

- $2.5 \mathrm{~mm}$ or 0.098 inches

- $5.7 \mathrm{~mm}$ or 0.222 inches

- $7.7 \mathrm{~mm}$ or 0.301 inches

- $9.7 \mathrm{~mm}$ or 0.379 inches

- Through crack

The results of the electrical analyses for all these models are studied and analyzed and then compared for the change in the Electrical Current Density values. This is mainly studied as earlier at the tip of the crack, where the optimum change in the Electrical Current density occurs. The Electrical Current Density values are compared for the open and the closed cracks and then studied for any small change in the Electrical Current Density. The Contour plots are also studied before and after the force is applied i.e. contour plot for the electrical analyses of the closed and open cracks is studied and electrical current density values studied.

The analysis is started off with the crack having the minimum dimensions i.e. with a length of 0.043 inches. In this model the dimension of the crack along the $\mathrm{Y}$-direction is also the same. In the consecutive models, the length along the Y-direction is maintained constant while the length along the Z-direction is changed, the following models will have the dimensions of $2.5 \mathrm{~mm}, 5.7 \mathrm{~mm}, 7.7$ $\mathrm{mm}, 9.7 \mathrm{~mm}$ respectively. Then when it becomes a through crack the dimensions 
along the Y-direction is increased gradually maintaining the crack length in Zdirection constant. Then accordingly the various parts of the analysis are carried out and then results analyzed again. The output file of the ABAQUS ${ }^{T M}$ analysis helps us identify the changes in the electrical current density values, which in turn changes the magnetic field associated with it. The magnetic analysis carried out in the latter part of this thesis validates the theory of electromagnetic induction.

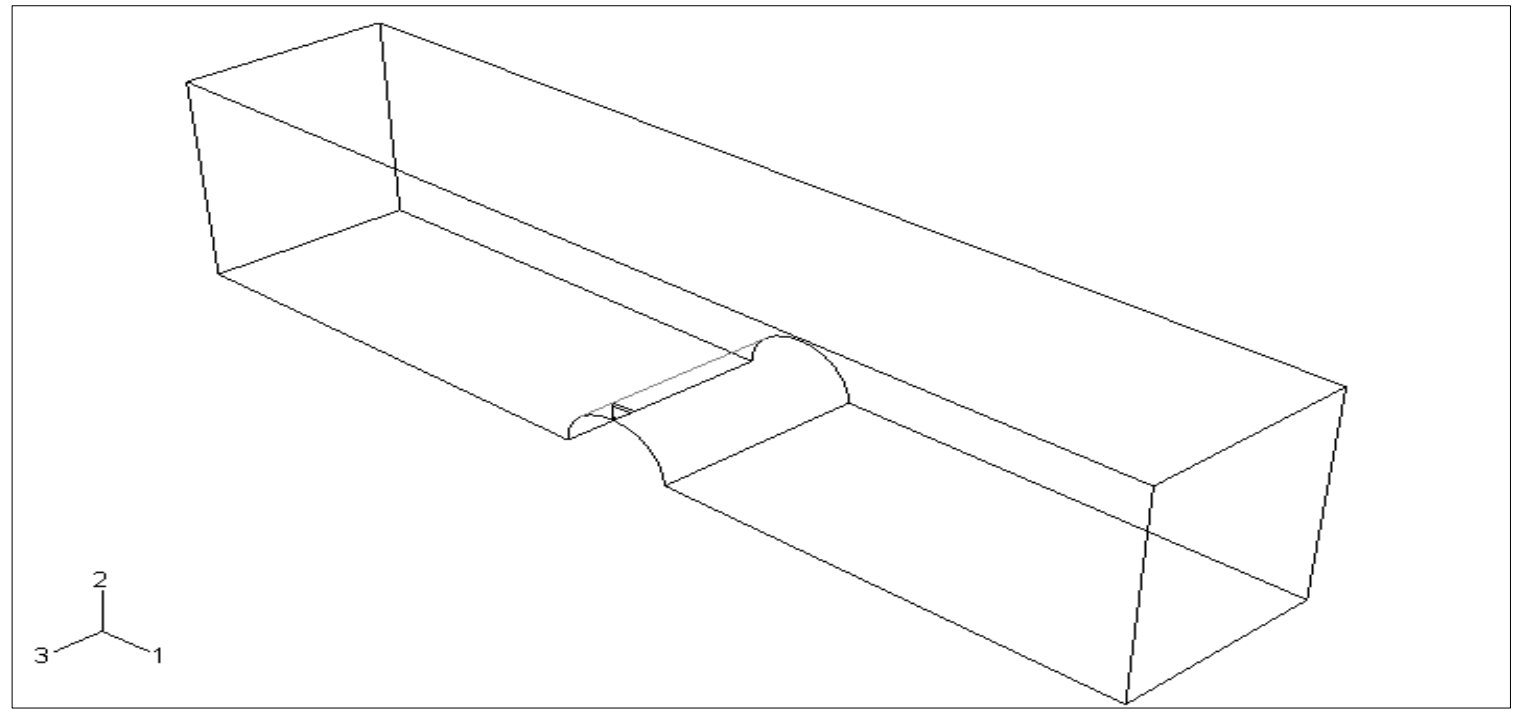

Figure 14. Isometric view of the model with the crack.

We follow the steps followed for the two dimensional model. The close up image shows that the crack tips. Figure 14 shows the crack emanating from the circumference of the three-dimensional rivet-hole while the Figure 15 shows the magnified view of the crack tip. 


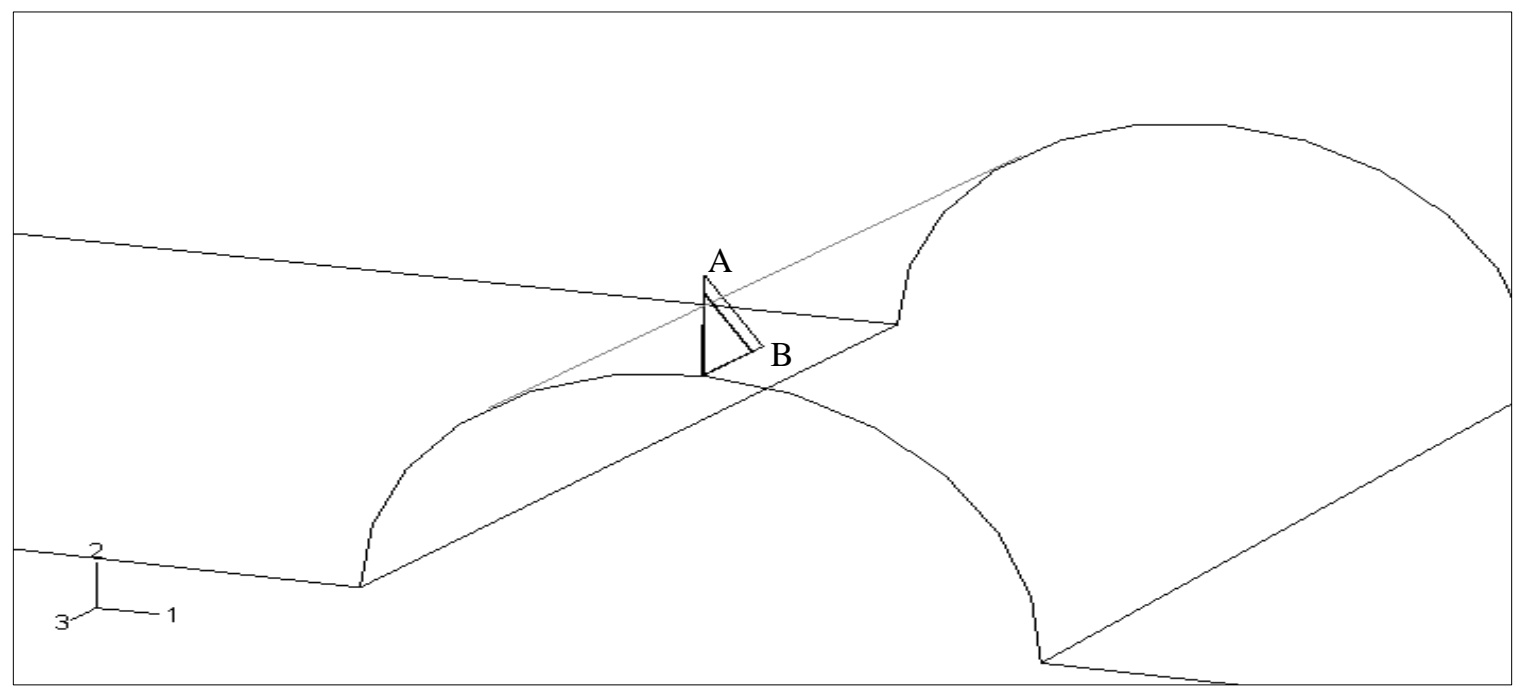

Figure 15. Magnified view of the crack

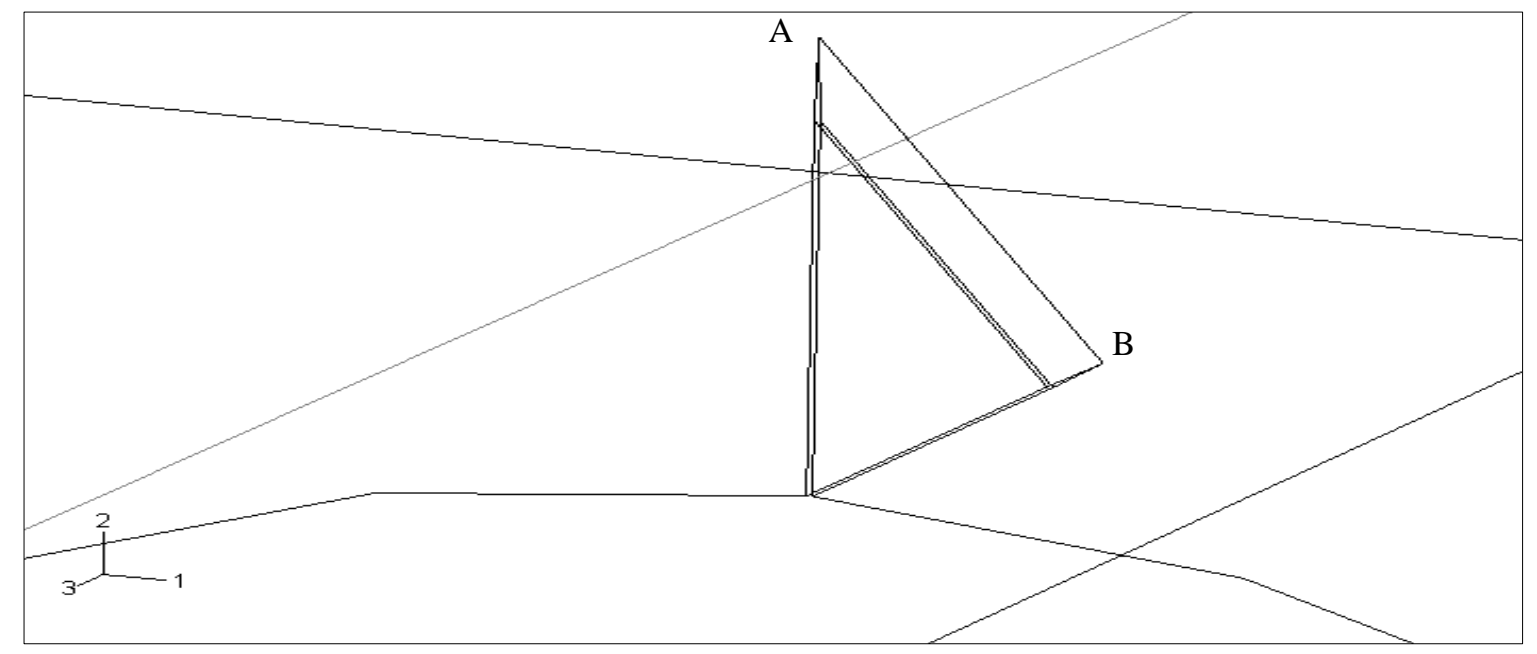

Figure 16. Another magnified view of the crack. 


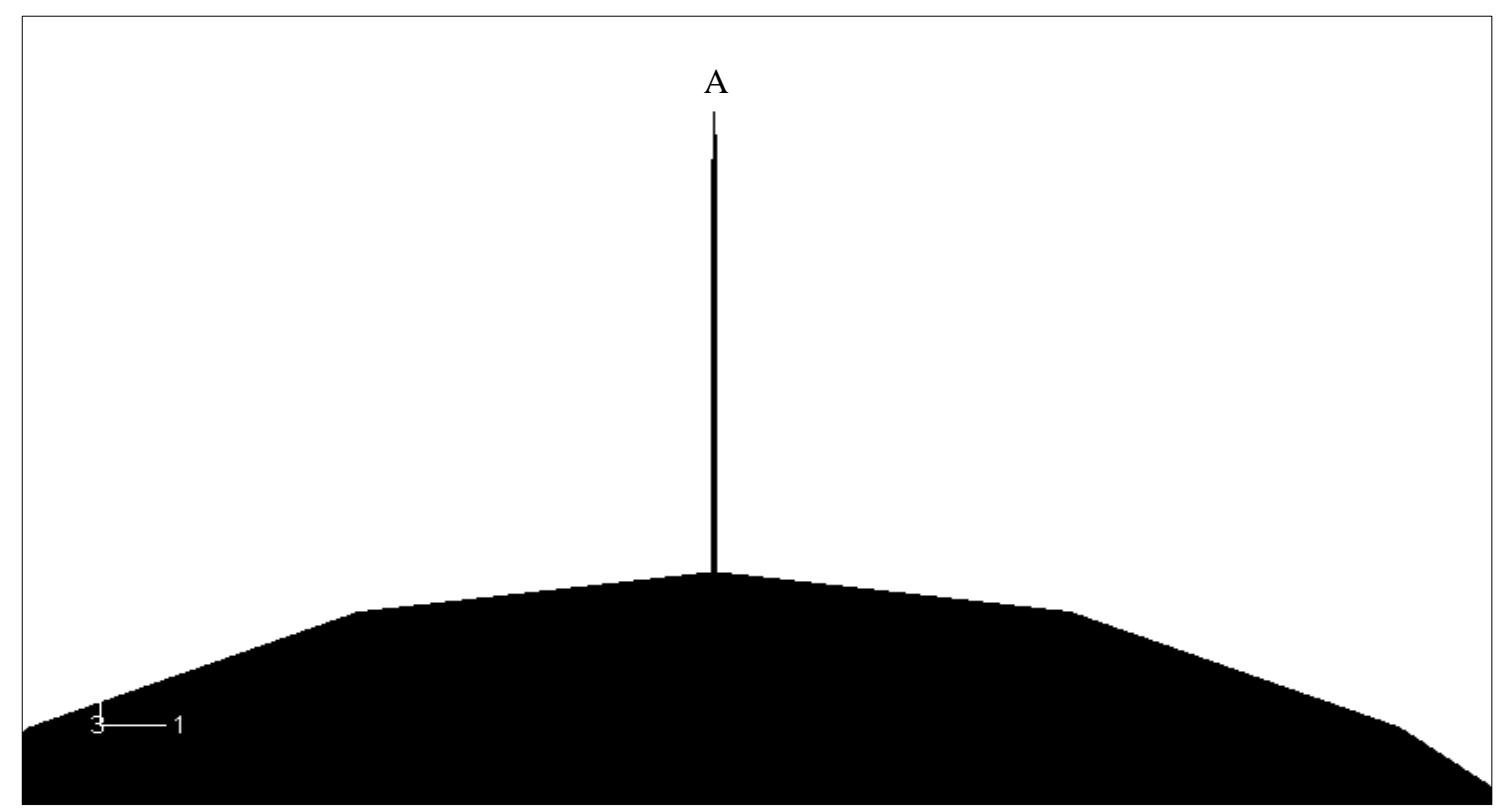

Figure 17. Front magnified view of the crack.

The plate with the hole was assigned the properties of Aluminum metal, which depicts the metal, found in Aircraft wings. The Young's modulus was again defined as 73000 and the poison ratio defined as 0.33 . The Density of the material was defined as $2700 \mathrm{~kg} / \mathrm{m}^{3}$.

The load and the boundary conditions are all defined in the same manner as defined in the two-dimensional analyses. There is a small difference though. In a two dimensional model, the load conditions and the boundary conditions of the model is assigned to one of the edges of the plate, while in the three dimensional model, the load and the boundary conditions are applied to one of the surfaces of the model i.e. face on one side of the plate. The load in the form of current is applied to all the nodes on one face of the plate maintaining a lower potential at the other side of the plate. To make things less complex, a potential of the other side is maintained as zero, which is obviously at a lower potential, 
when compared to the other side. Therefore the applied current flows from a region of higher potential to a region of lower potential. On its way to the other side, it encounters the crack. The current tried to flow across the crack, thus producing a high current density distribution at the tip of the crack. This is obtained from the output file of the ABAQUS ${ }^{\mathrm{TM}}$ analyses. This change in the electrical field changes the magnetic field associated with it. Therefore a different magnetic field value is obtained at the tip of the crack. The change in the magnetic field also is studied and analyzed later in this thesis.

Because of the complex shape of the crack in the three-dimensional model, it is practically impossible to mesh the model with a quad mesh. Therefore a tetrahedral mesh element shape is provided to the mesh controls. The shape of the crack also requires us to provide the model with this mesh so that there are two triangular elements at the two edges of the V-shape. Like earlier, the meshing in the plate is heavily concentrated at the tip of the crack where the effects of the current density have to be studied closely. The meshing is made fairly denser around the circumference of the hole and the densest at the tip of the crack while it is made less dense at the other locations on the plate. 


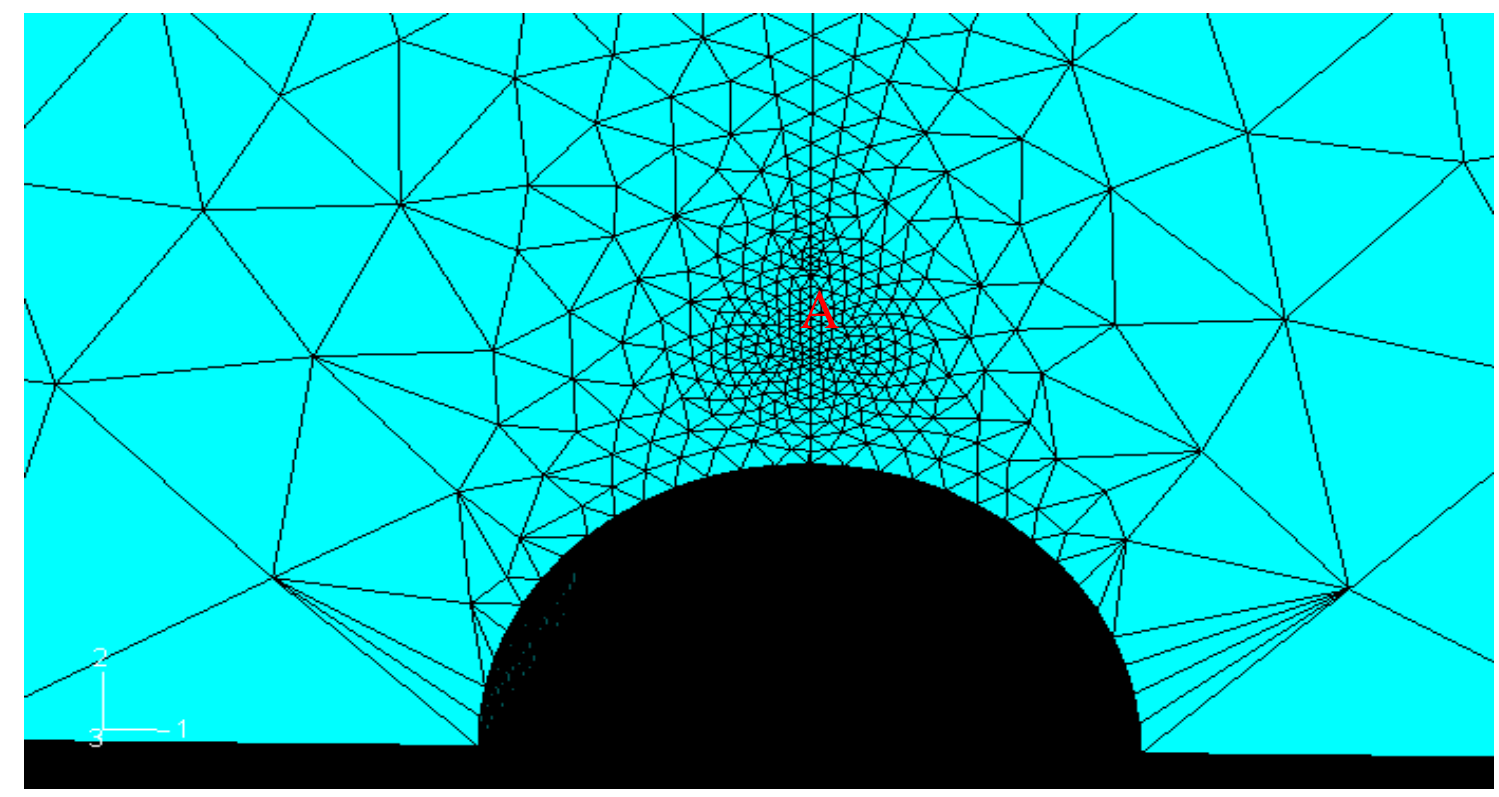

Figure 18. Close-up view of the crack tip

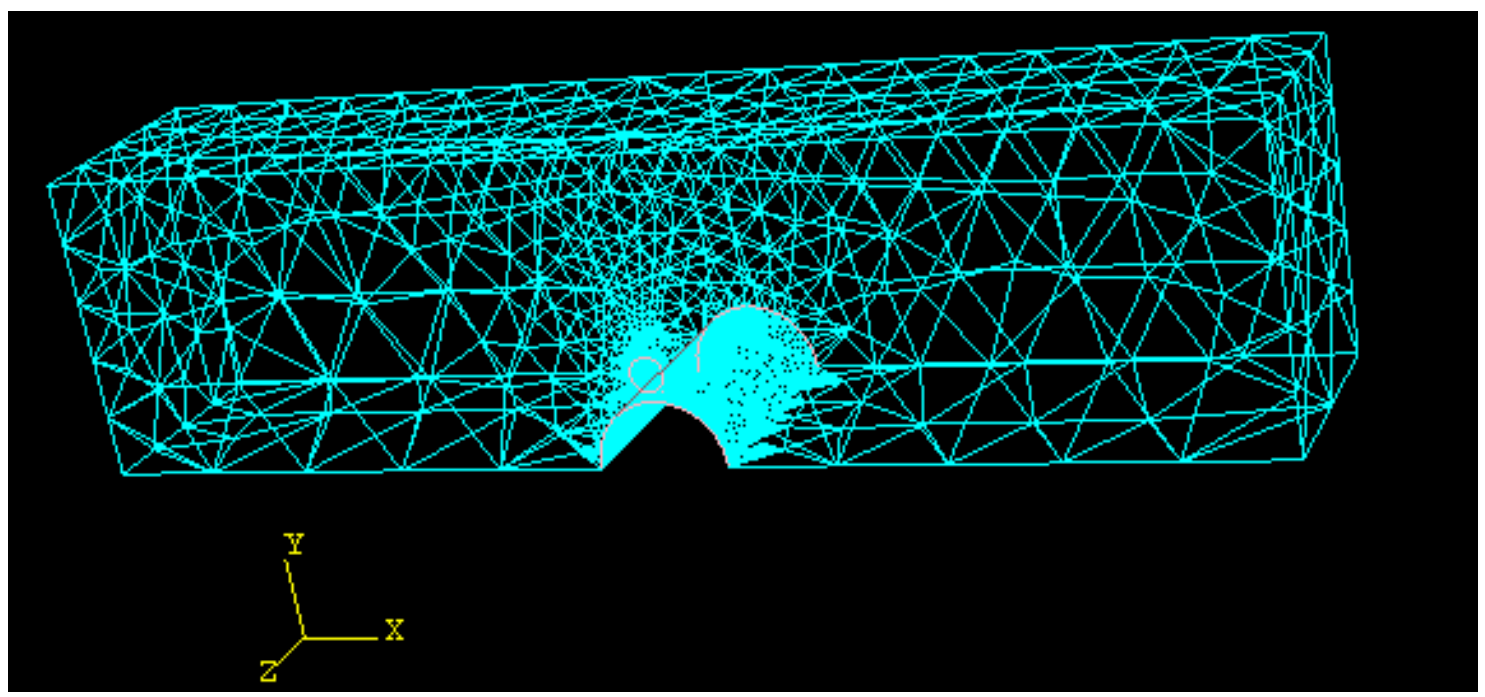

Figure 19. Meshing of the model.

The Figure 18 shows the meshing carried out on the three-Dimensional model with the density increase towards the tip of the crack. The Electrical Analysis is carried out on the model with the above said Boundary Conditions. As 
mentioned earlier it is quite important to obtain all the elemental values of the ECD (Electrical Current Density) at the elements of the tip of the crack and therefore we obtain the elemental values of the ECD from the output file of the analyses. The elemental labels at the tip of the crack are as shown in the Figure 20 below.

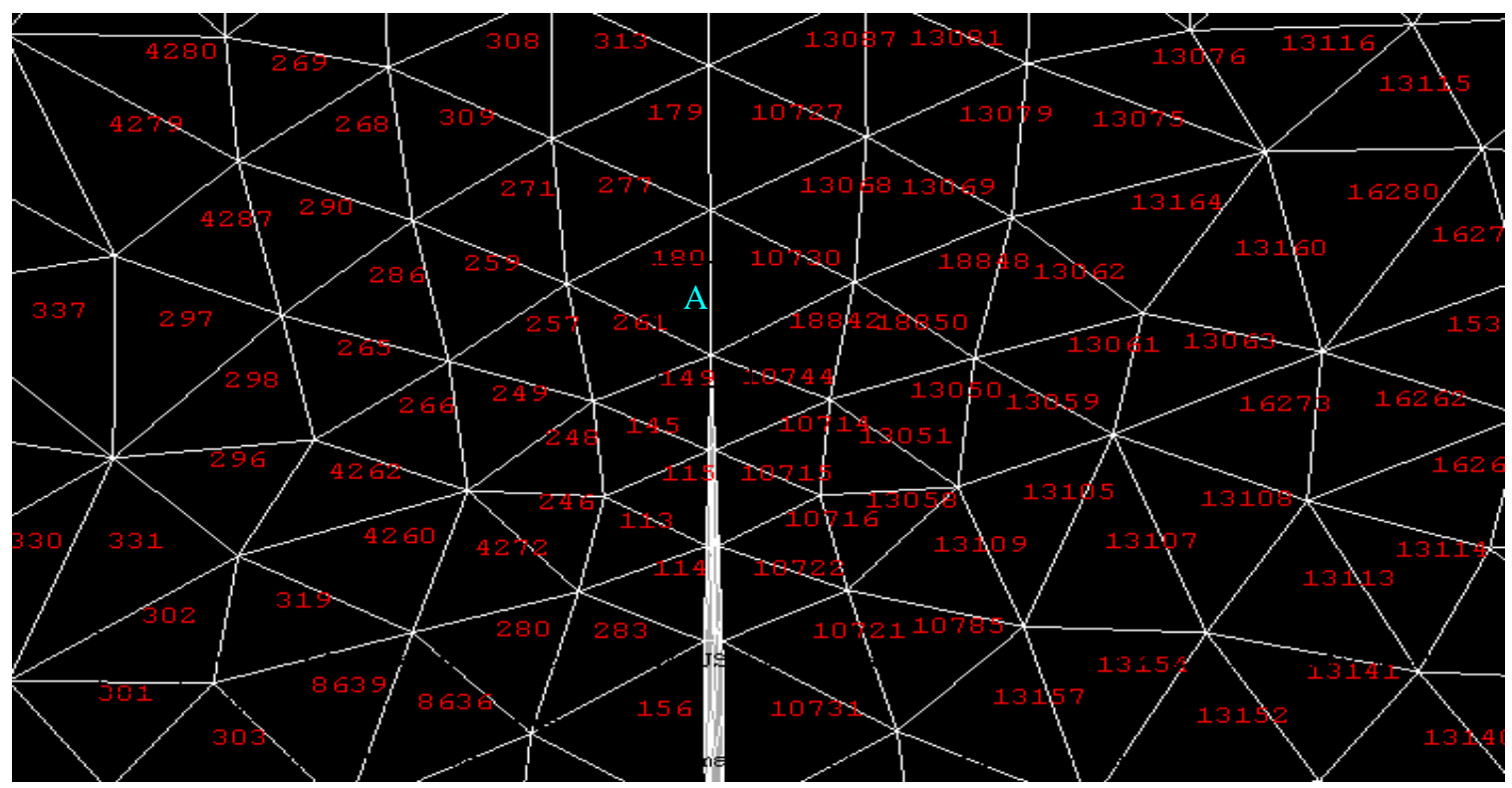

Figure 20. Elements near the tip of the crack.

Similarly the elemental labels at the tip of the crack along the depth were also analyzed. The analysis is now run for the above said model. The request for the Electrical Current density was submitted and the contour plot obtained. The ECD contour plot of the three-Dimensional model analysis is as shown below in Figure 21. As assumed and expected the maximum value of the ECD was obtained near the tip of the crack, which decreased as we moved away from the crack tip. There were fairly high values of ECD around the hole and the least at a fair distance from the crack. 


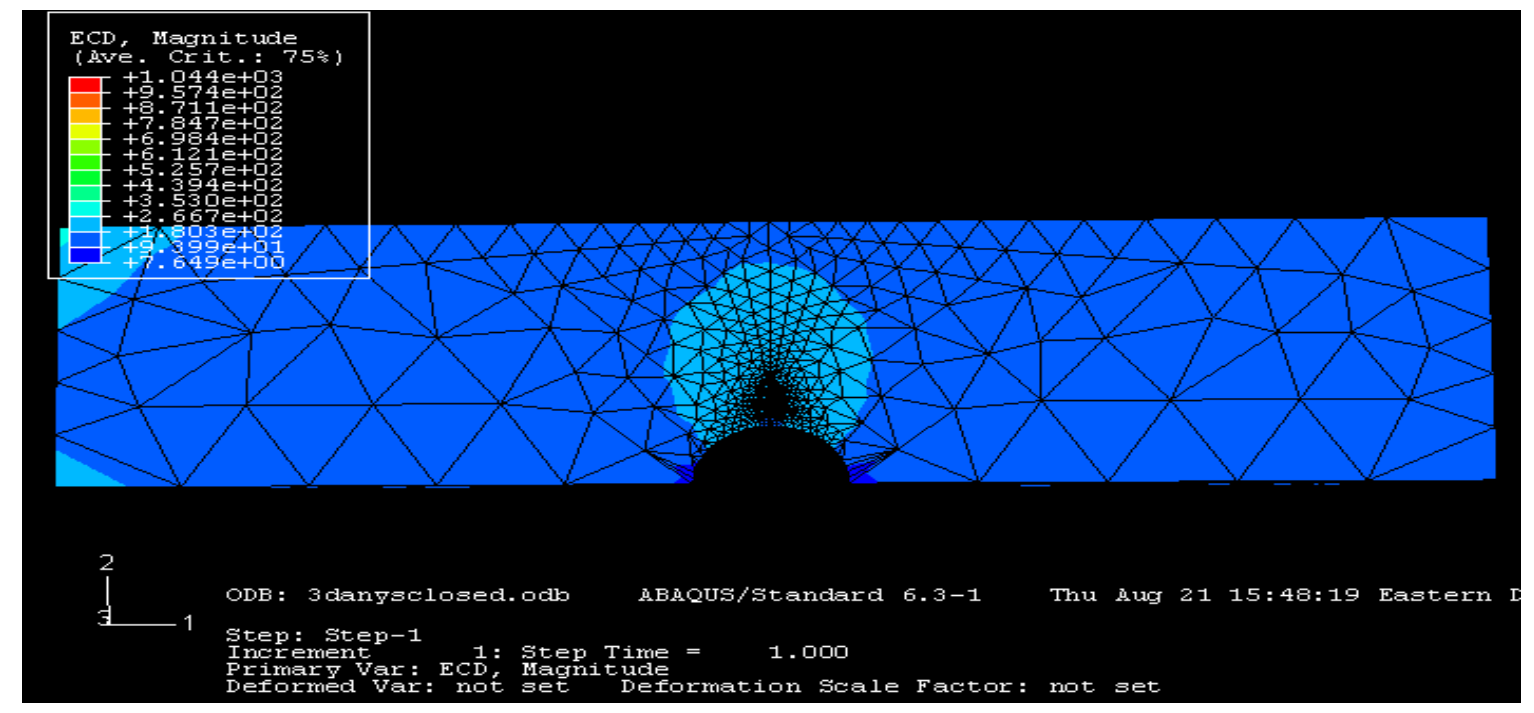

Figure 21. Contour plot of the Electrical Analysis on closed crack.

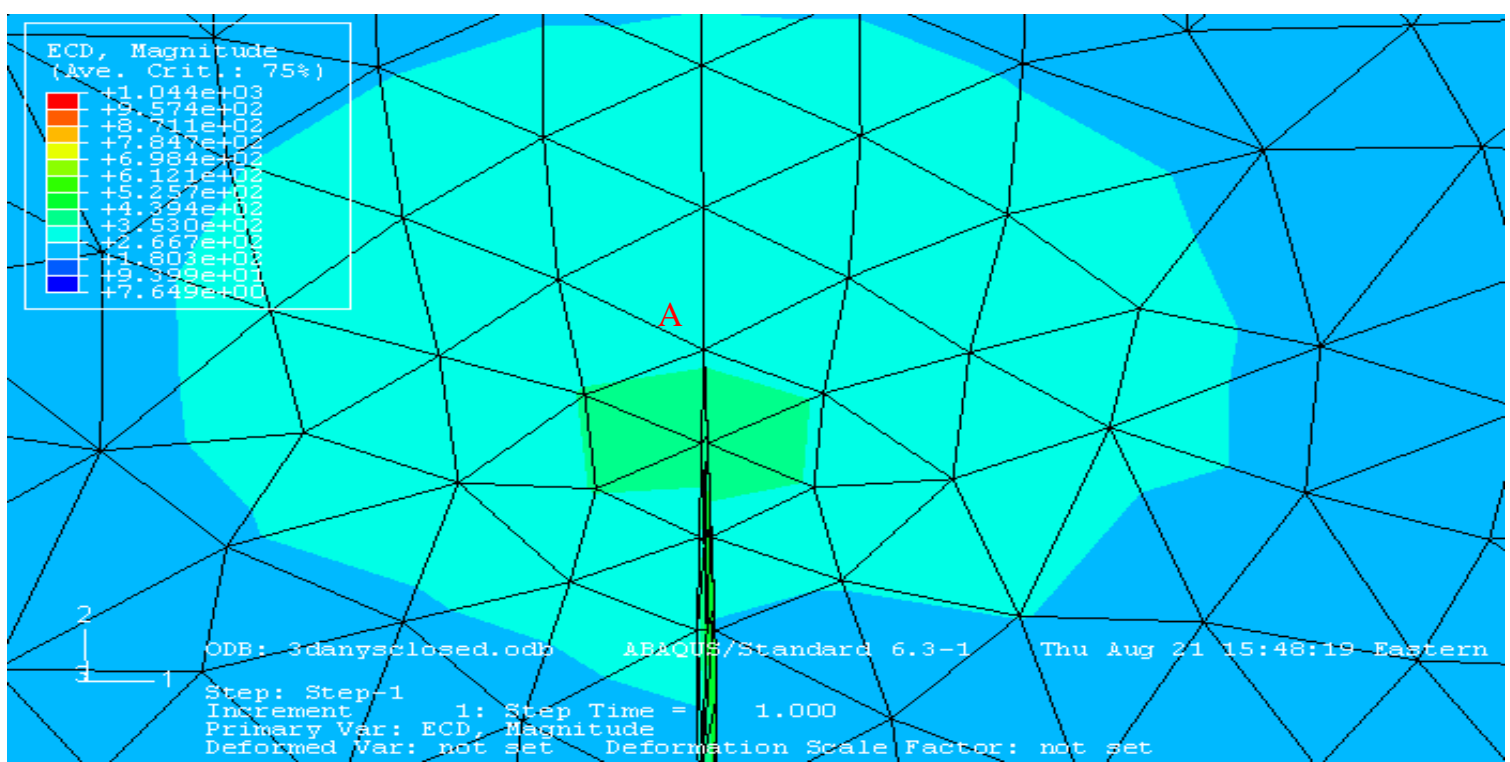

Figure 22. Close up view of the tip of the crack.

Similar to the results obtained from the two-dimensional results, the Figure 22 above shows that the Electric current density at the tip of the crack (point $A$ ) is high compared to the other areas of the crack. There is also a high value of Electrical current density around the hole but then eventually the maximum value 
of the current density was recorded at the tip of the crack, definitely because the current flows around the tip of the crack (point A). To study more about the elemental outputs of the Electrical Current Density for the elements around the tip of the crack, we first try to figure what the elements are and then we try to deduce the values of the Electrical Current Density of all these elements. This is obtained by adding two separate commands to the input file, one to obtain the element numbers and the next to obtain the elemental values for all those elements. The element numbers can be obtained through the user-interface of the ABAQUS ${ }^{T M}$ software while the values of the Electrical Current density can be obtained by including the command as mentioned in the input file of the analysis.

The fatigue loading in aircrafts make these cracks wider and this also extends in the y-direction. Efforts have been made to study cracks of all shapes and sizes. Normally due to tensile loading the cracks get wider i.e. it opens up. Now as we discussed earlier it is very unreasonable to undo the rivets and examine it each time. Therefore it would be much more viable to examine the cracks as a Non-Destructive testing mechanism. Therefore the system should be strong enough to measure and detect even the smallest opening of the crack with time due to fatigue loading conditions so that it would be easier for maintenance engineers to check for the airworthiness of the flights. When they realize that the crack is propagated enough and more in either the Y-Direction or the Z-Direction, then they would have to remedy the fatigue crack or declare the aircraft 'unworthy' to fly. 
To study the effect of ECD distribution in the presence of an opening crack, a small force is applied to cause opening of the 3D crack. The purpose is to study the change of ECD values as a result of the opening of the crack. The new coordinates of the opened crack are obtained from the output file of the ABAQUS ${ }^{T M}$ analyses when the closed crack was subjected to a tensile force. This new coordinates are then used to build a model and rerun the FE electrical analysis. The new contour plot is shown in Figure 24.

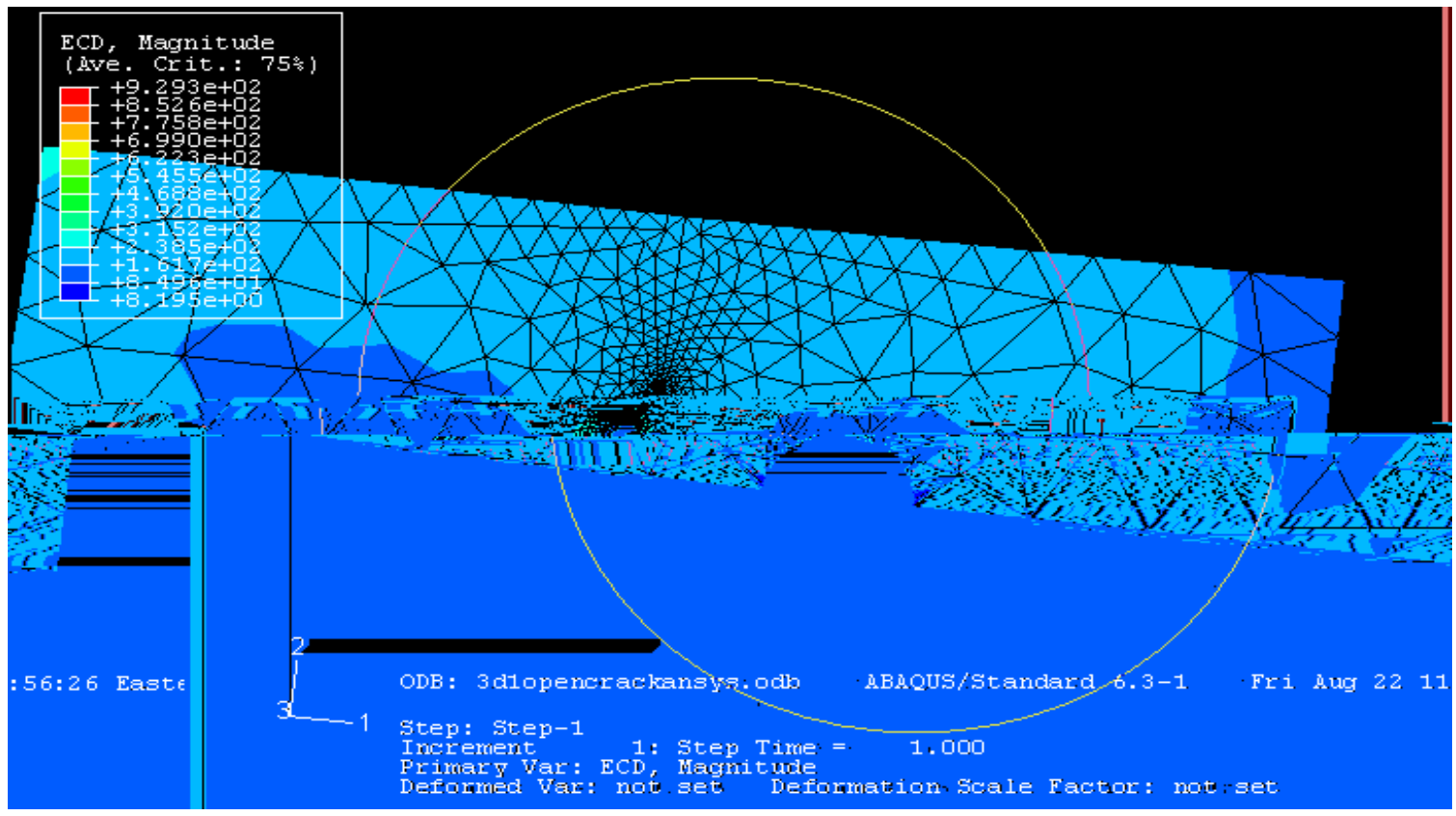

Figure 23. Contour plot of Electrical Analysis of Open crack.

To know the exact region of the model where the ECD values are highest, a high range of ECD values was considered and then the contour plot for the ECD in the visualization module re-plotted. 


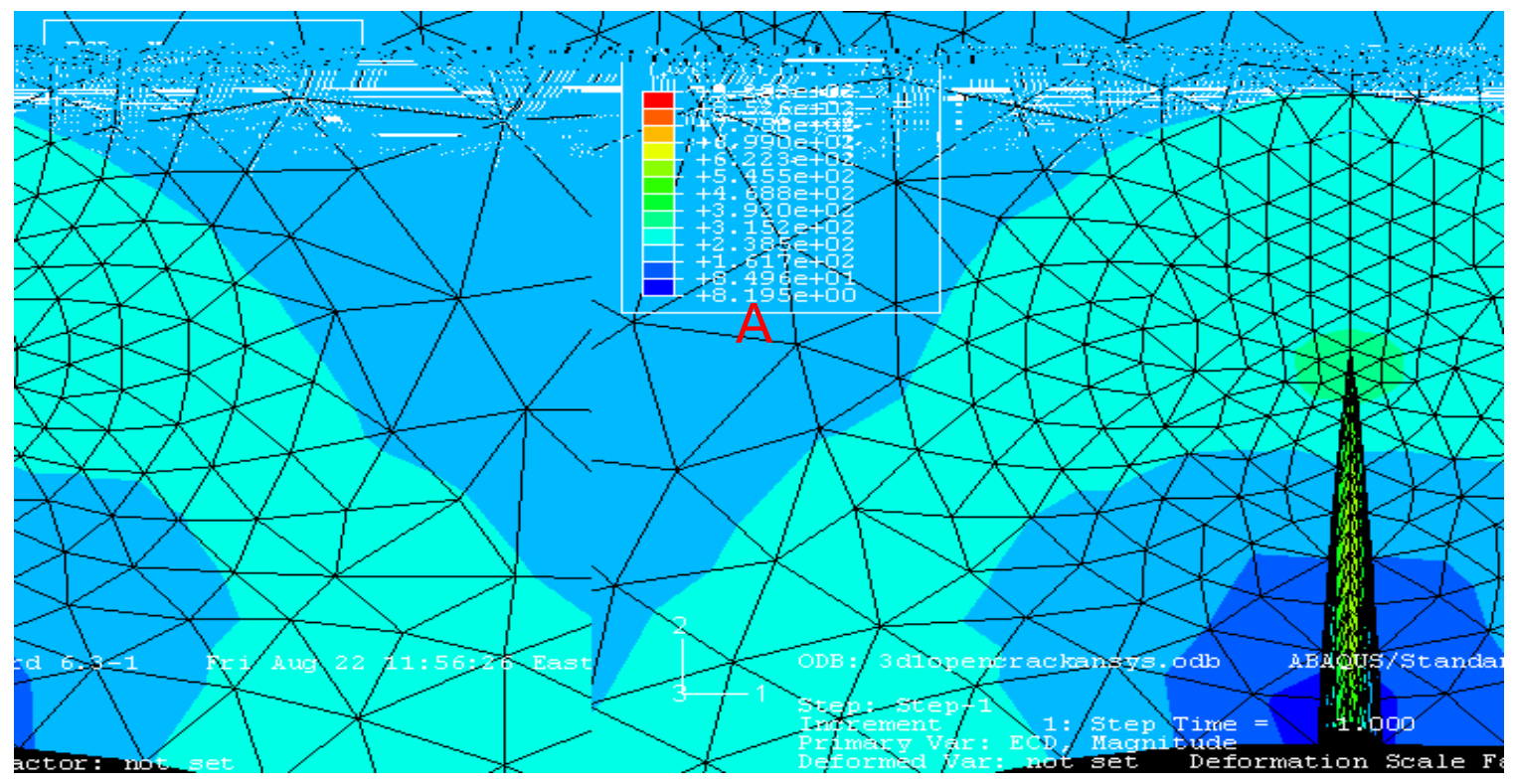

Figure 24. Close up of the opened crack

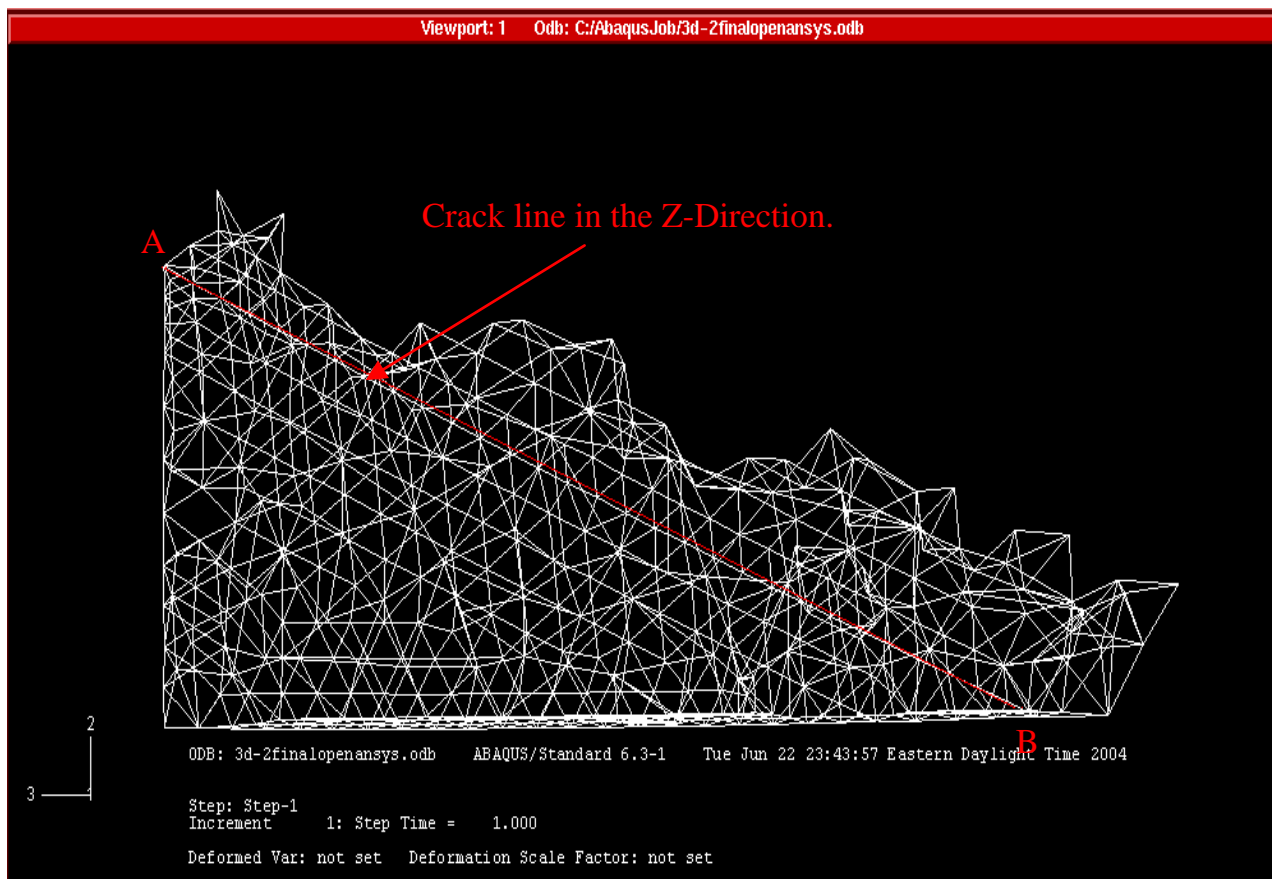

Figure 25. Crack line in Z-direction

To determine where the maximum value of ECD lies, we make a sliced cut to obtain the sectional view of the model and determine where the maximum value of ECD lies along the crack length in the Z-direction. The sliced cut is made in 
the model with the ECD contour plot in the visualization module. Figure 25 shows the sliced cut sectioned view of the crack.

The red line denotes the crack length in the Z-direction. Figures 25 and 26 shows the contour plots for the closed and the open models around the crack length denoted by the red line. Sectional cuts are made on the ECD contour plot of the open and closed crack model to study the ECD magnitude in and around the crack line. Point $A$ and point $B$ are the two tips of the crack model, as discussed earlier.

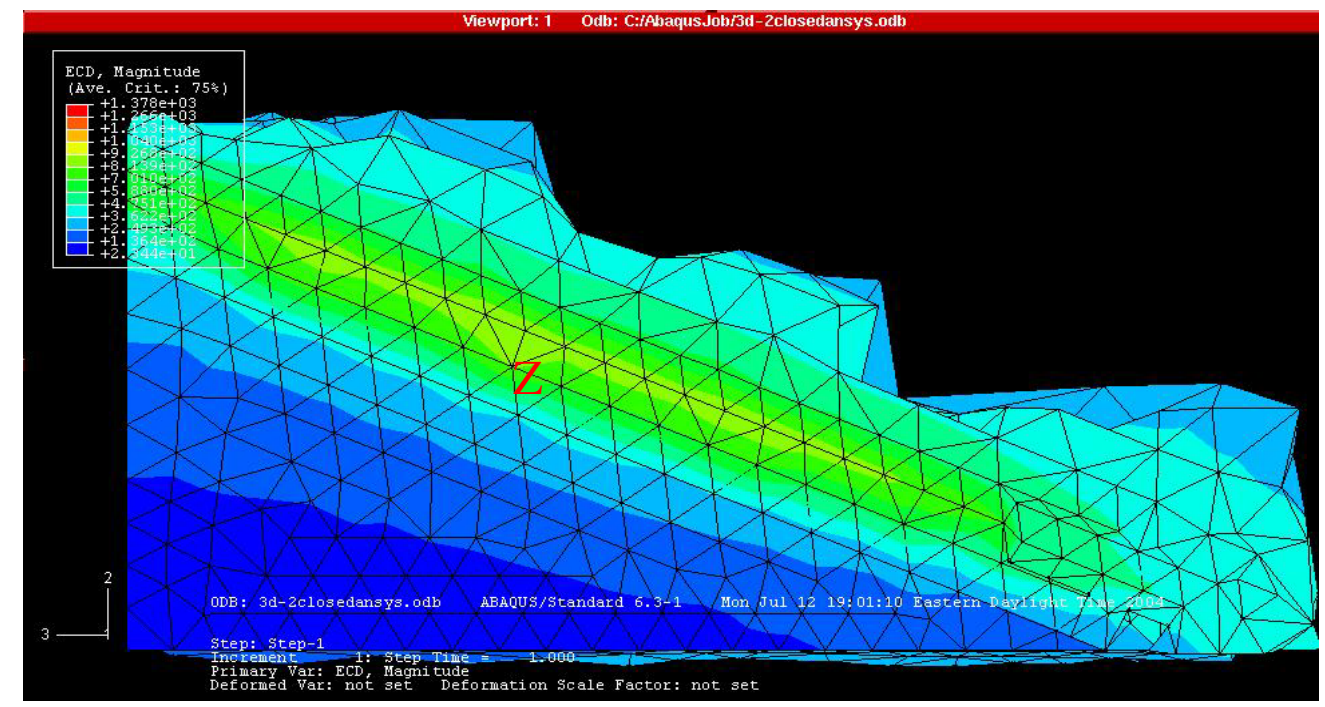

Figure 26. Cross-sectional ECD plot of the closed crack model 


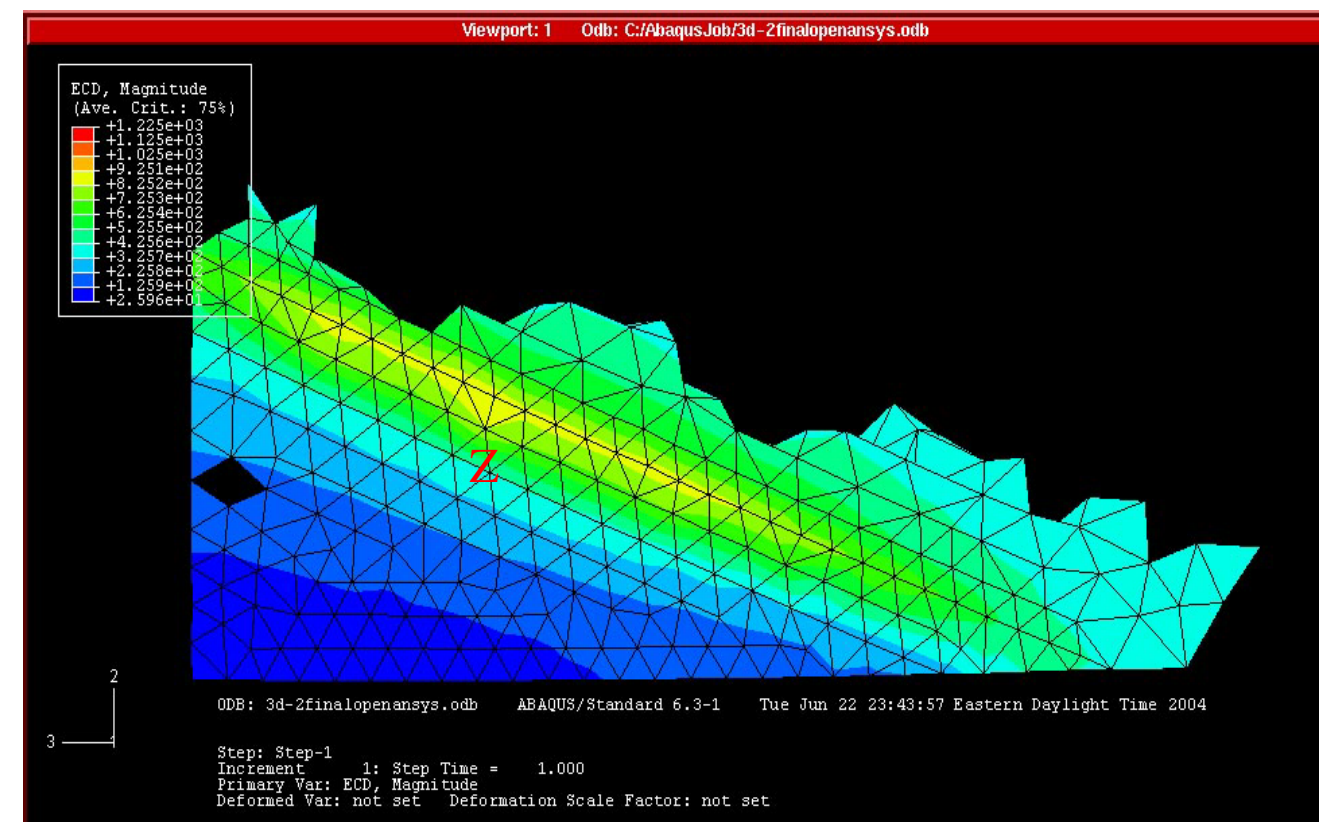

Figure 27. Cross-sectional ECD plot of the open crack model

Figures 26 and 27 prove that the ECD value is highest at a region closer to the top portion of the crack line (Point A), when compared to other regions along the crack line. This trend is followed for both the closed and the open crack models as shown in Figures 26 and 27. Point $Z$ in the figures represents the region which has the highest ECD. This point $Z$ is located close to point $A$ along the crack line. The elemental value of ECD at point $Z$ is 1106 for the closed crack model and 1079 for the open crack model.

As discussed earlier every Electrical field is associated with a magnetic field. As the crack length increases in the Z-direction, the electrical field increases and the maximum ECD value at point $Z$ increase. The magnetic field and magnetic flux density values correspondingly increase. The magnetic sensor picks up this magnetic field when it is positioned above the point $Z$ as it moves on 
top of the aircraft wing. Thus one can easily figure out the crack length by the resultant magnetic field or resultant magnetic flux intensity values.

Sometimes the contour plots wouldn't tell the perfect story because the change of values doesn't seem evident. But, there is a more accurate way of proving that there is a change of ECD values with the opening of the crack. Table 2 shows the changes in ECD values with the opened and closed cracks.

\begin{tabular}{|cc|c|}
\hline $\begin{array}{c}\text { Element } \\
\text { no }\end{array}$ & Closed & Open \\
\hline 149 & 372.2 & 345.2 \\
\hline 10744 & 385.5 & 343.7 \\
\hline 145 & 378.3 & 338.3 \\
\hline 10714 & 370.2 & 328.9 \\
\hline 261 & 354.5 & 330.7 \\
\hline 18842 & 350.7 & 343.2 \\
\hline
\end{tabular}

Table 2. ECD Values for three-dimensional model

Table 2 clearly shows that the ECD values change when the analysis is run for closed and open cracks. Let's analyze the results closely for the above said crack for both conditions and then go on and see for any change of the ECD values with the change in the shape and the size of the crack. Therefore to summarize, the analysis is considered in two perspectives. This involves the study of the change of ECD values due to two main things. They are,

- Change in the values of the Electrical Current Density for one crack (crack with dimension 1.1-mm for example) under consideration when it is in open and closed condition. 
- Also compare the changes in the ECD values when the open and the closed electrical flow potential analysis is carried out in cracks with dimensions ranging from $1.1 \mathrm{~mm}$ to when it is a through crack (This can only be done when the elemental values of all electrical current density values are taken and analyzed and compared).

Let's now analyze the results obtained from tabular column [2], which denotes the change in the ECD values for the open and closed crack conditions. The two things that can be deduced from the two models or the two analysis is that,

- Like the two-dimensional analyses, the Electrical Current Density value of the element at the tip of the closed crack is higher than that of the open crack (crack opened up after force is applied).

- Similar to the two-dimensional analysis, the Electrical Current Density values of the elements along the $\mathrm{V}$-section of the crack is higher than the values of the elements at the rest of the plate for open and closed electrical analysis. The electrical current density records a high value along the V-shape cross-section of the crack. The elements close to the $\mathrm{V}$-shape of the crack, including the tip of the crack form the portion of the model where the highest values of electrical Current Density are recorded.

The explanation for the two conclusions is as follows,

- The governing equations for the current flow through a cracked medium are theoretically similar to those of the cracked structure 
under loads, i.e. they all are characterized as Poisson equations and thus analogous to the stress analysis on sharp and v-shape cracks, stresses at a sharp crack tip are higher than those at a v-shape crack. Similarly, the ECD values at the opened crack tip region would be lesser than the ECD values at the closed crack tip region.

- The ECD at the tip of the crack is higher than the rest of the body because the current flows across the sharp edge of the crack with higher current flow gradients. Thus it accumulates more ECD intensity. If there is no disturbance or perturbance, the current just flows across, thus giving the elements of the plate a low value of Electrical Current Density, unlike the tip of the crack where the current flow gradients accumulate and thus giving the elements there, a high value of Electrical Current Density. 


\section{COMPARISON OF ELECTRICAL ANALYSIS OF MODELS WITH DIFFERENT CRACK LENGTHS ALONG THE THICKNESS (IN THE Z-DIRECTION) OF THE ALUMINUM PLATE.}

As discussed earlier, various models with different crack lengths along the thickness were made and the electrical analysis carried out on all these models with the same load and the boundary conditions as mentioned earlier in the original model. The length of the crack was increased in the Z-direction maintaining the shape and plate dimensions the same. The length of the crack was increased step by step until it became a through crack. The mesh and the element properties were made quite similar in all the cases and subjected to same load and boundary conditions. The various crack lengths used in the various models used in the analysis are,

- $1.1 \mathrm{~mm}$ or 0.043 inches

- $2.5 \mathrm{~mm}$ or 0.098 inches

- $5.7 \mathrm{~mm}$ or 0.222 inches

- $7.7 \mathrm{~mm}$ or 0.301 inches

- $9.7 \mathrm{~mm}$ or 0.379 inches

- Through crack.

The crack length increase is as shown in Figures 31-35, which denotes the shift of point $B$ through the cross-section of the model, until it becomes a through crack. Point A remains constant. 


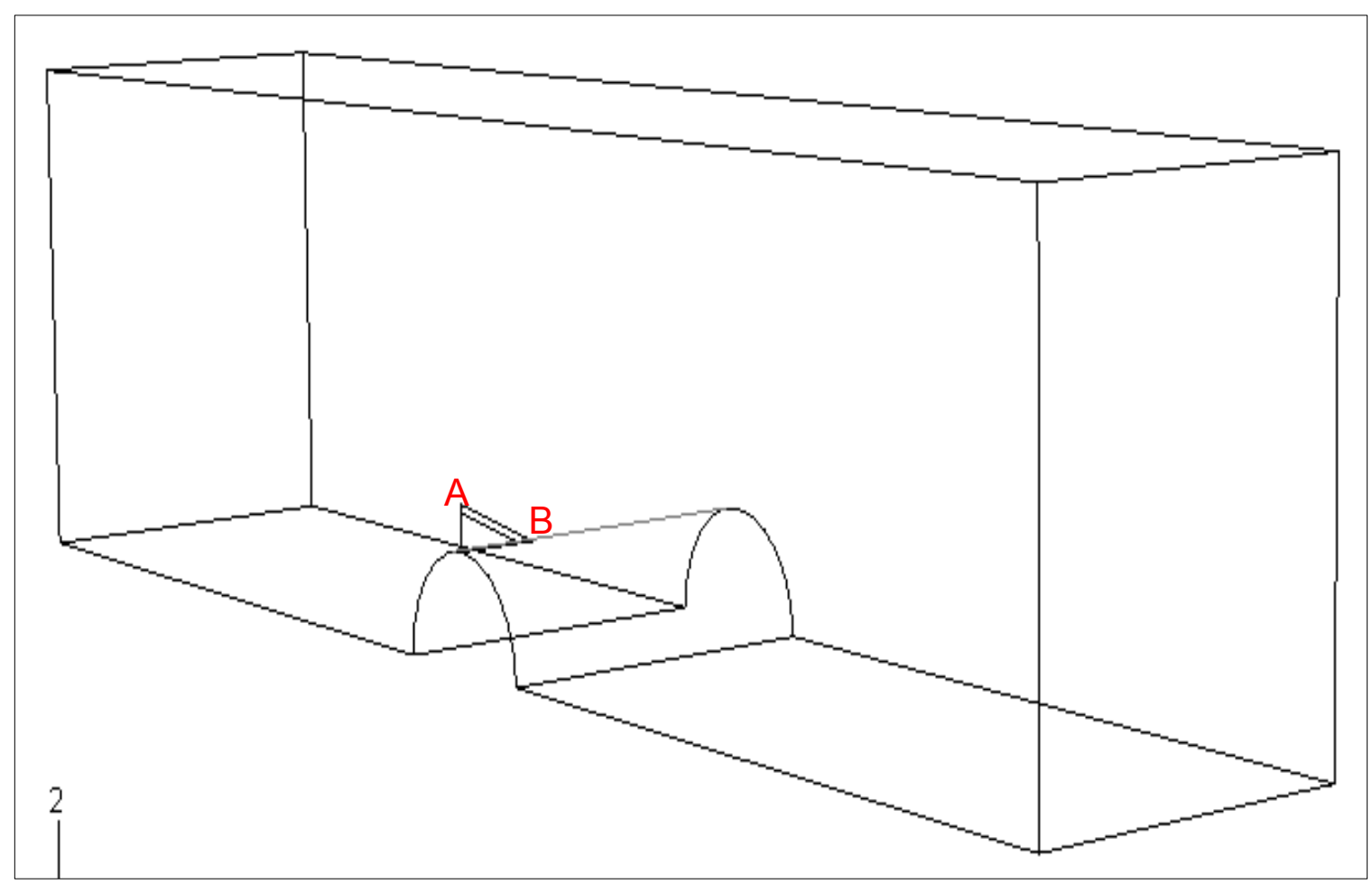

Figure 28. Isometric view of the plate with crack length $2.5-\mathrm{mm}$

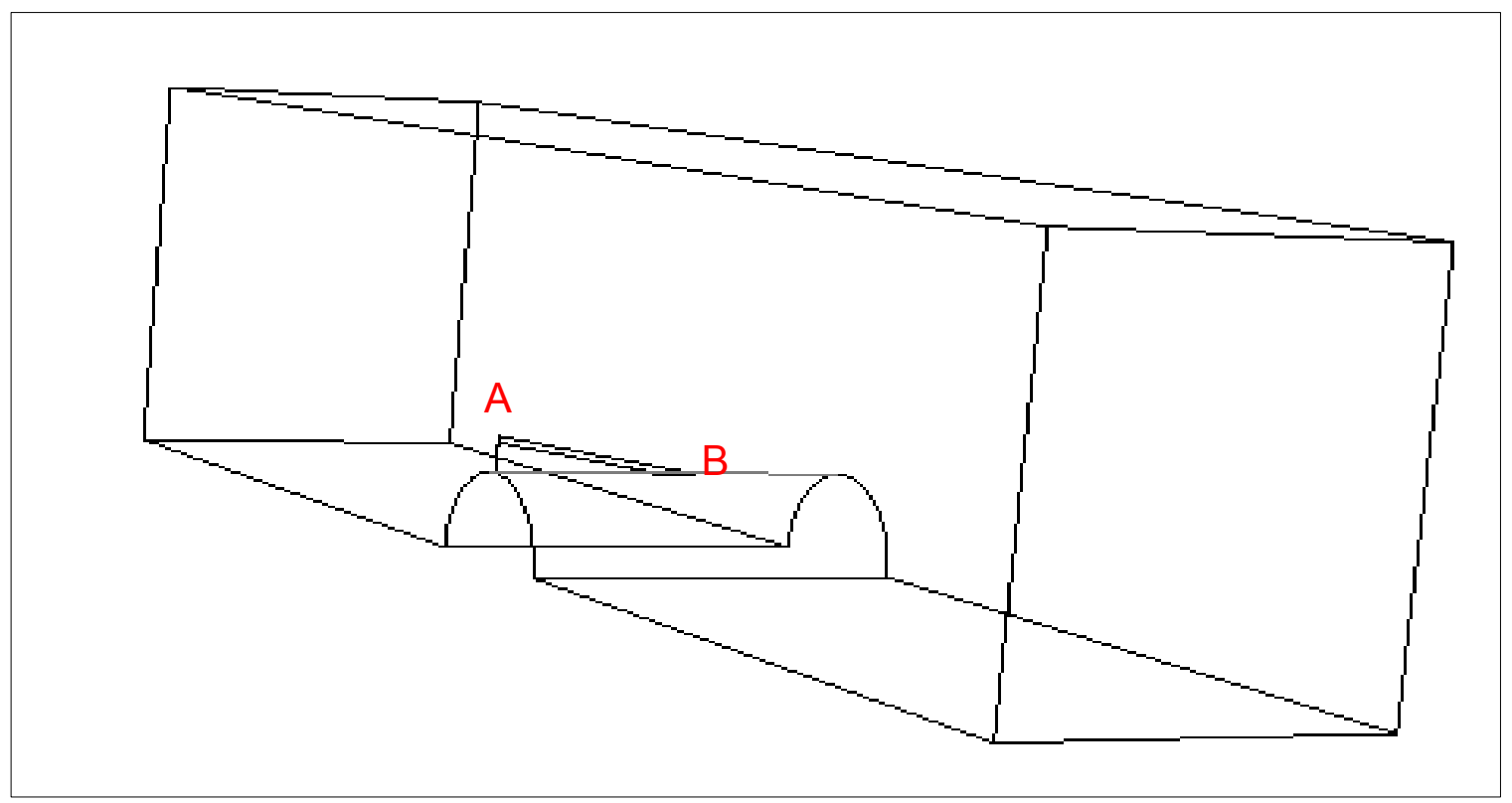

Figure 29. Isometric view of the plate with crack length $5.7-\mathrm{mm}$ 


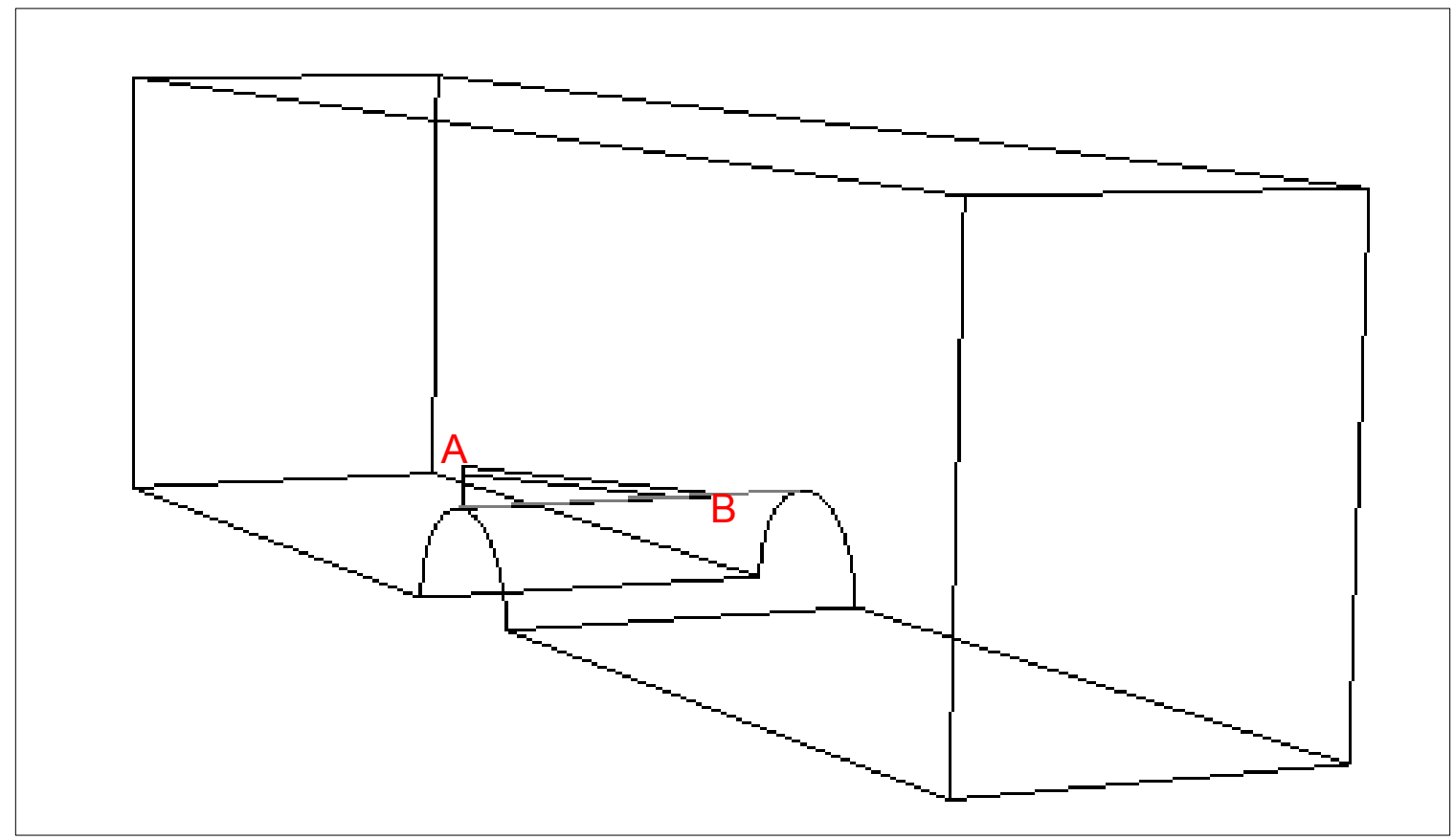

Figure 30. Isometric view of the plate with crack length $7.7-\mathrm{mm}$

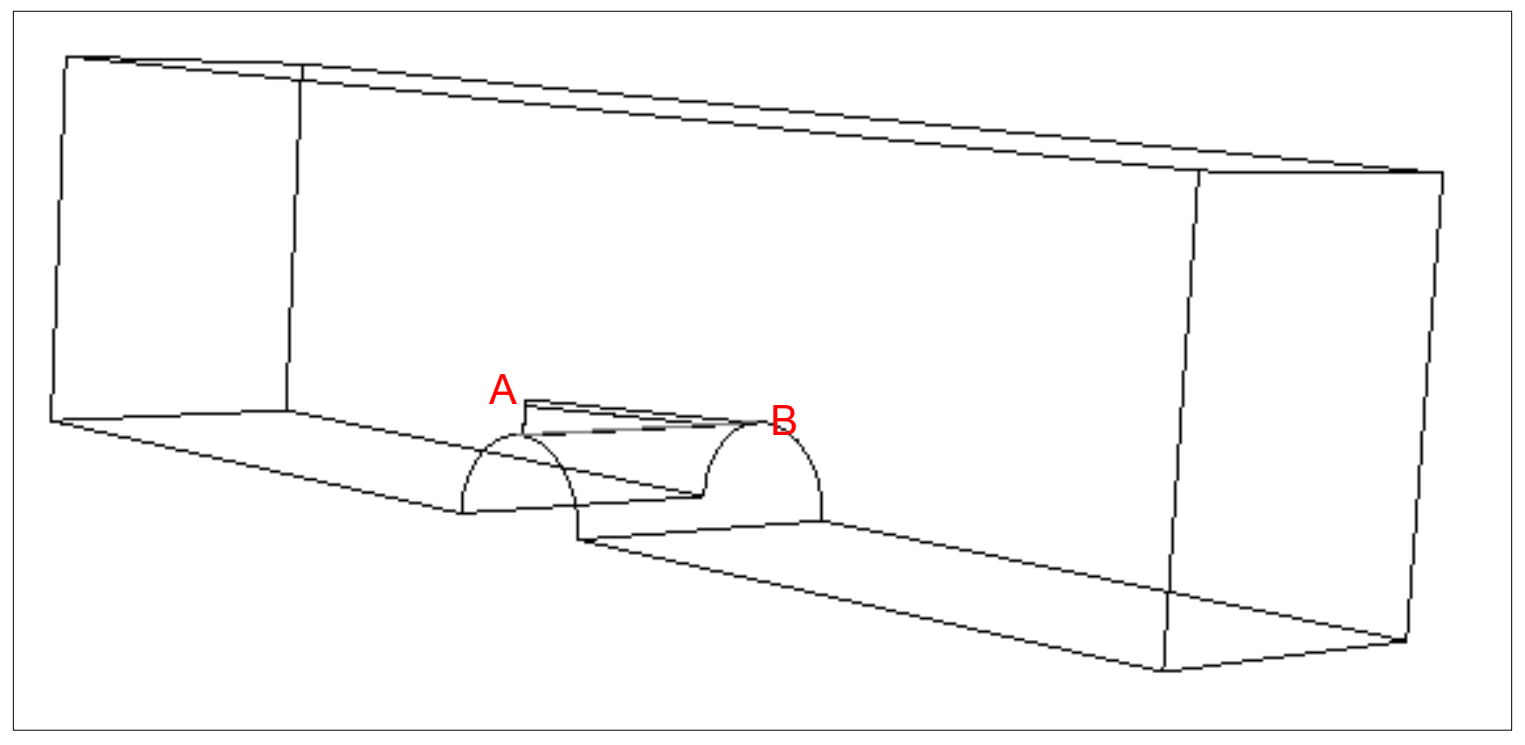

Figure 31. Isometric view of the plate with crack length 9.7-mm 


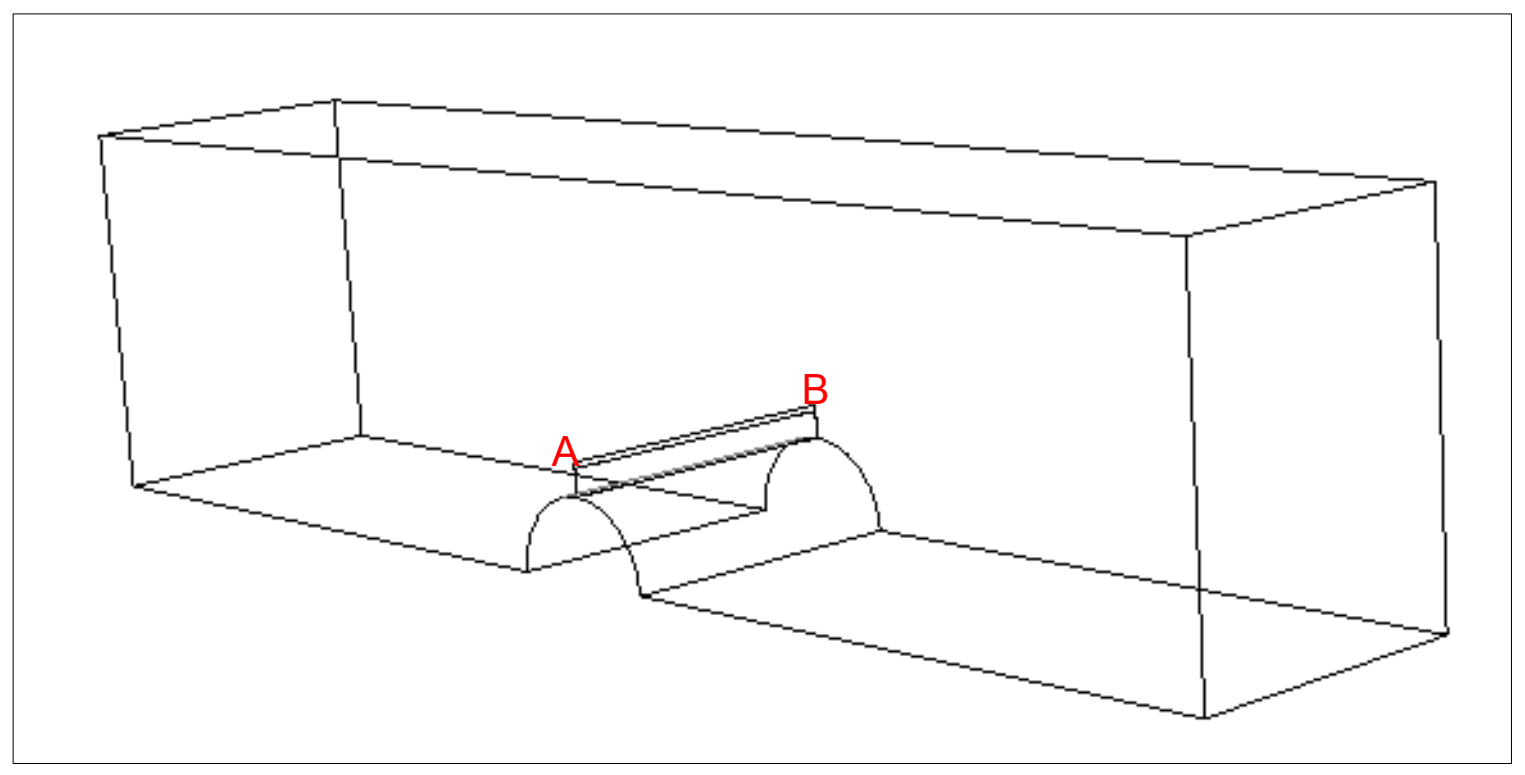

Figure 32. Isometric view of the plate with a through crack

The electrical analysis was run for the opened and closed crack models for all these crack lengths and then compared as done for the analysis of 1.1-mm crack mentioned earlier. Now eventually the Electrical Current Density values obtained from the output file of electrical analysis of models with different crack lengths mentioned above are all compared in an excel file. Elemental ECD values of elements closed to the crack cross-sectional are also studied. 


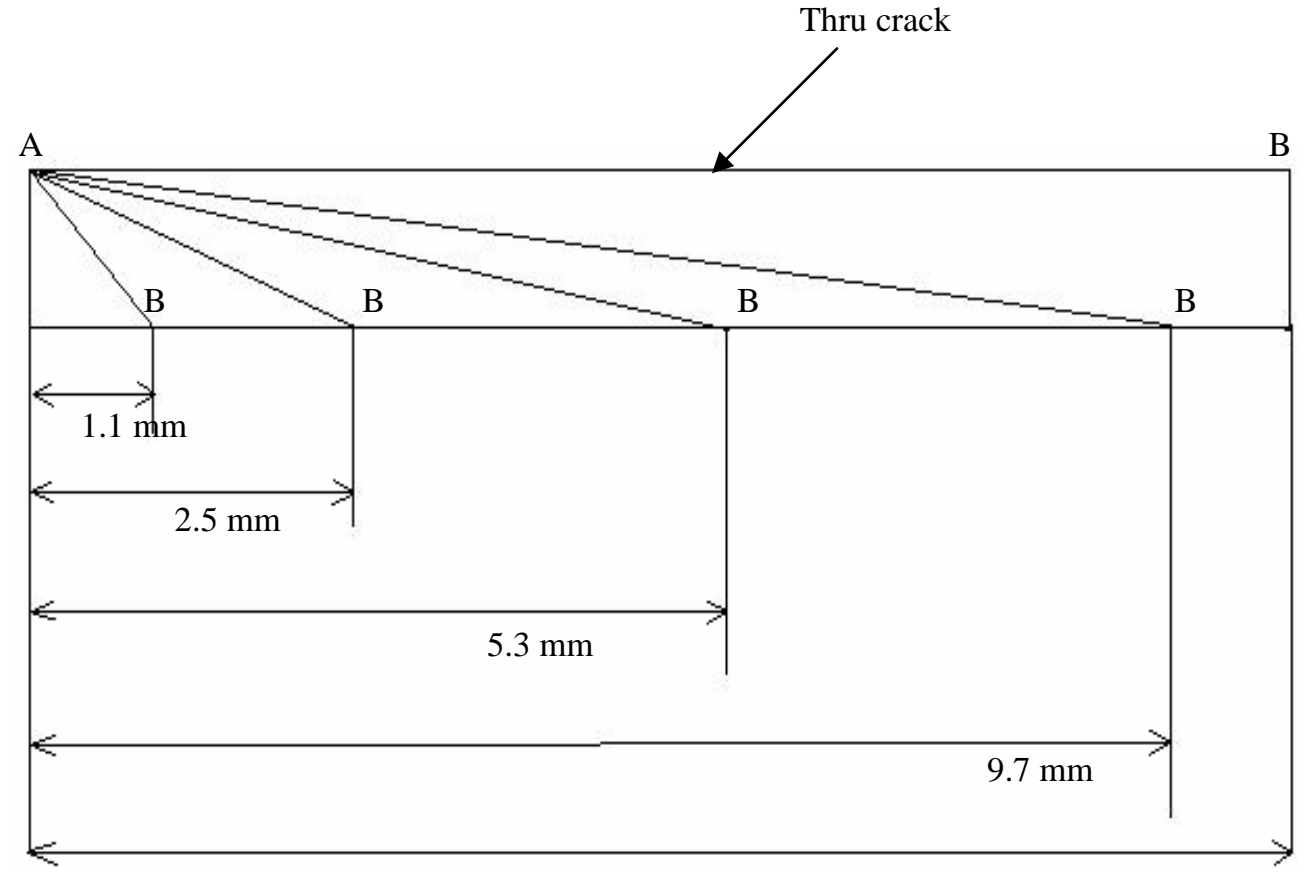

Crack length increases until it becomes an extended through crack.

Figure 34. Sectional cuts denoting increase of crack length along Z-direction

The ECD contour plots along the crack line in the $Z$ direction was studied by producing sectional views of the output models obtained from the visualization module of the various crack models. Figure 34 represents the increasing crack lengths in the Z-directions. Sectioned cuts were made in the models so that the maximum part of the crack line is visible. The ECD contour plots and the elemental values of ECD around the crack line vary with various models, as the crack length increases. The contour plots for the various crack models are as shown in the Figures $35,36,37,38$, and 39 . 


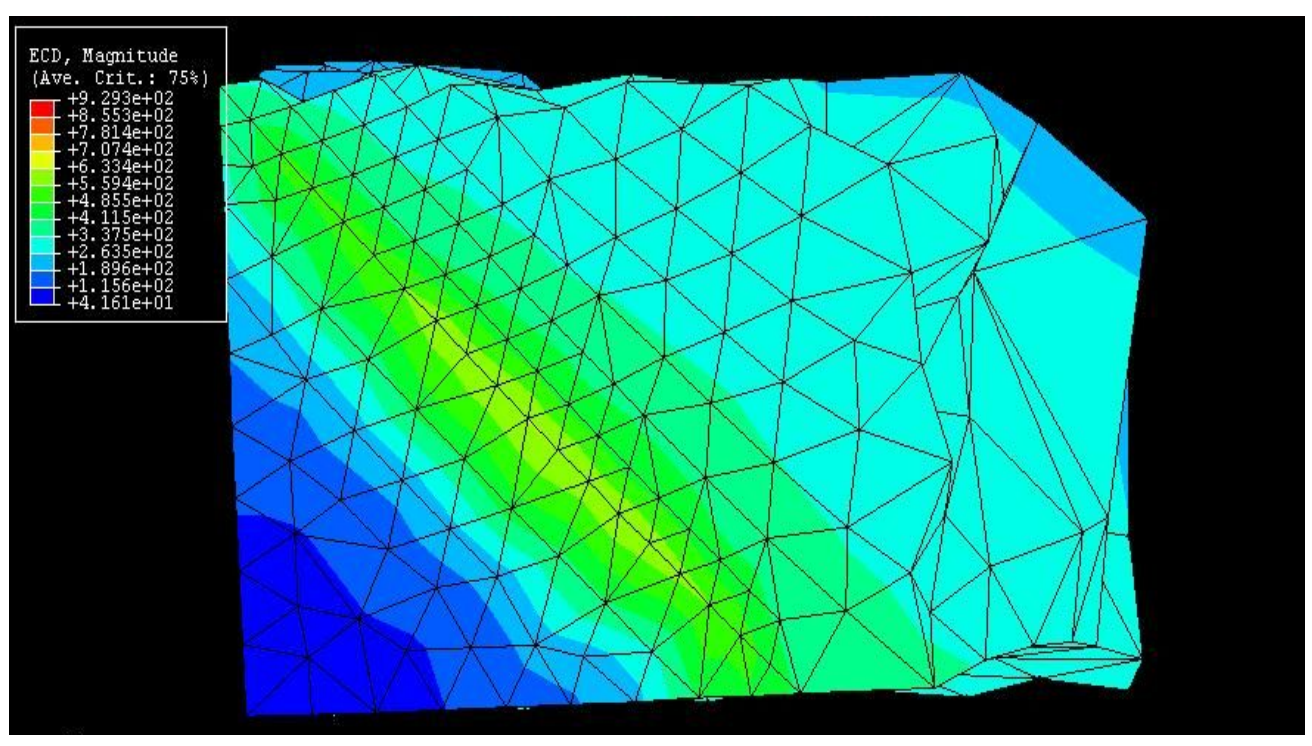

Figure 35. Sectional view of $1.1 \mathrm{~mm}$ crack.

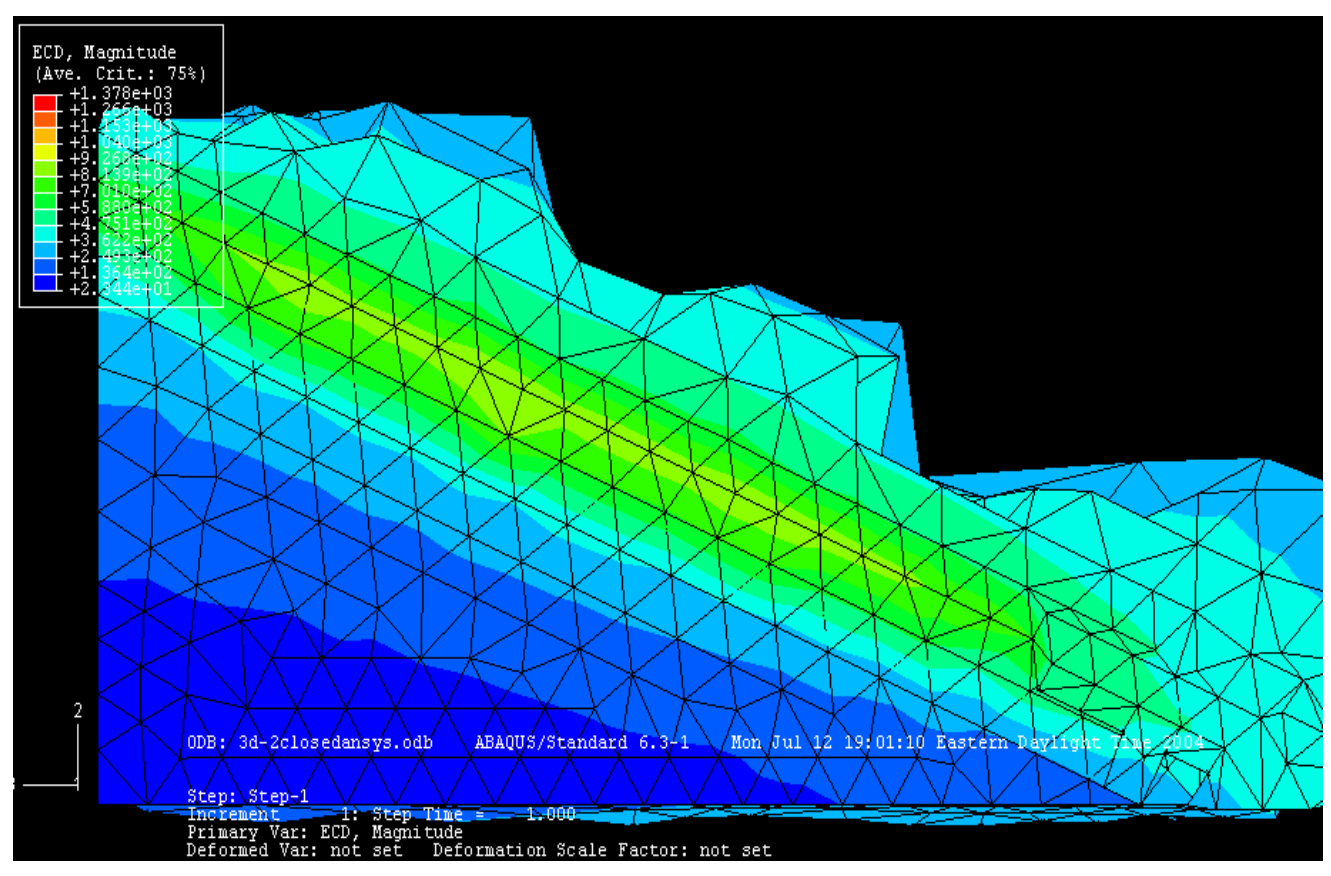

Figure 36. Sectional view of $2.5 \mathrm{~mm}$ crack 


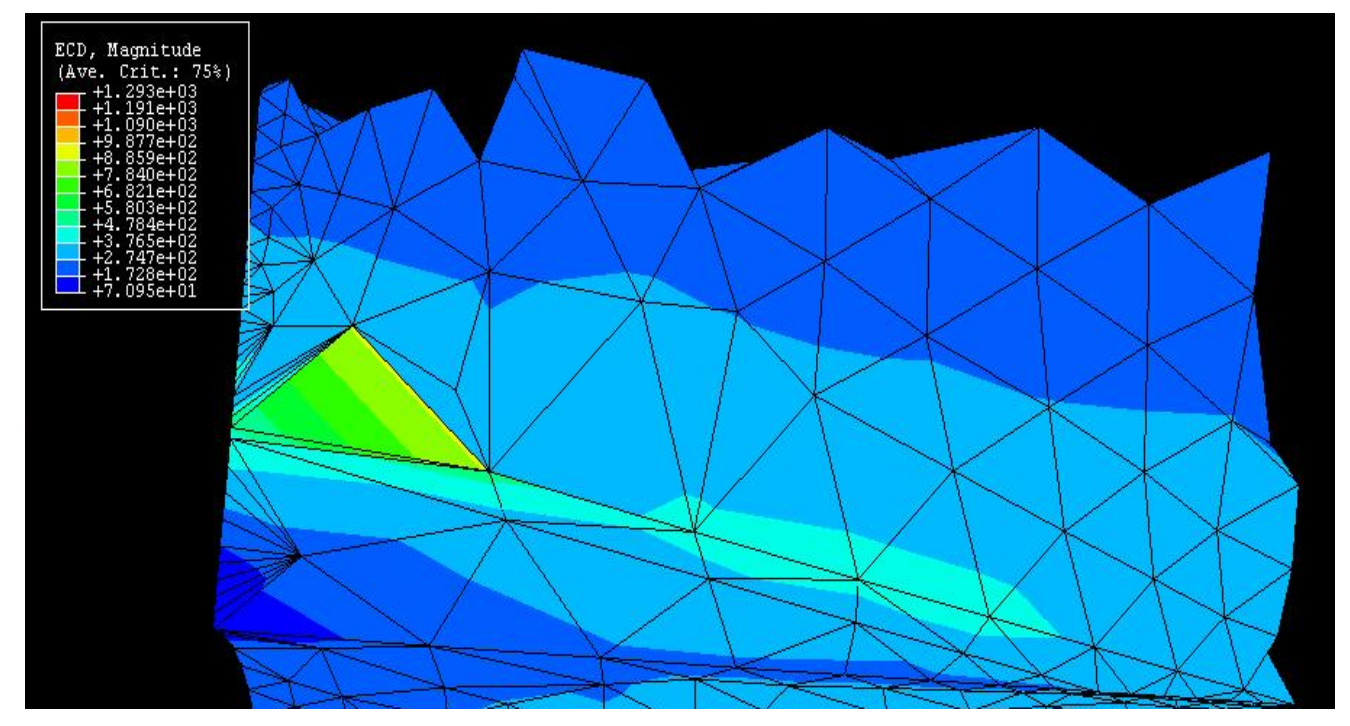

Figure 37. Sectional view of $5.3 \mathrm{~mm}$ crack

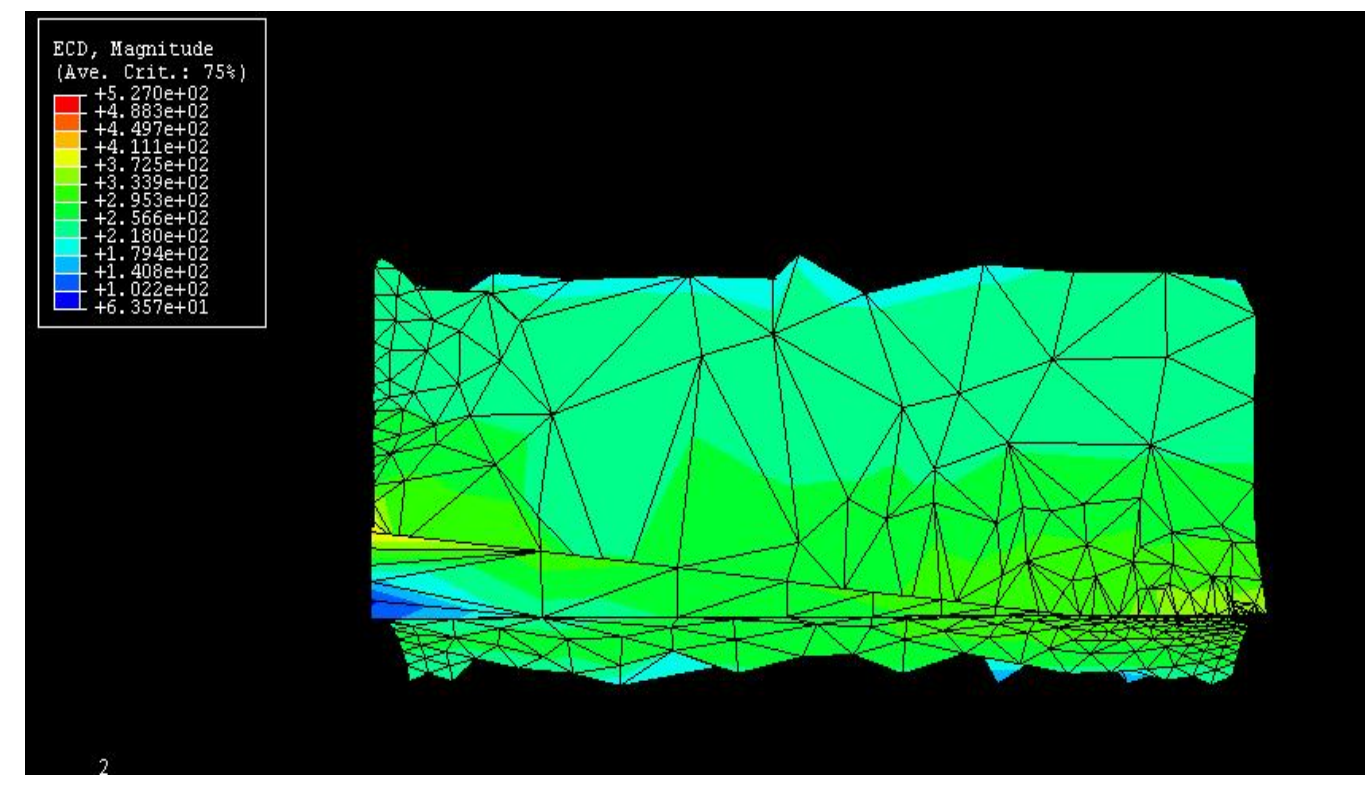

Figure 38. Sectional view of $9.7 \mathrm{~mm}$ crack 


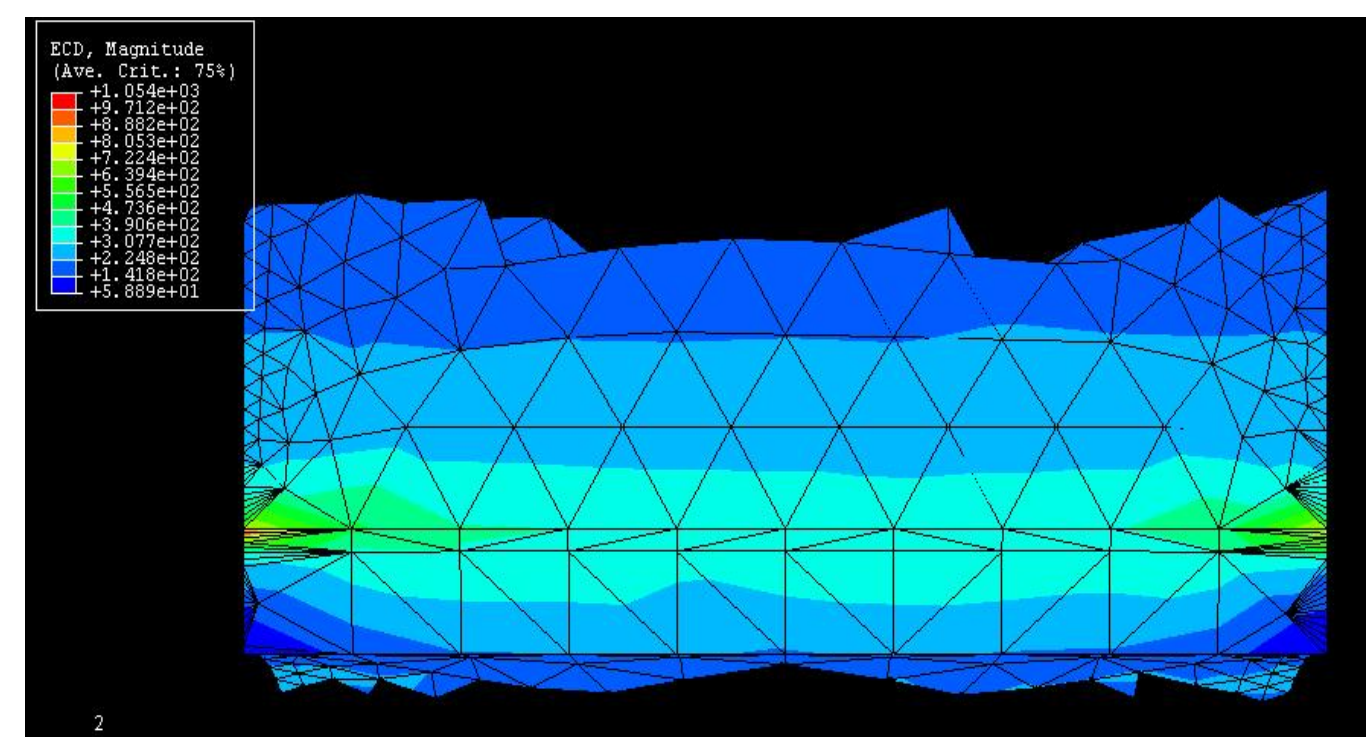

Figure 39. Sectional view of a through-crack

\begin{tabular}{|c|cc|}
\hline $\begin{array}{c}\text { Crack length in } \\
\text { mm }\end{array}$ & Closed & open \\
\hline Through crack & 1083 & 1025 \\
\hline 9.7 & 674.1 & 658.3 \\
\hline 7.7 & 563.1 & 552.1 \\
\hline 5.3 & 559 & 547.9 \\
\hline 2.5 & 405.4 & 401.3 \\
\hline 1.1 & 385.5 & 343.7 \\
\hline
\end{tabular}

Table 3. Comparison of ECD values for different crack lengths in the Z-direction. 


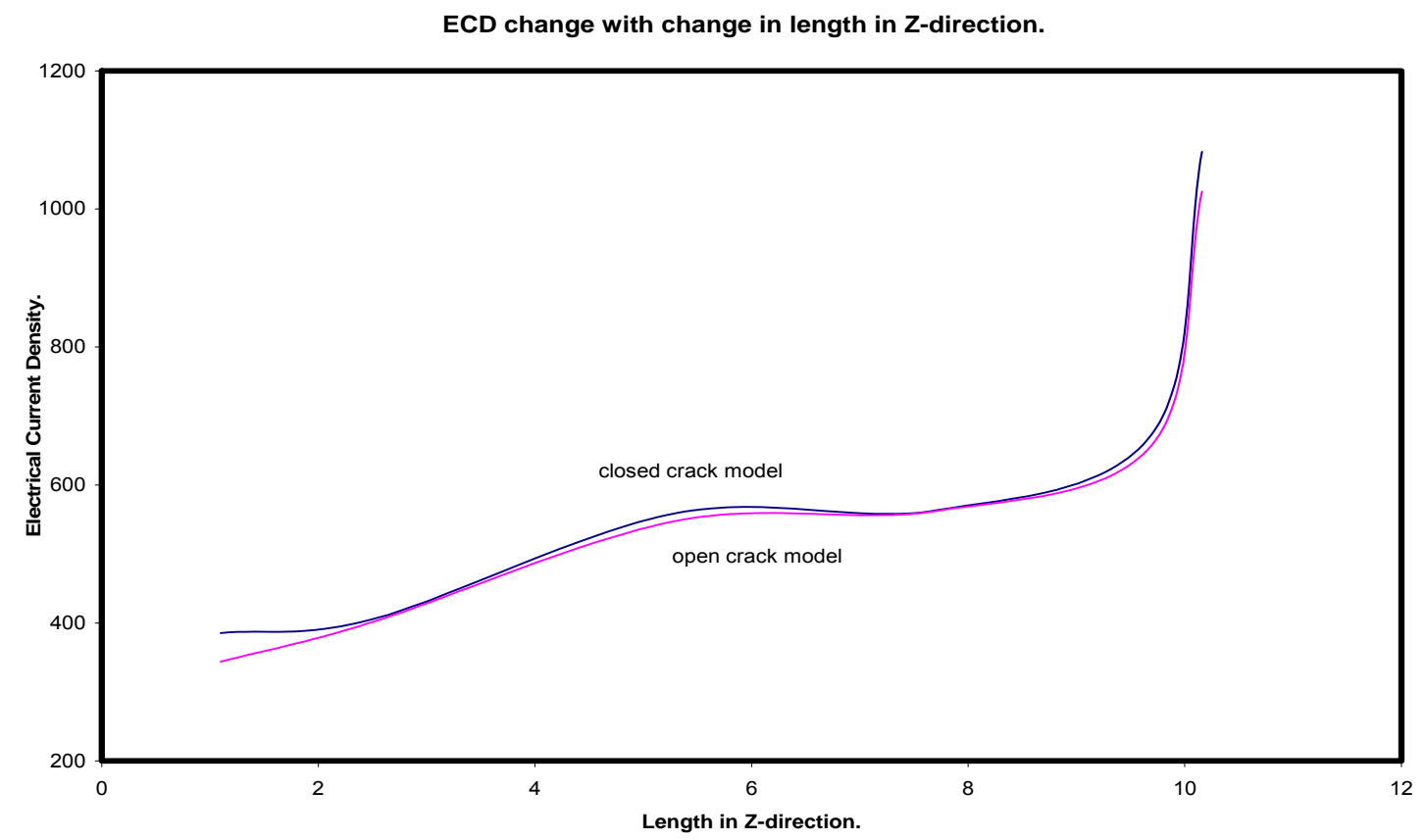

Figure 40. Change in Electrical Current density with change in length in Zdirection.

The results in Table 3 clearly show that the Electrical Current Density values for different crack fronts are different at the tip of the fronts. Now as mentioned earlier the Electrical Current Density values are studied at the two crack tips, one seen in the front view of the plate and the other crack tip seen at the bottom of the plate. Here is an analysis of the results that can be deduced from the analysis of plates with different crack lengths.

- As seen clearly from the tabulated results, and as mentioned earlier, the Electrical Current Density for any crack length is more for the closed crack than for the open crack.

- As mentioned earlier for the model with 1.1-mm crack, the value of the Electrical Current Density will be more along the section of the crack 
than any other place of the plate. The electrical current density records a high value along the cross-section of the crack. The elements close to the section of the crack, including the tip of the crack, form the portion of the model where the highest values of electrical Current Density are recorded. This was found to be very true with respect to the plates with other crack lengths also.

- When the Electrical Current Density for the models with various crack lengths were analyzed, it was found that the values of the elements at the tip of the crack showed distinct changes with changes in the crack length. A closer look into the tabulated results revealed that the Electrical Current density at the two tips of the crack (tip revealed in front and bottom views of the plate) increased as the crack length increased in the Z-direction.

\subsection{ANALYSIS OF RESULTS}

- As discussed earlier in the previous section, the governing equations for the current flow through a cracked medium are theoretically similar to those of the cracked structure under loads, i.e. they all are characterized as Poisson equations and thus analogous to the stress analysis on sharp and v-shape cracks, stresses at a sharp crack tip are higher than those at a v-shape crack. Similarly, the ECD values at the opened crack tip region would be lesser than the ECD values at the closed crack tip region. The ECD at the tip of the crack is higher 
than the rest of the body because the current flows across the sharp edge of the crack with higher current flow gradients. Thus it accumulates more ECD intensity. If there is no disturbance or perturbance, the current just flows across, thus giving the elements of the plate a low value of Electrical Current Density, unlike the tip of the crack where the current flow gradients accumulate and thus giving the elements there, a high value of Electrical Current Density. Stresses all along the crack cross-section accounts for the value of ECD values. So, when the crack length increases in the Z-direction the current flow gradients along the cross-section of the crack increases with the dimensions of the crack thus increasing the ECD values at the tip of the crack. Bigger the crack cross-section, bigger the current flow gradient accumulation and this in-turn increase the ECD values at the tip of the crack. 


\section{COMPARISON OF ELECTRICAL ANALYSIS OF MODELS WITH THROUGH CRACKS OF DIFFERENT CRACK LENGTHS IN THE Y-DIRECTION}

In this section, or type of models, we increase the crack lengths in the $\mathrm{Y}$ direction, maintaining the length of the crack in the Z-direction constant i.e. the length of the crack through the thickness has to be made constant while increasing the length of the crack in the Y-direction. To maintain the crack in the Z-direction, the shape of the crack is constantly maintained as a through crack and then the length along the Y-Direction is increased. The electrical analysis for the open and the closed crack is carried out and similar to the above cases, the Electrical Current Density values for the cracks studied, tabulated and analyzed.

The definition of crack length in the Y-direction is the length of the crack starting from the circumference of the rivet hole to the tip of the crack. The various crack lengths for the model in the Y-direction for which electrical analysis was run were,

- $1.1 \mathrm{~mm}$ or 0.043 inches

- $2.5 \mathrm{~mm}$ or 0.098 inches

- $3.5 \mathrm{~mm}$ or 0.137 inches

- $4.5 \mathrm{~mm}$ or 0.177 inches

- $5.7 \mathrm{~mm}$ or 0.224 inches

For these models, the point $A$ is seen to extend along the face of the plate, while point $B$ remains constant. 

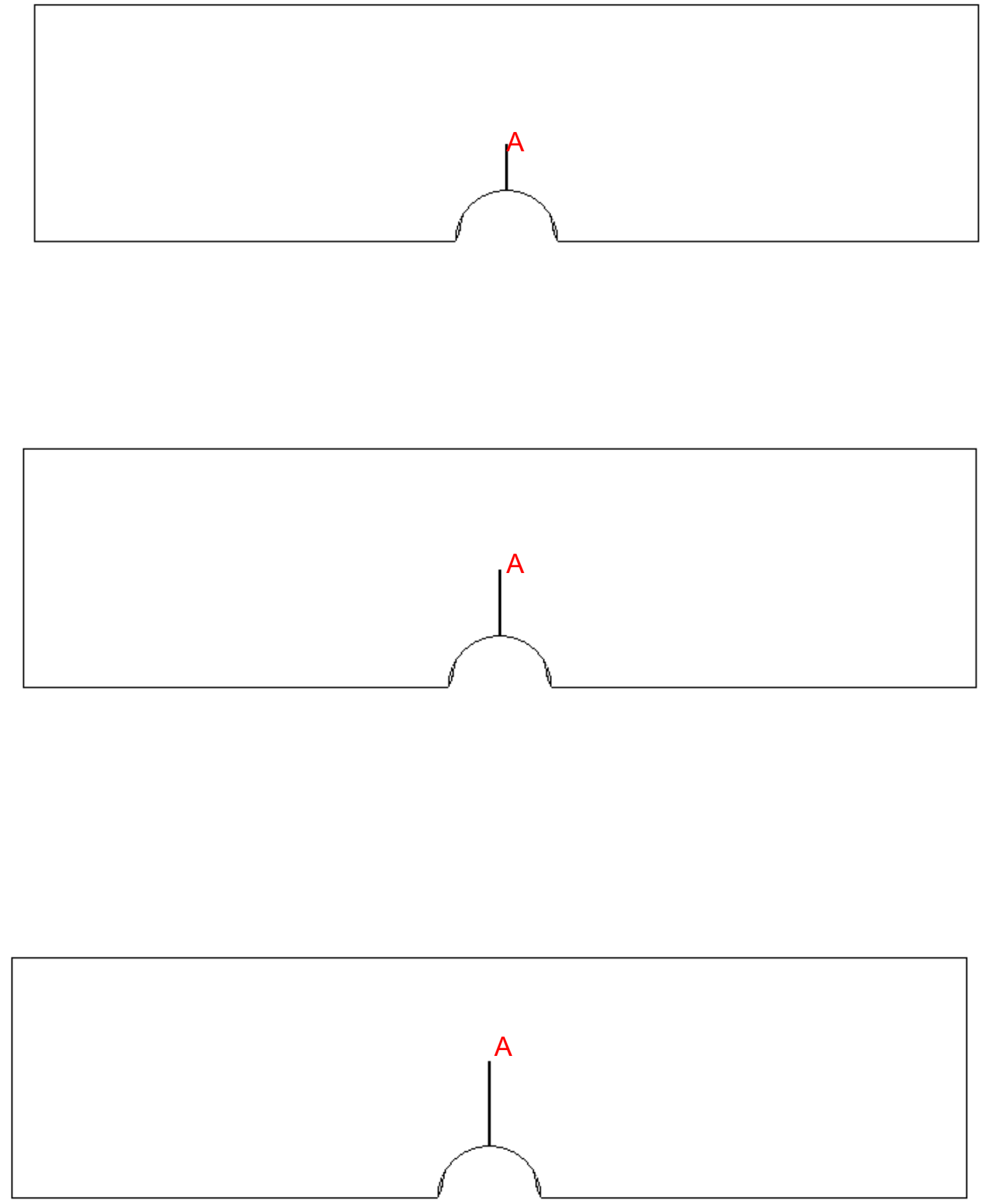


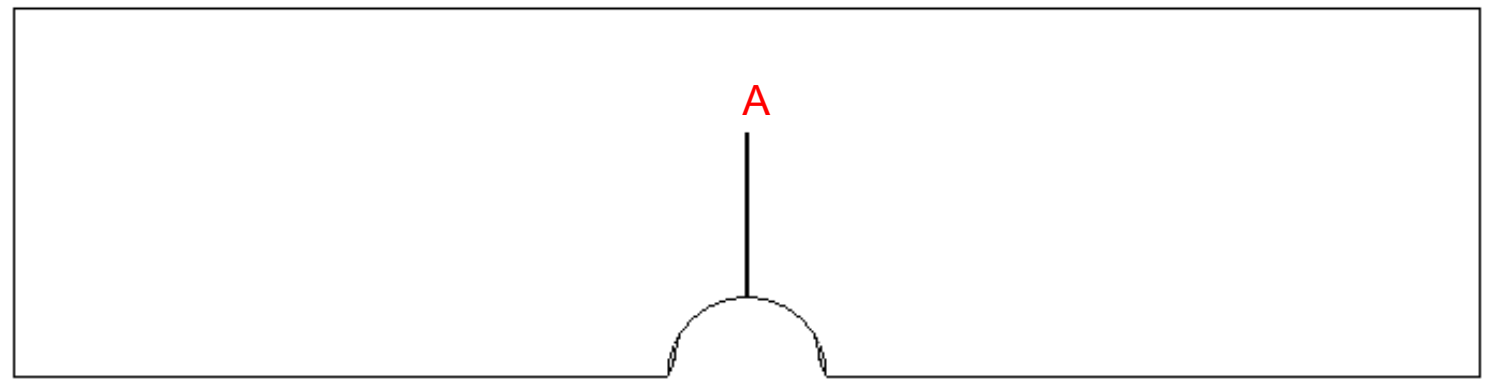

Figure 41. Crack length increase in the Y-direction (, $2.5 \mathrm{~mm}, 3.5 \mathrm{~mm}, 4.5 \mathrm{~mm}$, and $5.7 \mathrm{~mm})$

\begin{tabular}{|c|c|c|}
\hline $\begin{array}{c}\text { Crack length in } \\
\mathrm{mm}\end{array}$ & Closed & Open \\
\hline 1.1 & 1083 & 1025 \\
\hline 2.5 & 1546 & 1484 \\
\hline 3.5 & 2240 & 2197 \\
\hline 4.5 & 2593 & 2546 \\
\hline 5.7 & 2981 & 2958 \\
\hline
\end{tabular}

Table 4. Comparison of ECD values for different crack lengths in the Y-direction

The tabulated results shown in Table 4 clearly states or proves the following, which are the exact conclusions as drawn from the results obtained when the crack was extended in the Y-direction. Except for the values of the Electrical Current Density, the way the density behaves with the change in the length of the crack is quite similar to the previous comparison. The conclusions drawn similarly are, 
- As seen clearly from the tabulated results, and as mentioned earlier, the Electrical Current Density for any crack length is more for the closed crack than for the open crack.

Change in ECD with the change in length in Y-direction.

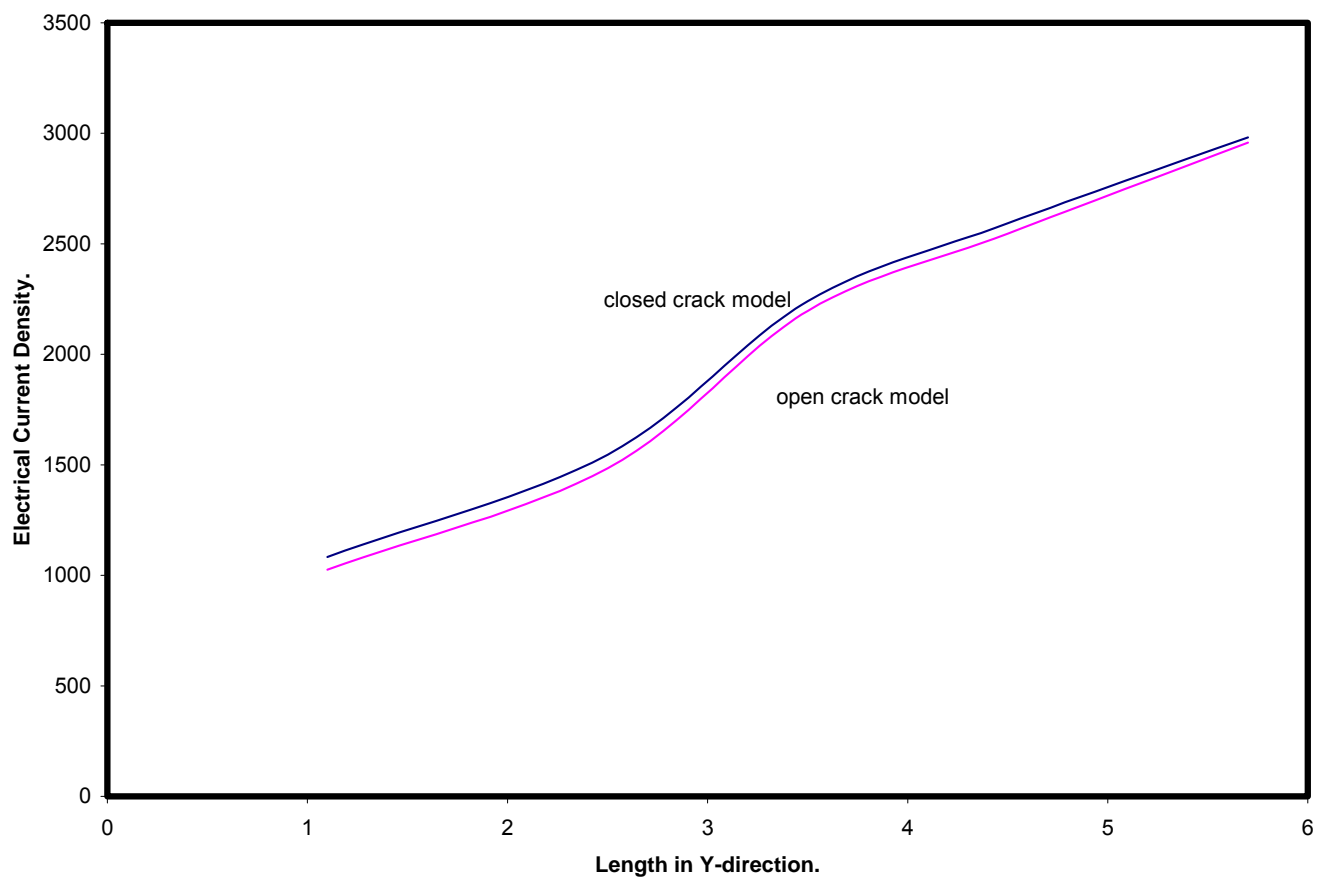

Figure 42. Change in ECD with change of length along Y-direction.

- As mentioned earlier, the value of the Electrical Current Density will be more at the tip of the crack rather than any other place of the plate. The electrical current density records a high value along the V-shaped cross-section of the crack. The elements close to the cross-section of the crack, including the tip of the crack form the portion of the model where the highest values of electrical Current Density are recorded. 
This was found to be very true with respect to the plates with other crack lengths also.

- When the Electrical Current Density for the models with various crack lengths were analyzed, it was found that the values of the elements at the tip of the crack showed distinct changes with changes in the crack length. A closer look into the tabulated results revealed that the Electrical Current density at the tip of the crack, increased as the crack length increased in the Y-direction.

\subsection{ANALYSIS OF RESULTS}

- As discussed earlier, stresses all along the crack cross-section accounts for the value of ECD values. So, when the crack length increases in the Y-direction the current flow gradients along the crosssection of the crack increases with the dimensions of the crack thus increasing the ECD values at the tip of the crack. Bigger the crack cross-section, bigger the current flow gradient accumulation and this in-turn increase the ECD values at the tip of the crack. The presence of defect diverts current away from the part and concentrates it near the ends of the crack. Thus, if the length of the crack is more in the $\mathrm{Y}$ direction, the concentrated current intensity increases and thus the accumulated current density is proportional to the increase in length of the crack. 


\section{MAGNETIC ANALYSIS OF THE ALUMINUM PLATE}

As discussed earlier, the magnetic sensor detects the magnetic field associated with the electrical current as current flows across the aluminum plate. When the current flows from one side to the other, it generates a magnetic field and the sensor picks up this magnetic field. Now as we studied earlier, there is a high electrical current density around the tip of the crack, and eventually there has to be a high magnetic field associated with this high electrical current density.

A current flowing across the crack produces a distinct Electrical Current Density around and at the tip of the crack, and correspondingly there would be an Electromagnetic field associated with it. The CFM (Current Field Measurement) Micro-gauge captured this electromagnetic perturbation. The locations and the values of the peaks and troughs in this electronic instrument have been proved successful in crack detection and sizing. Corresponding signals produced as an output (detected by a magnetic sensor) are as a result of the change of the inductance of the inductance coil of the Micro-gauge. The value of inductance is proportional to the size and shape of the crack.

Therefore it is very important to study the magnetic field associated with the electrical current, which flows from one side to another. This study here is just to realize that the magnetic field changes with the disturbance in the electric field due to the presence of a crack. Therefore, the magnetic analyses for all the cracks are carried out. This magnetic analysis is just done on the closed cracks, 
before the force is applied. The model is the same, modeled in SOLIDWORKS ${ }^{\mathrm{TM}}$ software and then imported into ANSYS ${ }^{\mathrm{TM}}$ software as an IGES file. Now the main area of concern is where the maximum value of magnetic field lies and what the value is and how it changes with respect to the shape and size of the crack. The elemental values of the magnetic field and flux are obtained from the output tables of output file of ANSYS ${ }^{\mathrm{TM}}$.

The models mentioned earlier for the electrical analysis are all subjected to this magnetic analysis and the maximum value of magnetic field studied. The magnetic field for one of the models is done as was done for the electrical analysis. The magnetic analysis is done on a through crack of length $1.1 \mathrm{~mm}$ along the Y-direction.

Now magnetic analysis was done on all models with various crack lengths and sizes, so that one can deduce where the maximum magnetic field and magnetic flux density is. We also need to deduce how the magnetic field of the model changes with respect to the change in the length of the crack. Due to the restrictions in the software, a magnetic analysis and structural analysis couldn't be coupled; therefore the magnetic analysis couldn't be completed on the crack after a force was applied to it.

For carrying out the magnetic analysis, the electrical current density we obtained from the electrical analysis for a particular crack model is the boundary condition. The output obtained from the electrical analysis is thus the input for magnetic analysis from which we obtain the magnetic field and the magnetic flux density contour plots. This is done for all subsequent models to study the change 
in magnetic field with the change in dimensions of the crack. Magnetic analysis is carried out for the various crack models with length of the cracks increasing in the Y-direction. The changes in values of the magnetic field and the magnetic flux density with change in the crack length in the Y-direction are then studied. Figures 39, 40, 41 and 42 depict the magnetic flux intensity and magnetic field contour plots for the crack model with crack length $1.1 \mathrm{~mm}$ (y-direction).

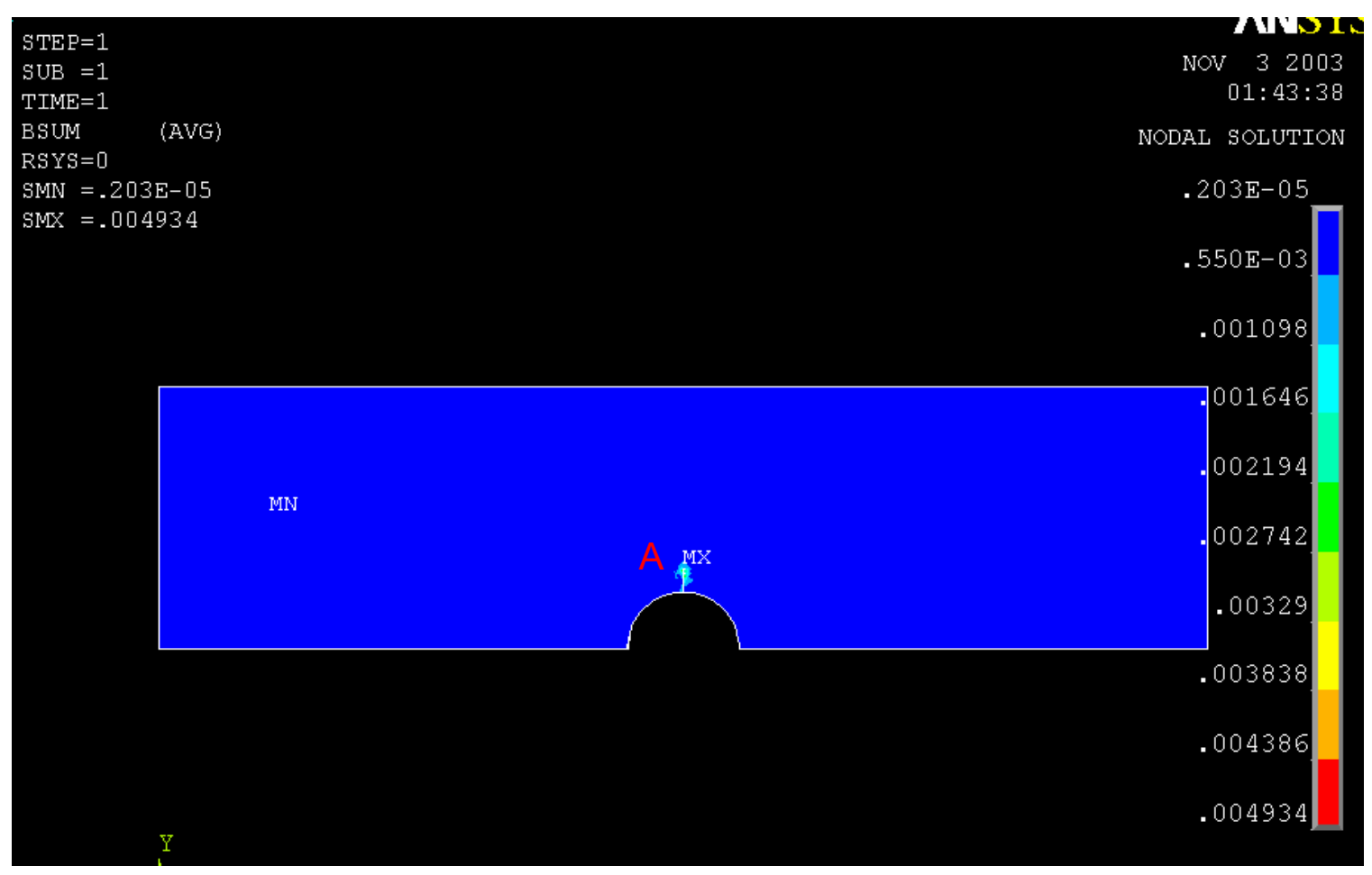

Figure 43. Contour plot for magnetic flux density. 


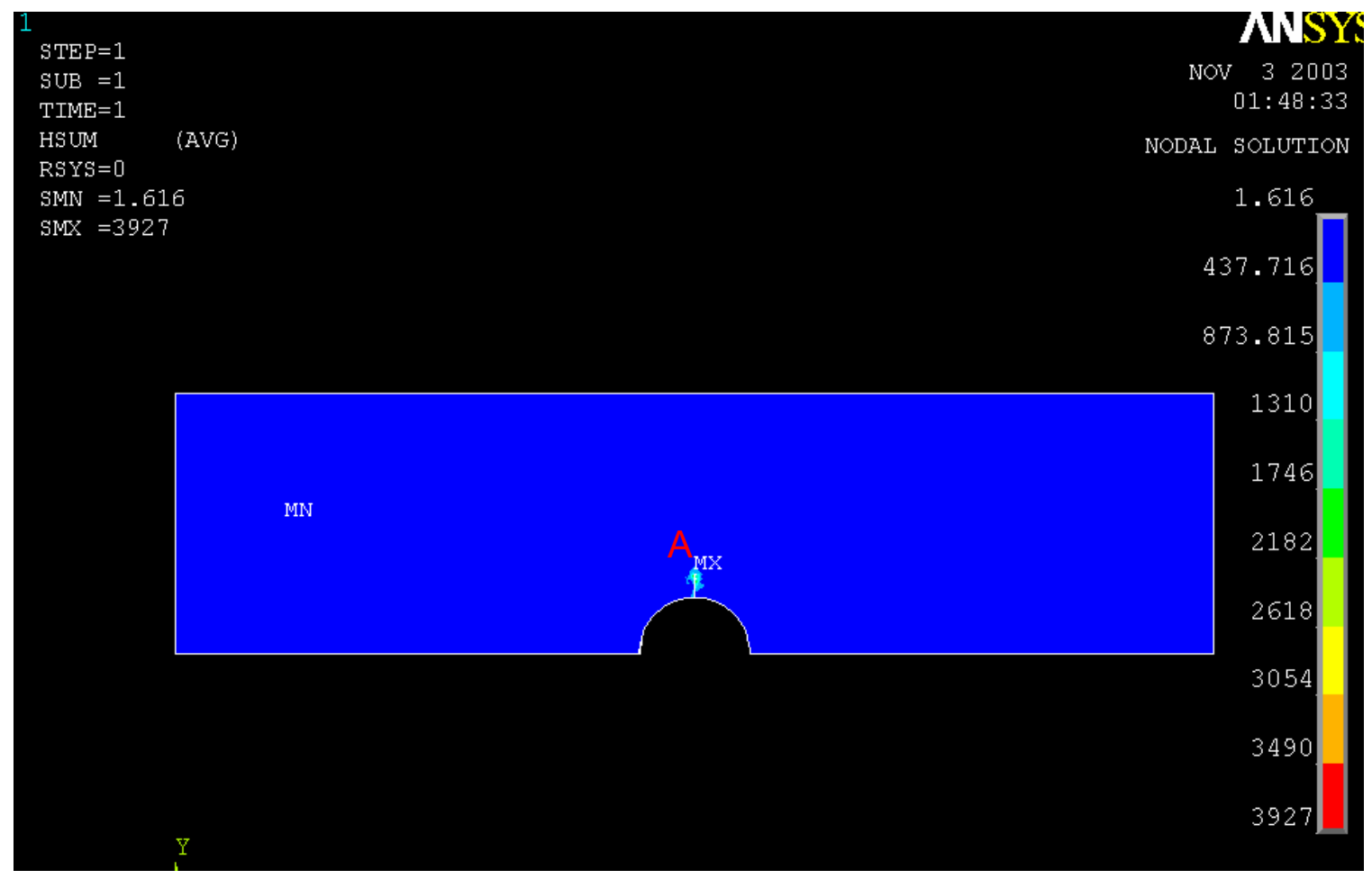

Figure 44. Contour plot for magnetic field.

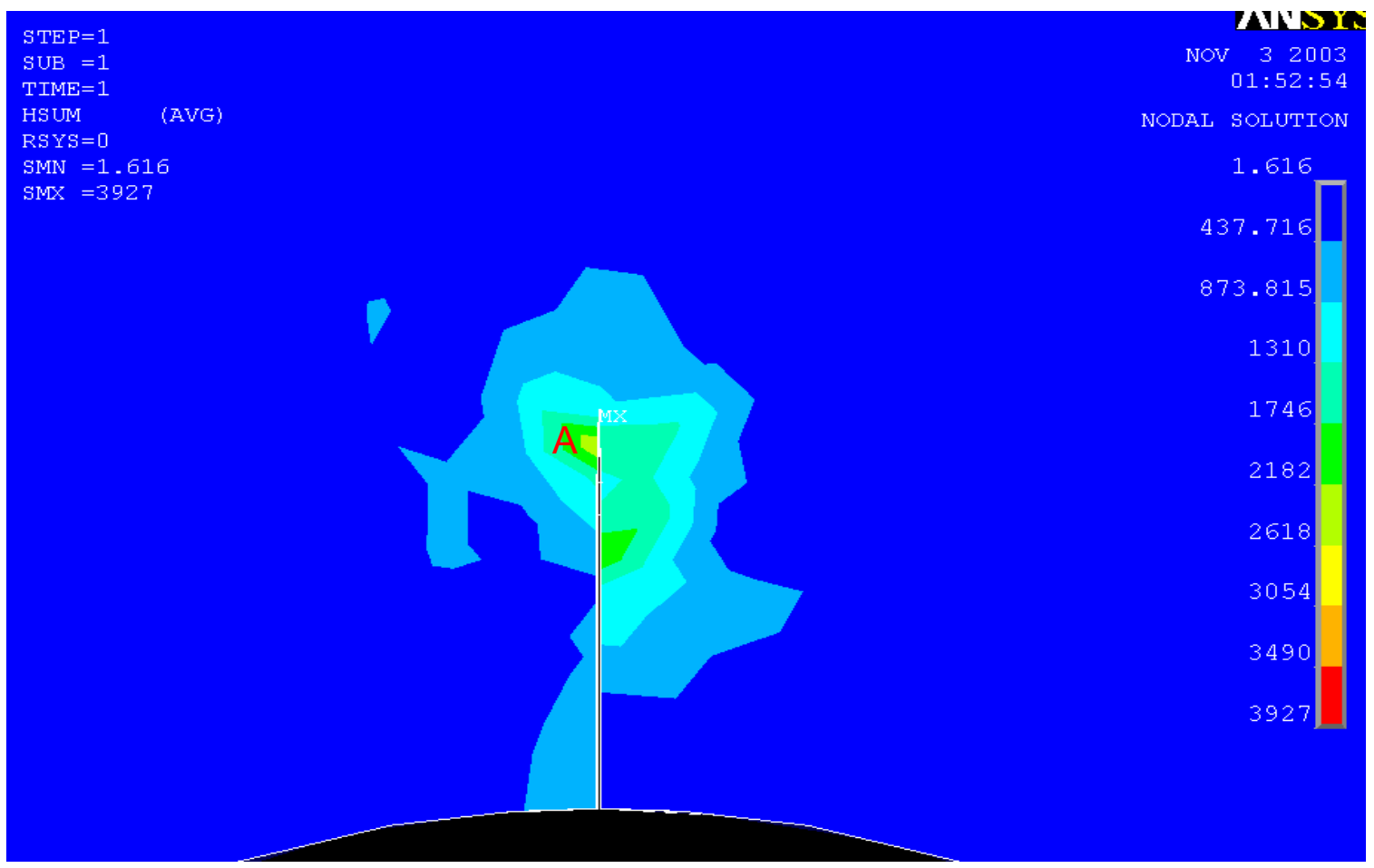

Figure 45. Close-up views of the magnetic field near the crack. 


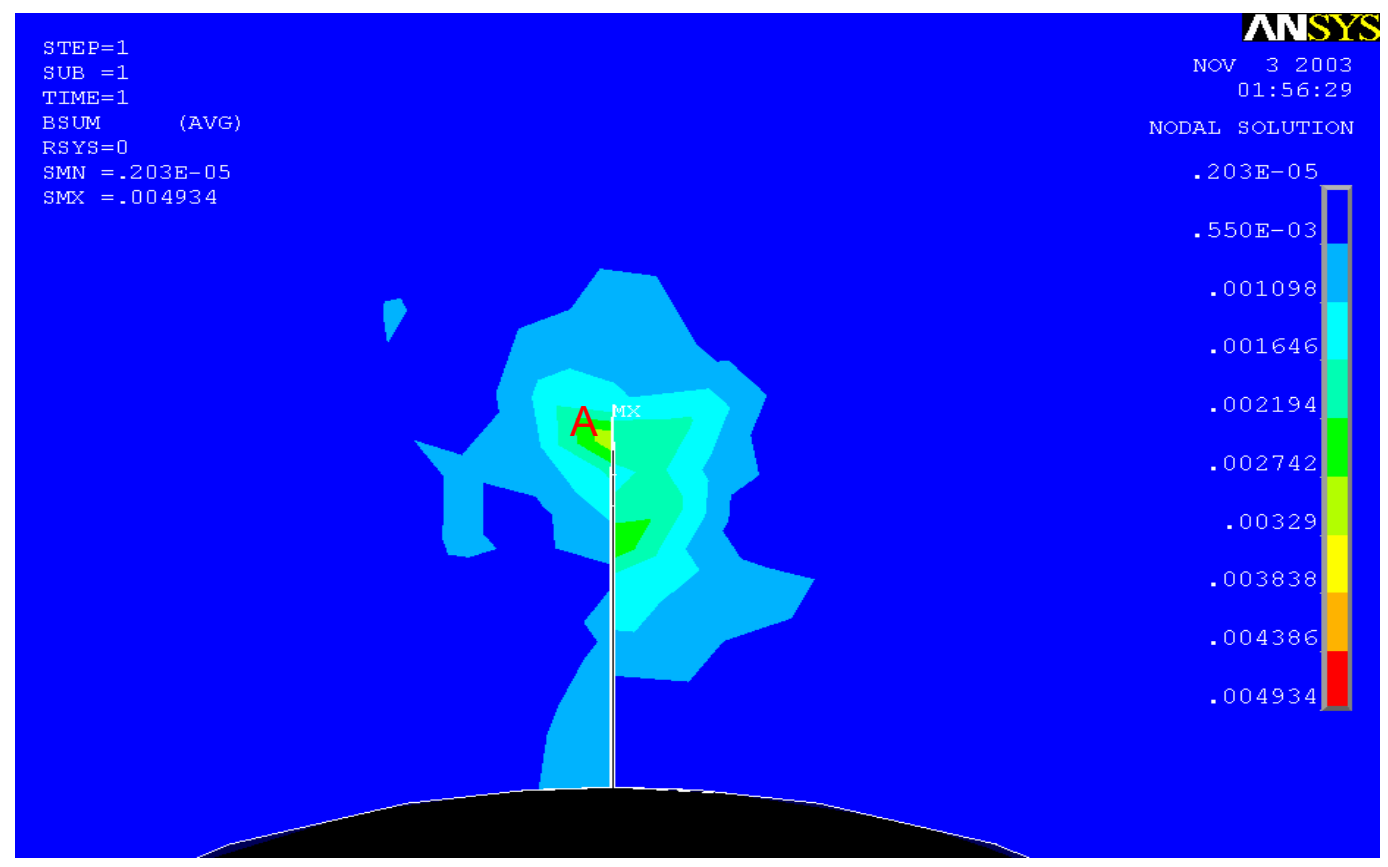

Figure 46. Close-up views of the magnetic flux density near the crack.

From the elemental table obtained from the output file of the analysis the maximum value of magnetic field and maximum flux density was found out. This element from the contour plot was located very close to the tip of the crack. Now therefore when the micro-probe scans the plate and when it reaches the tip of the crack, the magnetic field value is the highest there because of the high magnetic field present at the tip of the crack.

The magnetic field associated with the models should help in the deduction of the length of the crack. In fact the magnetic field and magnetic flux intensity associated with the crack should have a relation to the shape and size of the crack. This magnetic field is measured on the surface of the model. The results of the magnetic field near the tip of the crack are obtained from the contour plot and then compared with respect to the various lengths of the crack. The magnetic sensor would pick this maximum magnetic field, thus helping in the 
deduction of the shape and size of the crack. In the previous chapters, electrical current density values were found to have increased with the length of the crack. Now, every electrical field has a magnetic field associated with it. Therefore the magnetic field is expected to increase with the increase in the size of the crack. The tabular column with the maximum magnetic flux intensity and the maximum magnetic field for the various lengths of the crack is shown below.

$\begin{array}{ccc}\begin{array}{c}\text { Crack length } \\ \text { (inches) }\end{array} & \begin{array}{c}\text { Magnetic Flux } \\ \text { (Webbers) }\end{array} & \begin{array}{c}\text { Magnetic } \\ \text { Field (Tesla) }\end{array} \\ 1.1 & 2.60 \mathrm{E}-05 & 20.664 \\ 2.2 & 1.12 \mathrm{E}-04 & 89.473 \\ 5.7 & 8.32 \mathrm{E}-04 & 142.354 \\ 9.5 & 2.57 \mathrm{E}-03 & 216.563 \\ \text { Through crack } & 9.39 \mathrm{E}-03 & 743.228\end{array}$

Table 5. Magnetic field and Magnetic Flux density vs. crack length

The results from Table 5 clearly show that the magnetic field and the magnetic flux intensity associated with the model and the crack increases with the length of the crack. As the crack length increases in the Z-direction, the recorded magnetic field increases. Thus the micro-gauge voltage reading tends to increase with the length of the crack. The amplitude of the crests and trough patterns obtained in the micro-gauge output screen would increase as the length of the crack in the Y-direction increases. 
Length versus Magnetic Flux

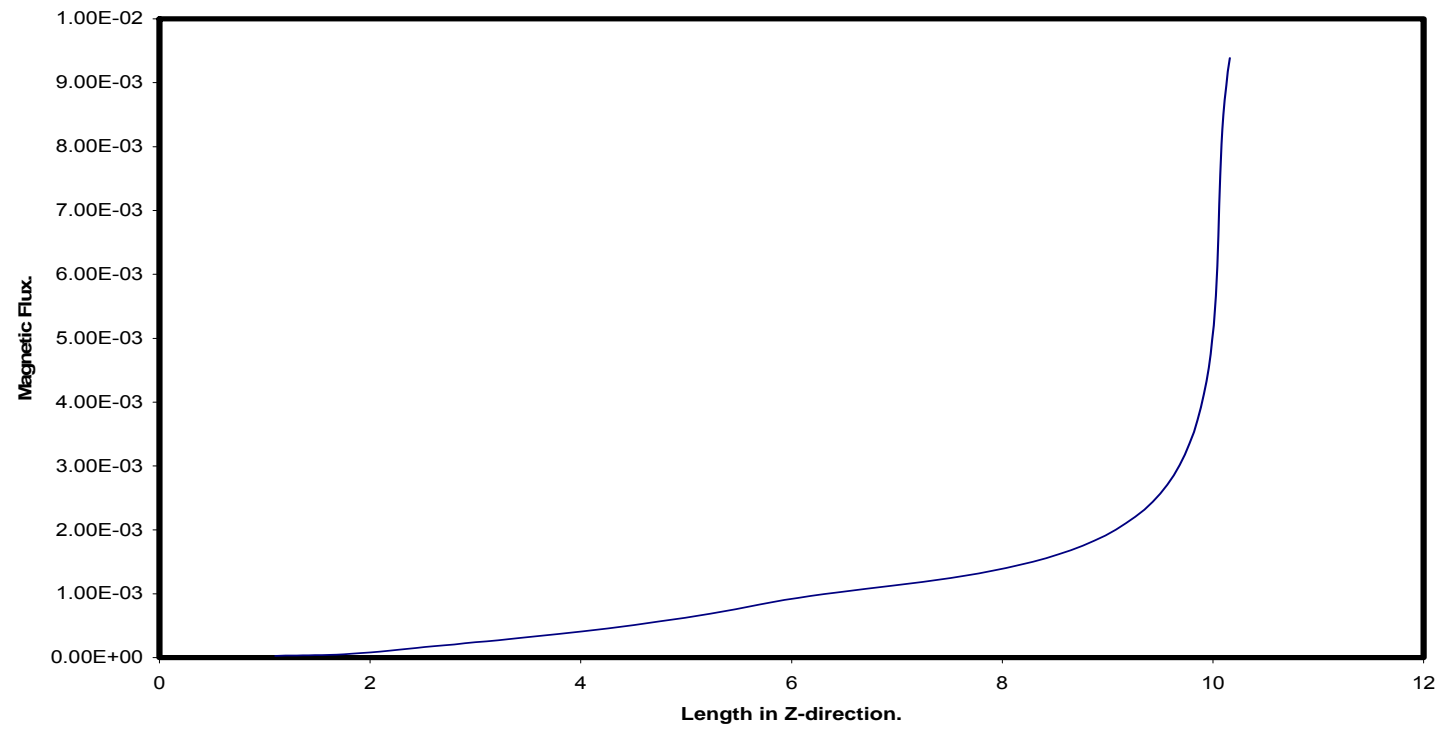

Figure 47. Change of Magnetic flux intensity with change in length.

Length versus Magnetic Field

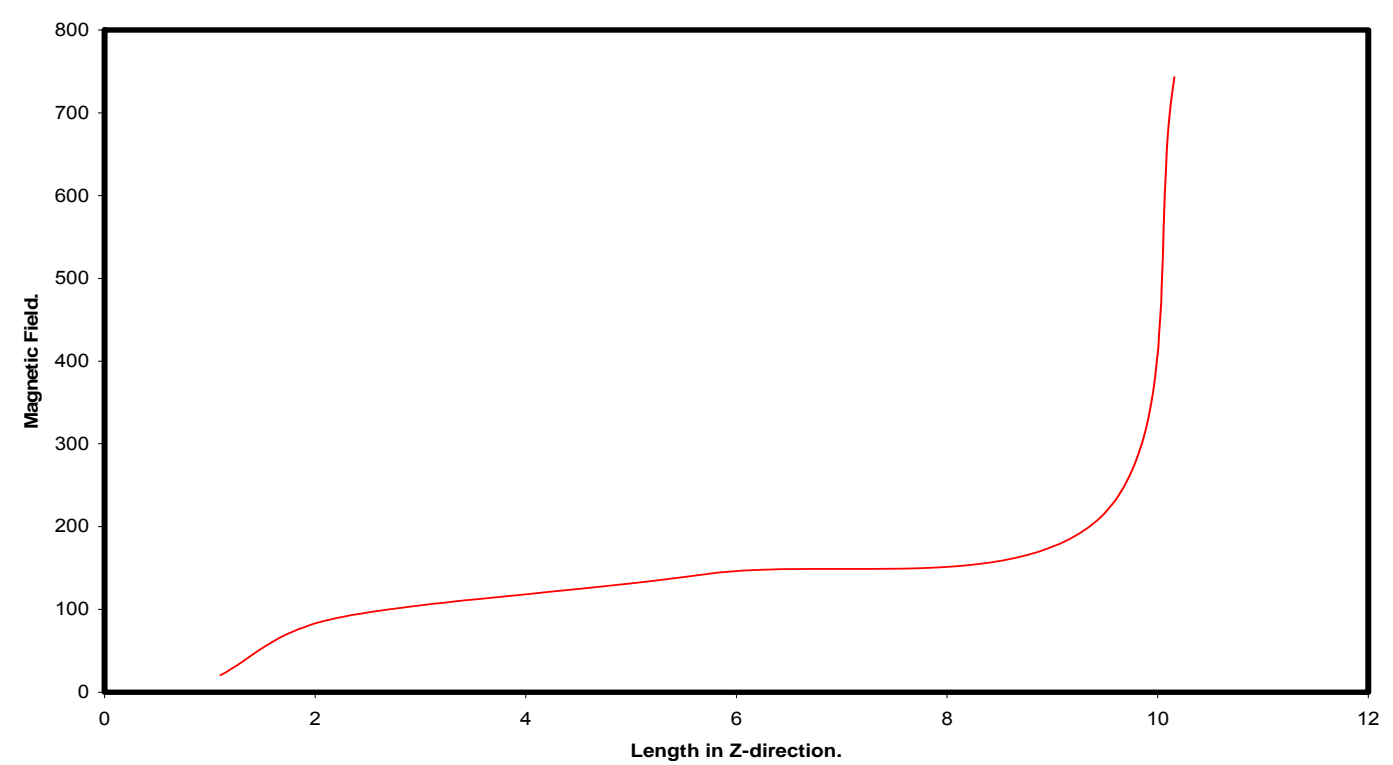

Figure 48. Change in Magnetic field with change in length. 


\subsection{ANALYSIS OF RESULTS.}

The magnetic analysis on all the models revealed that similar to the magnetic model for the through crack mentioned above, every model definitely has a high magnetic field close to the tip of the crack.

The element just near the tip of the crack in all models has the highest value of magnetic field and thus this is the region where the micro-gauge should record the maximum value of magnetic field.

The high concentration of electrical current near the tip of the crack produces a high magnetic field associated with it as electrical current is proportional to magnetic field associated with it according to Bio-Savart's law. Therefore this CFM micro-gauge would record a high value of magnetic field near the tip of the crack and thus helps the maintenance engineers detect the location of the crack.

The Magnetic sensor should also help the maintenance engineers deduce the size and shape of the crack. From the crests and the troughs obtained from the computer attached to the magnetic sensor one should deduce the size of the crack. The intensity of the crests and troughs obtained would be associated with the magnetic field associated with the model, which in turn is associated with the size of the crack.

As obtained from the output file, the table 5 clearly shows how the magnetic field changes with the change in the size of the crack. The magnetic field obtained neat the tip of the crack, i.e. the maximum magnetic field obtained from the model is directly proportional to the length of the crack. With the increase in 
the length of the crack, the magnetic field increases, thus helping the Microgauge detect it.

To understand why the magnetic field changes with the change in the size of the crack, one has to turn back and study the change in the electrical current density with the change in the length or size of the crack. It was clearly stated and concluded that the electrical current density obtained near the tip of the crack increased as the length of the crack increase. Now following the simple principle of Bio-Savart's law it is quite clear that change in the magnetic field is directly proportional to the change in the electrical field of the conductor. Now here, the magnetic field associated with the tip of the crack, therefore changes with the changes in the ECD obtained from the analysis. Due to the fact that the electrical current density increases with the increase in the length of the crack, the magnetic field associated with it also increases with the increase in the length of the crack. This explains the tabular column 5 and the increase in the values of magnetic flux density and magnetic field with the increase in the length of the crack.

It is however not possible to run a magnetic analysis for opened up crack in ANSYS $^{\mathrm{TM}}$, the reason being that software doesn't permit us to run a coupled magnetic analysis after a structural analysis was performed on the model. This is because of the fact that the element type for a structural analysis is different from the element type used for magnetic analysis. But then, the magnetic field for the opened up crack has been established, by deriving a connection between ECD 
and magnetic field of one element in the closed crack analysis. This can be done by using Bio-Savarts law mentioned in the literature earlier. 


\section{CONCLUSIONS DRAWN FROM ANALYSIS}

- For two-dimensional and three dimensional analyses, the Electrical current density is maximum at the tip of the crack and higher around the vshaped section of the crack, when compared to the other parts of the plate.

- The electrical current density is always higher at the tip of the closed crack when compared to the electrical current density at the tip of the open crack. Closed crack model is the model with the initial crack, while open crack model is the model with the opened up crack due to the application for force

- The Electrical Current Density measured during analysis increases with increase in the length of the crack, both in the Y-direction and also in the Z-direction.

- The magnetic field and magnetic flux density due to the flow of electric current is the highest for the model near the tip of the crack where there is a maximum value of electrical current density.

- The magnetic sensor detects the highest value of magnetic field vector near the tip of the crack and thus helps the maintenance engineers detect where the crack is located in the aluminum plate.

- The magnetic field and the magnetic flux density increase with the increase in the length of the crack, following the principle of Bio-Savart's law. 


\section{RECOMMENDATIONS}

This method of non-destructive testing utilizing magnetic field and ECD can be used in various applications in day to day life to detect cracks in structures. Cracks in any metal or good conductors of electricity can be detected and their shapes and sizes determined. Future work has to be done to standardize and optimize the entire set-up and layout of this non-destructive mechanism. Smallest change in the Electrical Current Density has to be captured by the magnetic sensor. Design of a magnetic sensor with high sensitivity is very vital. 


\section{REFERENCES}

1. Champion, E.R. and Ensminger, J.M., 1988, "Finite Element Analysis with Personal computers," Second Edition, Vol.1, MARCEL DEKKER, INC, New York.

2. Martin, H.C. and Carey, G.F., 1973, "Introduction to finite element analysis" First Edition, Vol.1, McGraw Hill, New York.

3. Zienkiewicz, O.C. and Taylor, R.L., 1889, "The Finite Element Method," Fourth Edition, Vol. 1, McGraw Hill, New York.

4. Zienkiewicz, O.C., 1977, "The Finite Element Method", Third Edition, McGraw Hill, New York.

5. REddy, J.N., 1992, "Introduction to Finite Element Method", McGraw Hill Book Co., New York.

6. Burnett, D.S., 1988, "Finite Element Analysis- From Concepts to Applications", AT\&T Bell Laboratories.

7. Bailey, C.D., 1976, "Computer methods in Applied Mechanics and Engineering", Vol. 7, No. 2.

8. Blitz. J, "Electrical and Magnetic Methods of Non-destructive Testing", Adam Hilger, 1991

9. Wikswo, J.P, jr., Crum, D.B, Henry, W.P, Ma, Y.P, Sepulveda, and Staton, D.J., "An improved method for Magnetic identification and Localization of Cracks in Conductors", J.Nondestr, Eval. 
10. Sepulveda, N.G. and Wilkswo, J.P., "A Numerical Study of Magnetometers to Detect Hidden Flaws in Conducting Objects", J. Applied Physics.

11.Wiksmo, J.P., Jr., and SQUID Sensors: Fundamentals and Applications, H. Weinstock, Kluwer Academic publishers.

12. Enokizono, M., Todaka, T., Tuchida, Y. and Hachiki, N., "Finite Element Analysis of a moving Magnetic Flux Type Sensor developed for Non-destructive Testing".

13. Wincheski, B. and Namkung, M., "Electromagnetic Detection of Fatigue Cracks under Protruding Head Ferromagnetic Fasteners.

14. Xiong, Y. and Bedair, O.K., "Analytical and Finite Element Modeling of Riveted Lap Joints in Aircraft Structure"

15. Bucci, R.J. and Warren, C.J and Starke, E.A, Jr., "The need of new materials in aging Aircraft Structures.

16. Zhou, J., Lugg, M.C., and Collins, R., "A non-uniform model for alternating current field measurement of fatigue cracks in metals. 


\section{VITA \\ Ramkumar Kumar Geetha}

Date of Birth

Place of Birth

Education
May $26^{\text {th }} 1980$

Trivandrum (Kerala), INDIA

MS in Mechanical Engineering,

West Virginia University, WV, USA

Date of Graduation: Aug 2004.

B-Tech in Mechanical Production Engineering,

Kerala University, INDIA

Date of Graduation: May 2001. 